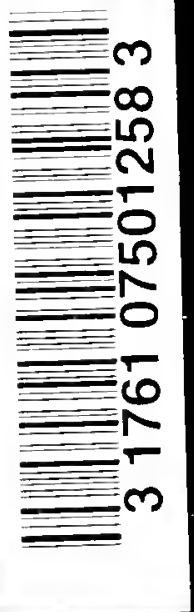

$H B$

501

$\mathrm{M} 5$

$\mathrm{O}_{7}$ 



\title{
DAS GRUNDGESETZ
}

DER

\section{ARXSCHEN GESELLSCHAFTSLEHRE}

DARSTELLUNG UND KRITIK

YON

\section{FRANZ OPPENHENIE?}

\author{
NEUDRUCK 1919
}

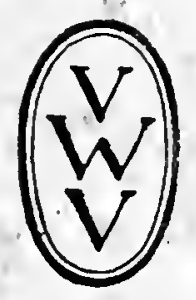

BERLIN UND LEIPZIG

VEREINIGUNG WISSENSCHAFTLICHER VERLEGER WALTER DE GRUYTER \& CO.

YORMALS G.J. GÖSCHEN SCHE VERLAGSHANDLUNG - J. GUTTENTAG VERLAGSBUCHHANDLUNG - GFORG REIMER - KARL J. TRUBNER - VEIT \& COMP. 


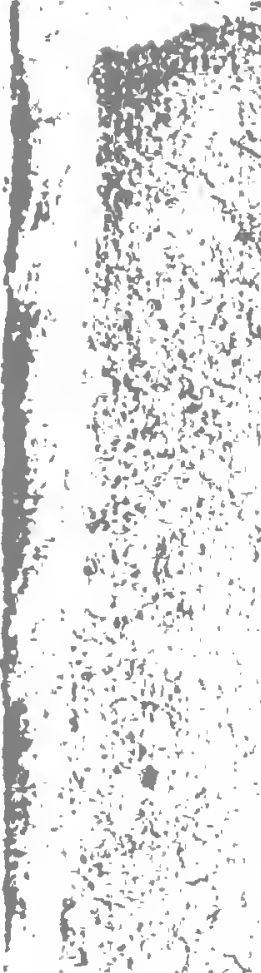

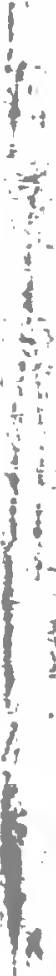

atos

$-10$

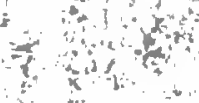

*31

$f \quad 1^{2}$

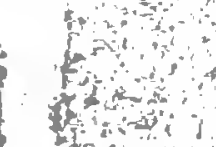

(1) $13-10^{2}$

if

8

bit:

sot

(3)

inition

cion

H.

Ny

* 115

(r)

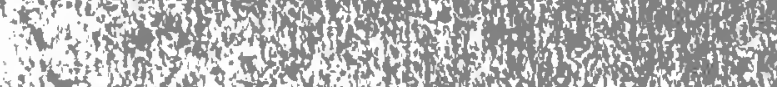

12.

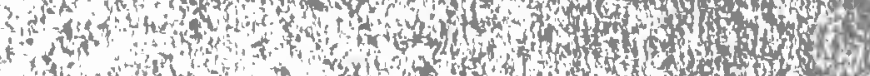

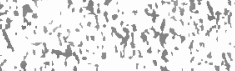

40

1

3

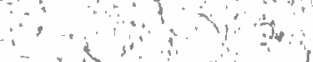

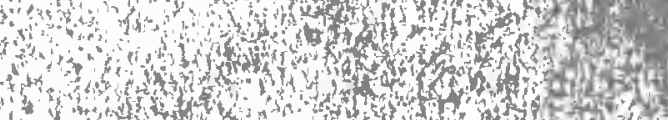

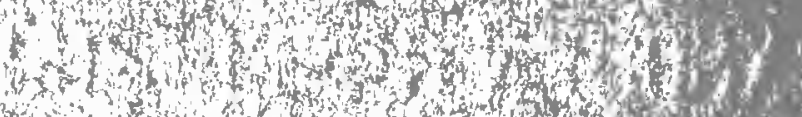

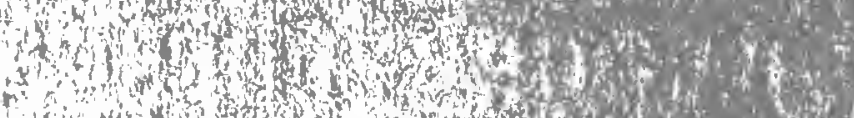
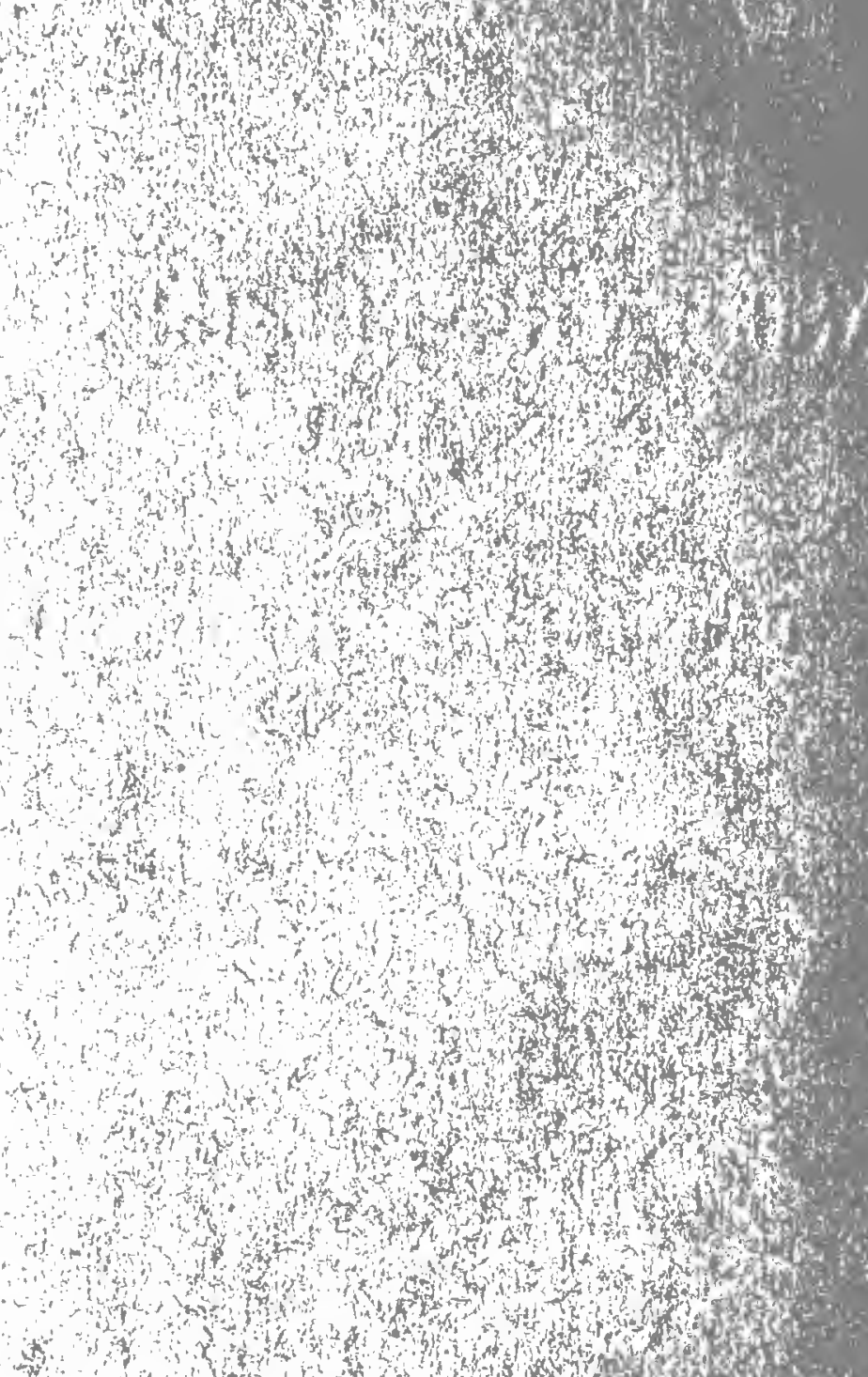

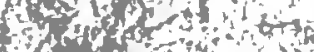

s.

and

nof

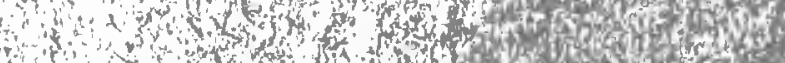

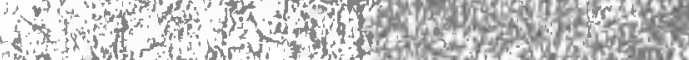
c.

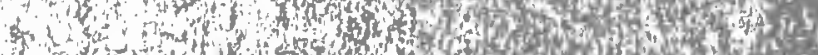

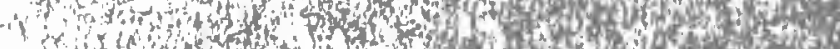

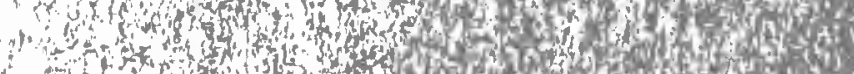

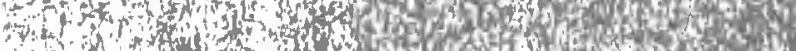

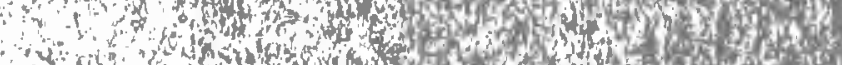

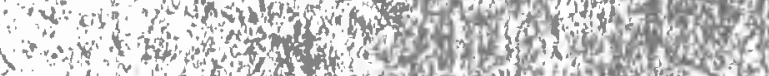

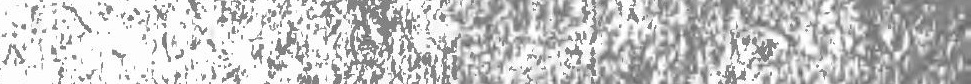

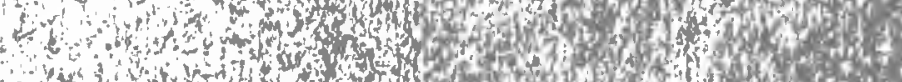
6 on

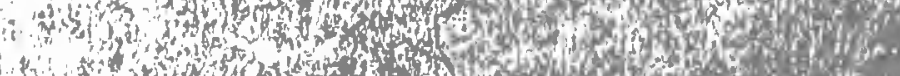
$1 \mathrm{~s}^{5} \mathrm{~s}$ ( 5.

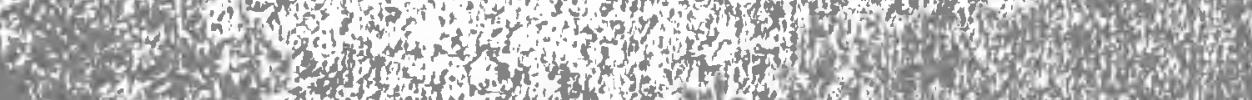

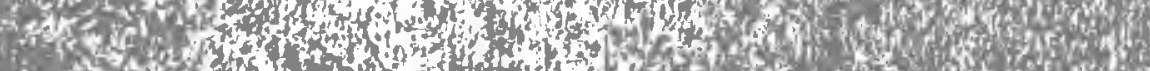

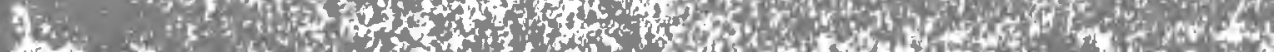




\title{
DAS GRUNDGESETZ
}

\author{
DER
}

\section{MARXSCHEN GESELLSCHAFTSLEHRA}

\author{
DARSTELLUNG UND KRITIK
}

PON

FRANZ OPPENHEIMER

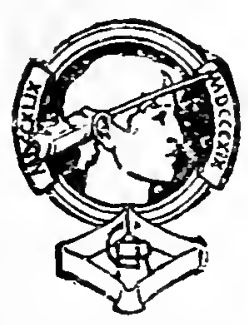

B E R L I N

DRUCK UND VERLAG VON GEORG REIMER 1903. 


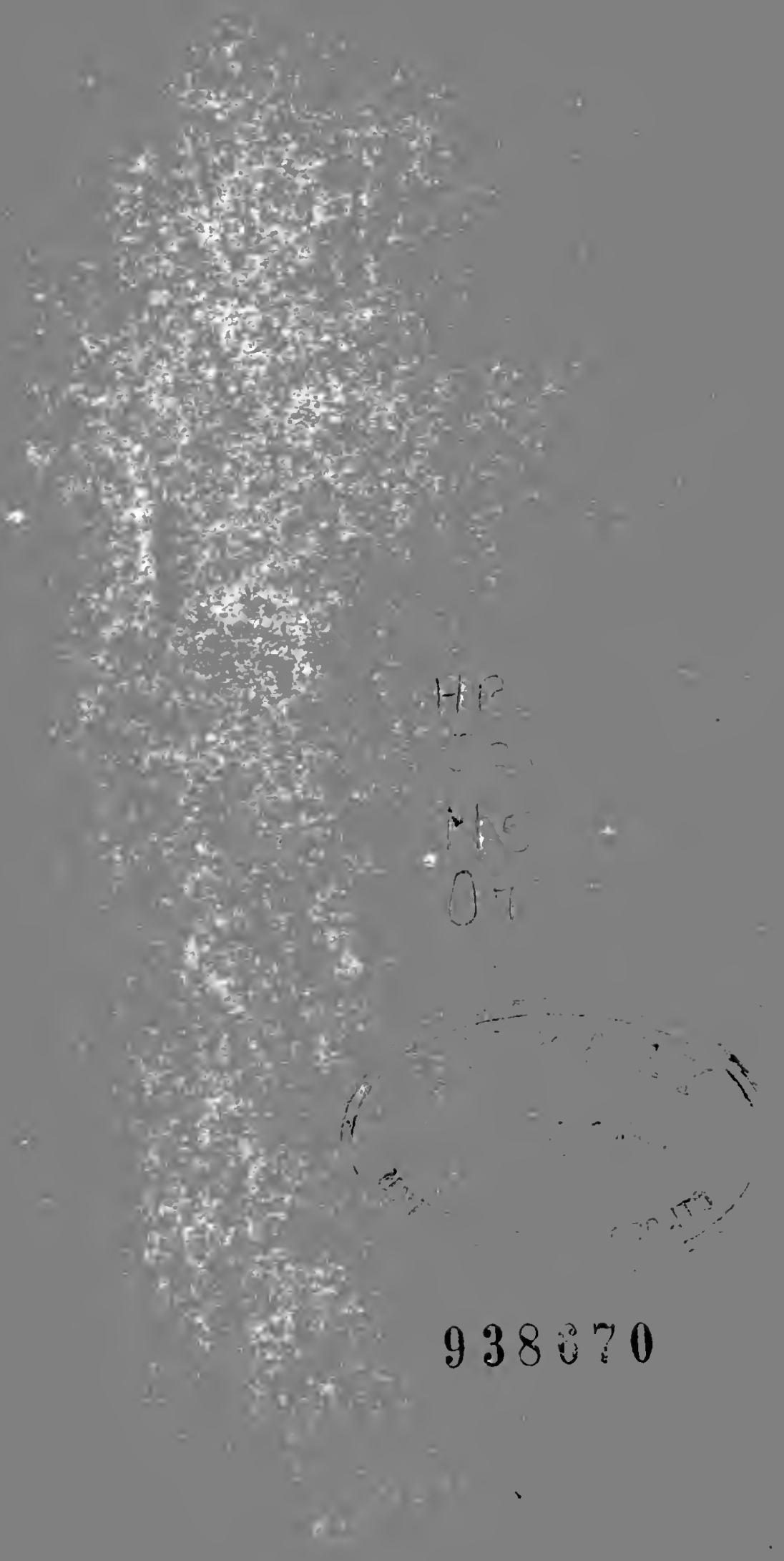




\section{Inhaltsverzeichnis.}

\section{Erster Teil.}

\section{Der Grundpfeiler der Marxschen Gesellsehaftslehre.}

1. Kapitel. Das Gesetz der Akliumulation und seine Konsequenzen ..................... 5

2. Kapitel. Akkumulationsgesetz und Mehrwertlehre... 9

Zweiter Teil.

\section{Der Marxsche Beweis.}

3. Kapitel. Díe Entstehung des Kapitalverhältnisses. (Die ursprüngliche Aklumulation) . . . . . . . . .

4. Kapitel. Die Reprodukiou des Kapitalverhältuisses. (Das Gesetz der kapitalistischeli Akkunulation? . . . . . . . . 25

5. Kapitel. bur Marxiche liettensuhlub . . . . . . . 2!1

A. Darstellung . . . . . . . . . . . . . . . . 29

B. Kritik . . . . . . . . . . . . . . 33

\section{Dritter Teil.}

Die Marxsehe Behauptang in Lichte der Tatsachen.

6. Kapitel. Die Tatsachen der industriellen Entwicblung. (Die „Freisetzumg» des Arheiters und die Kompensationstheorie)

7. Kapitel. Vie Tatsachen der landwirtschaftichen Fintwicklung. (Zentralisation, Expropriation und Freisetzung in der Agrikultur) . . . . . . . . . . . . . . 68

a) Die Koukurrenz in der Laudnirtschaft ........ 71

b) Die Akkumulation und Zentralisation des Agrikulturkapitals . 74

c) Groß- und Kkleinbetrieb in der Landwirtschaft . . . . . . 80

d) Die Freisetzuny des Landproletariats . . . . . . . . . . 84 
8. Kapitel. Dio Tatsachen des kapitalistischen Gesamtprozesses. (Die Urbanisierung der Bevölkerung). . . . . 93

Vierter Teil.

\section{Die Ursache der kipitalistischen Exploitation.}

9. Kapitel. Grundeigentumsverteilung und ländliche Wanderbewegung. . . . . . . . . . . . . . 101

10. Kapitel. Antikritisches Z $\mathrm{wisch}$ cuspiel . . . . . . 110

11. Kapitel. Skizze einer Lolhtheorie... . . . . . . 122

12. Kapitel. Die Tendenz der kapitalistischen Entwichlung 128

Scblußwort.

Die Klassentheorie................ 142 


\section{Vorwort.}

In Karl Marx” "Kapital" ist das . logische Gefüge der Gedanken zum Teil durch Polemiken, zum Teil duren geschichtliche Exkurse und gegenständliche Schilderungen in einem solchen Maße verhüllt, duß das Verständnis des gewaltigen Werkes für alle erschwert und für viele unmöglich gemacht wird. Ich habe mich bemüht, den leitenden Gedankengang des grundlegenden ersten Bancies des „Kapital“ aus dem üppigen Beiwerk herauszuschälen: dabei ergab sich wieder unzweideutig, daß die marxistischen Theoretiker vollig im Rechte sind, wenn sie die Lehre von der Eutstehung der Reservearmee unbeschäftigter Arbeiter für den Kernpuikt, des gesamten Systems erklären: nur ron hier ais ist in der Tat ein rolles Terständnis der uher das ganze Gebiet der Geselischaftslehre verzweigten Theorie zu gewinnen.

Darum hätce aber auch eine gründliche kritische Untersuchung an diesem Punkte einsetzen müssen. Das ist, so weit ich sehen kann, bisher nicht geschehen. Gerade dieser entscheidende Teil der Marxschen Okonomik hat zwar manche Aniechtung oder Anzweifelung, aber niemals eine eindringliche wissenschaftiiche Kritik erfahren. Die Ursache dürfte wohl darin zu suchen sein, 
daB es sich hier um Gedanken handelt, die Marx mit nur geringen Änderungen aus der älteren Theorie herübernahm, und die somit die gemeinsame Lehrmeinung sowohl der bürgerlichen wie auch der sozialistischen Wirtschaftswissenschaft bilden.

Die angedeutete Lücke möchte das vorliegende Buch ausfüllen. Angesichts der unbestrittenen Bedeutung der Marxschen Theoretik fur die Wissenschaft - um von ihrer gar nicht zu überschätzenden Bedeutung für das öffentliche Leben unserer: Zeit zu schweigen — scheint mir eine an ihren Kernpunkt greifende Kritik ein unabweisbares wissenschaftliches Bedürfnis zu sein.

Ich hoffe, durch die von mir vorgenommene Analyse das Marxsche System, das bisher nur Fachmannern im engen Sinne zugänglich war, dem Verständnis auch eines weiteren Leserkreises năher gebracht und damit gleichzeitig den Boden für eine truchtbarere wissenschaftliche Erörterung vorbereitet zu haben.

Es ist mir eine liebe Pflicht, an dieser Stelle meinem verehrten Freunde Gregor Itelson meinen Dank $a b_{7}$ zustatten für die Winke und Anregungen, die seine wahrhaft produktive Kritik in mündlicher Unterhaltung mir für die Ausgestaltung dieses Buches zukommen ließ.

Berlin-Wilmersdorf,

Oktober 1903.

Franz Oppenheimer. 


\section{Thesen.}

1. Der Grundpfeiler der Karl Marxschen Gesellschaftslehre, die wichtigste Prämisse ihrer sämtlicheu wichtigen Folgerungen, ist das, Gesetz der kapitalistischen Akkumulation".

2. Der von Marx gelieferte Beweis für dieses Gesetz ist unhaltbar.

3. Das „Geset\% der kapitalistischen Akkumulation“ besteht nicht.

4. Mit ihrer wichtigsten Prämisse werden die sämtlichen wichtigen Folgerungen der Marxschen Gesellschaftslehre hinfällig. Die Tatsachen der kapitalistischen Entwicklung verlangen eine andere Erklärung und lassen eine solche zu.

In der ersten These befinde ich mich in Übereinstimmung mit den Anhängern Narxens; sie ist ausschließlich gegen seine bürgerlichen Gegner gerichtet, die in der Werttheorie das Zentrum sciner strategischen Stellong erblicken.

Die übrigen Thesen richten sich gegen die Theoretiker des Marxismus. 



\section{ERSTER TEIL.}

\section{DER GRUNDPFEILER DER}

\section{MARXSCHEN GESELISCHAFTSLEHRE.}





\section{Kapitel. \\ Das Gesetz der Akkumulation und seine Konsequenzen.}

Das Gesetz der Akknmulation ist von Marx selbst an der entscheidenden Stelle folgendermaken formuliert worden: ${ }_{n} \mathrm{Jc}$ größer der gesellschaftliche Reichtum, das funktionierende Kapital, Umfang und Energie seines Wachstums, also auch die absolute Größe des Proletariats und die Produktivkraft seiner Arbeit, desto größer die industrielle Reservearmee. Die disponible Arbeitshraft wird durch dieselben lirsachen entwickelt, wie die Expansivkraft des Kapitals. Die verhältnismäßige Größe der industriellen Reservearmee wächst also mit den Potenzen des Reichtums. Je größer aber diese Reservearmee im Verhältnis zur aktiven Arbeiterarmee, desto massenhafter die konsolidierte Übervölkerung, deren Elend im umgekehrten Verhältnis zu ihrer Arbeitsqual steht. Je größer endlich die Lazarusschichte der Arbeiterklasse und die industrielle Reservearmee, desto größer der offizielle Pauperismus. Dies ist das absolute, allgemeine Gesetz der kapitalistischen Akkumulation. ${ }^{\text {(1) }}$

Dieses ${ }_{\eta}$ Gesetz schmiedet den Arbeiter fester an das Kapital, als den Prometheus die Keile des Hephästos an de: Felsen. Es bedingt eine der Akkumulation von Kapital entsprechende Akkumulation von Elend. Die Akkumulation von Reichtum auf dem einen Pol ist zugleich Akkumulation von Elend, Arbeitsqual, Sklaverei, Unwissenheit, Brutalisierung und moralischer Degra-

1) Kapital, 4. Auflage, Hamburg 1890, I. 609. 
dation auf dem Gegenpol, d. h. auf seiten der Klasse, die ihr eigenes Produkt als Kapital produziert". ${ }^{1}$ )

Das Gesetz ist die wichtigste Prämisse für die sämtlichen wichtigen Folgerungen der Marxschen Gesellschaftslehre. Mls diese spreche ich an: a) die Zusammenbruchstheorie, b) die Lehre rom kollelitivistischen Zukunftsstaat, c) die materialistische Geschichtsauffassung.

a) Wenn ilas Geset\% richtig ist, so ist der schließliche Zulsimmenbruch der kapitalistischen Gesellschaft unvermeidbar. Das immer zahlreicher in den Industriezentren zusammengedrängte, durch das Kapital selhst immer straffer organisierte Proletariat mulu unter diesen Cinständen einmal an einen l'unkt getrieben werden, wo die innere Empörung sich in offene Empörung innsetzt, in die „Empörung der stets anschwellenden und durch den Mechanismus des kapitalistischen Produktionsprozesses selbst geschulten, iereinten und organisierten Arbeiterklisse" “.

b) Ebeuso folgt die Jehre vom kollektivistischen Zukunftsstaat aus dein "Geseti der kapitalistischen Akkumulation".

Kapitalistische Akkumulation ist nämlich unter allen Umständen identisch mit der Zentralisation des Kapitals; deun der keine Kapitalist unterbietet den "eiufachen Warenproduzenten" und .wirft ihn aus dem Markte, und ebenso "expropriiert" der große Kapitalist den kleinen.

Dieser unzweifellhaft vorhandenen "Tendenz der kapitulistischen Wirtschaft" könnte nun aber unter bestimmten Verhältmissen eine Gegenkraft erwachsen, die sie zum Teil oder ganz kompensieren oder gar überkompeusieren könnte. lägen die Dinge derart, daß die große Volksmenge, das "Proletariat" im weitesten sinne, an den Errungenschaften der modernen Produktivität, wenn auch nur in bescheidenem Maße, seinen Anteil hätte, daß also die Quote der auf den eiuzelnen Proletarier entfallenden Genubyüter wüchse, so würden fortwährend neno kleine Kapitalieu und Kapitalisten (durch „Entsagung") sich bilden und

1) Kapila] I. G11: vgl. Fr. Lingels, Herrn Eug. Dührings l'ıwälzunğ (Huttingen 86) 1. 139.

2) Kapital 1. $7: 8$. 
in neu entstehenden, zunächst kleinkapitalistischen Zweigen der Produktion Lnterkunft und Beschäftignng finden, bis auch diese Zweige für den großkapitalistischen Betrich reif wären, und die Expropriation auch hier Platz griffe. Derart wïrde die Gesamtvolkswirtschaft, dem Meere gleieh, immer an der einen Stelle die Küste abnagen, nur um sie an anderer stelle wieder anzuschwemmen, und der lrozeb könnte je nachdem verzögert oder in indefinitum verlängert werden.

Liegen die Dinge abel so, wie das Gesetz der Akkumulation behauptet, hat in der Tat das Proletariat an den Errungenschaften der modernen Technik gar lieinen oder nur einen ganz verschwindenden Anteil, so muls allerdings jener Prozeb der Zentralisation des Kapitals unaufhaltsam mit Riesenschritten fortschreiten und bald einen Zustand herheifïhren, in dem die gesante Produktion in wenigen Kolossalbetrieben zentralisiert ist mögen wir uns diesen Zustand nun hente vorstellen hönnen oder nicht - - ; und das siegreiche Proletariat hat wirklich dann kilum noch etwas anderes zn tun, als die Produktion in gleicher Art fortzuführen und nur die Verteilung der Produkte umzugestalten. Die Bourgeois, die höhnend vou.Marx und seinen Schülern einen genauen Aufriß des "Zukunftsstaates" verlangen, laben ihn nie verstanden.') Er hat eine "Tendenz" dirgestellt, die nach seiner Überzeugung sich ohne wesentliches IIindernis, von keiner erheblichen Gegentendenz anfgehalten, durchsetzte, und die zweifellos zu dem Zicle kollektivistischer Wirtschaft führen mußte, wenn sie sich durchsetzte. Mehr brauchte er nicht zu leisten, als diese Tendenz nachzuweisen und zu zeigen, dab sie durch keine erhebliche Gegentendenz kompensiert wird.

1), Weun die Ferren uncer Programm kritisieren wollen, ... sind wir stets bereit, ihnen Red' und Antwort zu stehen. Aber über die lionsequenzen mit ibmen $7 n$ streiten, wolehe die Verwirklichung unserer Forderungen nach sich ziehen könute, möchtc, dürfte, erscheint uns höchst iiberflïssig. Insere \%iele sind nicht willkürlich gesetat, sondern die Ziels der init Naturnotwendigkeit vor sirh gehenden äkonomischen Eutwicklung." K. K. ̈̈her V. Gatlurius ,Der Sozialismus", N. 7. 90!1, H. IHW. p. 6.;8. Ähnlich F. B. in :iner Anzeige von Wyncken, „Der soxialististhe Zukunftsstaat", N. \%. 94/5, II p. 249. 
So stellt sich das Gesetz der Akkumulation für die kritische Analyse als die wichtigste Prämisse der Marxschen Ökonomik dar. Aus ihr folgt jener verrufene Rest des von Ed. Bernstein so genannten "Putschismus" oder "Blanquismus", der der "Revolution im Heugabelsinne der Gewalt" mindestens als der Geburtshelferin der neuen Gesellschaft nicht entraten zn können glaubt; und aus ihr folgt ferner die Lehre vom "Zukunftsstaat". Wie sehr diese beiden Folgerungen ihrerseits, ins Praktische gewandt, wieder die Taktik der marxistischen Sozialdemokratio beeinflussen, wie sie die eigentlichen Stützen der „Freßlegende und dadurch das einzige ernsthafte Hindernis der Bildung einer großen demolkatischen Volkspartei sind, ist zu bekannt, als daß es hier ausgeführt zu werden brauchte.

c) Das Gesetz der Akkumulation ist ferner Prämisse einer anderen überans wichtigen nichtvolkswirtschaftliclien Folgerung, und zwar der "materialistischen Geschichtsanffassung".

Die ökonomistische Geschichtsphilosophie, d. h. die Lehre, $\mathrm{daB}$ das geschichtliche Geschehen ausschließlich oder weit überwiegend von der Gestaltung der wirtschaftlichen Grundlage bestimmt wird, erscheint bei Marx-Engels in einer besonderen $\mathrm{Zu}$ spitzung, die ich rorgeschlagen habe als die nproduktionistische“ Spielart zu bezeichnen. „Die Produktionsweise des materiellen Lebens bedingt den sozialen, politischen und geistigen Lebensprozeß überlanpt. ${ }^{\text {") }}$ ) Noch schärfer drückt Fr. Engels aus, daB die Distribntion der Produkte, der zweite Hauptteil aller Wirtschaft, keine selbständige Bedeutung für die Geschichtsentwicklung hat, sondern eine unmittelbare „Funktion“ der Produktionsverhältnisse ist. Er schreibt: ${ }^{\text {) }}$

„Die materialistische Anschaung von der Geschichte geht von dem Satz aus, daß die Produktion, und nächst der Produktion der Austausch ihrer Produkte, die Grundlage aller Gesellschaftsorduung ist; daB in jeder geschichtlich auftretenden Gesellschaft

') Marx' Vorwort zur „Kritik der Polit. Ökonomie“; vgl. dazu die sehr guten Erörteruagen von Heinrich Cunow, N. Z. 1898/9 IJ, p. 586/7 (in einer Polemik gegen P. Barth).

7) Autidülning p. 286; cit. nach Kautsky (Bernstein etc.) p. 16/17. Ebenso scharf in Herrn Eug. Dührings Umwälzung (Hottingen 86) p. 128, 
die Verteilung der Produkte, und mit ihr die soziale Gli derung in Klassen und Stände, sich darnach richtet, was und vie produriert und wie das Produzierte ausgetauscht wird. ${ }^{\text { I) }}$

Für diese grundsätzliche Auffassung hat das Dioskurenpaar nur einen Beweis beigebracht, eben das Gesetz der Akkumulation, wonach die Verteilung des Gesamtprodukts in der Tat nichts anderes ist als eine unmittelbare Folge der Produktionsweise. Läßt sich das Gesetz als falsch erweisen, so hätte die "produktionistische". Spielart der ökonomistischen Geschichtsanffassung viel an Kredit verloren, und meine eigene Auffassung ${ }^{2}$ ) dürfte erhöhte Beachtung beanspruchen.

Ein Angriff gegeu das Gesetz der Akkumulation zielt also auf das Herz nicht nur der ökonomischen, sondern der gesanten soziologischen Auffassung von Karl Marx.

\section{Kapitel.}

\section{Akkumulationsgesetz und Mehrwertlehre.}

Die Theoretiker des Marxisnus betrachten, in Übereinstimmnng mit den Auseinandersetzungen des ersten Kapitels das Gesetz der Akkumulation als die Zitadelle ihres Systems, das der Gegner zu erobern hat, der sich vermißt, Marx widerlegen zu wollen. Ihre bürgerlichen Kritiker aber haben, soweit ich sehen kann, durchweg die Theorie des Wertes und Mehrwertes angegriffen, $\left.{ }^{\prime}\right)$ ohne sich jemals ernstlich an das uns beschäftigende

1) Wie viel Wasser die Dioskureu selbst später in den reinen Wein dieser strengen Lehre gießen muBten, durüber bei Bernstein (Voraussetzungen des Sozialismus) p. $5 \mathrm{ff}$.

2) Vgl. mein „Großgrundeigentum und soziale Frage“, Berlin. 1898 p. $491 \mathrm{ft}$. Ich veröffentliche gleichzeitig eine ausführliche Darstellung meiner „sozial-ōkonomischen Geschichtssauffassung " in der Vierteljahrsschrift für wissenschaftliche Philosophie und Soziologie.

unter $\mathrm{F}$.

3) Vgl. Diehl: Artikel "Jark" im Hdwb. der St. W. 2. Anfi. IV. 790 
Gcsetz zu bekïmmeru. Wie einzigen mir bekannten Ausnahmen bilden Wenckstem") und Julius Woll. Wencksterns Kritik hält sich aber ituch hiẹ wit ïberall gänzlich an der Oberlläche. Er wieterholt eigrentlich nur einige Argunente aus der sogenannten "Komprensitionstheorie", die uns noch beschäftigen wird, oder polernisiert gegen Details, jene Hethode, von der Schopenhamer sagt, sie schlare gleichsam dic Fenster von aulen ein. - Dagegen ist .Jul. Irolf $^{2}$ ) vich tiefer in die Sache eingedrungen und hat in der 'lat den Kern des Problens berührt; leider hat ihn sein damaliger Standpmkt als Anhänger des Valthusianismus verhindert, es ganz zu lösen. ${ }^{3}$ )

Die ïbrigen „Bourgeois-“ resp. "Vulgiilökunomen" wurlen aber durch die sleiche Lehre verhindert, das Problem überhaupt zu stellen. Es hiudelt sich hier um nichts inderes als umi die Ilerkunft der , industriellen Reserve-Armee" - und die ist fïr den Malthus-Anhünger kein Problem. Es werden eben einfich zuviel Menschen erzengt!

Das ist einer der Gründe, warum Marxens bürgerliche Gogner mit solcher Eimmütigkeit nur die Wert- und Mehrwertlchre angegrillen haben. Ein anderer Girund ist darin zu finden, dab die Hehrwertehre rom Standpankte des Klassenliampfes zwischen Bourgeoisic und Proletariat ron ïberragender Redentung ist. Darüber mehr im Schlubkipitel!

llier liegt mir dilran, die Erörterung aluf deu einen entscheidenden Punkt zu begrenzen. Zu dem Zwecke will ich, vor dem Angriff auf das eigentliche Thema dieser Abhandlung, den Beweis erbringen, doß auch die Nehrvertlehre eine Folgerung ius dem Gesetz der Akhumulition ist. Mit dem Gesetz steht und fällt zwar nicht die Lehre vom ITert, wohl aber die Lehre vont Mehrwert.

Die Mehrwertlehre ist gewonnen aus einer ohue lange Elörterung der Grünle mul Gegengriinde last axiomatisch angenommenen Arbeitswertheorie. Die beliebig reproduziblen

1) Vgl. „Yarx", Leipzig. 1996. p. 39 it'.

$\Rightarrow$ Sozia!isnus und kapitalistische Geseltschottsordnung, Stuttgart 189?, p. 255 fi., narnentlich p. 267, 273 Amm.

3) Vol. mein "Malthus" p. 129, 130. 
Waren tauschen sich nach der in ihnen rergegenständlichten gesellschalftich notwendigen einfachen Arheitszeit. "I)ie verschiedenen Proportionen, worin verschiedene Arheitsalten auf culfache Arbeit als ihre Maßeinheit reduziert sind, werden durch einen gesellschaftlichen P'rozelB" (i e. don Tauschverkehr anf dem Markt) ,hinter dem liüiken der loduzenten fostgeset\%t und scheinen ilm diher durch das Herkummen gegeben." ")

Nun gibt es anf dem Markte eine Ware, die Arbeitskraft, die eine ihr allein eisentümliche Stellung eimnimmt. Hhr "Wert", d. h. der P'reis, für den sie in Durdschluitt auf dem Markt gekauft werten kann, ist wie bei jecler anderen Ware bestimm durch die fïr ihre Reprodutition notwendige Irbeitsze it, reskörpert in derjenigen Menge von subsistenzmitteh, die erforderlich sind, um die Arbeitskralt des Arbeiters selhst in ihrerr Bestande zu erhalten, und ihn zur Aufzucht und Vorbildung von so vielen Kindern zo befähigen, wie zur Reproduktion der Arbeiterklasse nötig sind.

Kauft der Untenehmer diose Ware „Arheitskraft" für eire Summe des allgemeinen Wortäquivalentes, des Geldes, fiir rinen Lohn also, der die oben bezeichnete Menge von Subsistenzmituch zu kaufen erlaubt, so hat er sie nach ihrem vollen Werte bezalhlt; der Arbeiter darf sich nicht beklagen, dali die Gesetze der freien Konkurrenz ibm gerenüber vorletzt worden seien, und der Kapitalist hat das wohlerworbene Recht, die in sein Eigentum übergegangene Ware zu ge- und verbrauchen.

„Der (iebranch ler Arbeitshraft ist die Arbeit selbst. Der häufer der Arbeitshraft konsumiert sie, indem er ihren rerkäufer arbeiten läßt ${ }^{2}$ ) . . . . und der Besitzer der Arbeitskraft gibt in der 'Tat nur den ron ihm rerkauften Gebrauchswert, indem er seine Arbeit gibt." "3)

Der Gebrauchswert der Arbeitskraft fïr ihren Käufer, den Kapitalisten, besteht darin, dal. sie Wert billet, den Produktionsmitteln Wert zusetzt, und zwar ceteris paribus in Verhält-

1) Sarx. Kapita! I. 11.

?) Marx. Kajpital I. 139.

3) Marx. Kapital I. 148. 
nis der verausgabten Arbeitszeit. Je mehr Stunden der Arbeiter schafit, umsomehr. Wert setat er dem Produktionsmittel zu; und diesen Wert realisiert dann der Kapitalist, als der Eigentümer der Profluhtionsmittel und der Arbeitskraft auch Eigentümer des fertigen Produkts, durch Verkauf der "Ware".

Marx hehauptet nun - und mit Recht - daß der Arbeiter in allen kapitalistischen Gesellschaften in einem vollen Arbeitstage mehr Wert schaflit, zusetzt, als die zur Reproduktiou seiner Arbeitskraft nötigen Subsistenzmittel an Wert enthalten." Ist beispielsweise das Quantum von Subsistenzmitteln, das eine $\mathbf{A r}$ beiterfamilie nach den geltenden Gewohnheiten täglich durchschnittlich brancht, in sechs Stunden einfacher Arbeit, gesellschaftlicher Durchschnittsarbeit", herzustellen, so setzt der Arbeiter auch in sechsstündiger Arbeit den Produktionsmitteln den Wert seines Lohnes zu. Der Kapitalist läßt ihn aber zwülf àbeiten und steckt den Wert, den jener in der zweiteu Hälfte des 'Tages den Arbeitsgegenständen zusetzt, in die eigene Tasche. Dieser während der "Mehrarbeit" geschaffene Wert heibt „Mehrwert" und ist die einzige Quelle allen Profits im weitesten Sinne, d. h. von Zins, Lnternehmergewinn und Grundrente.

Ich widerstehe der Versuchung, auf die der Mehrwertlehre zugrunde liegende Werttheorie einzugehen; da ich die Ricardosche Rentenlehre, die die Voraussetzung seiner Arbeitswertlehre ist, ${ }^{\prime}$ ) für falsch halte, so bätte ich wichtige prinzipielle Bedenken schon gegen den Ausgangspunkt. Ich könnte auch schwer zu beseitigende Einwände gegen die Brauchbarkeit dieser Werttheorie erheben, könnte auf mehrere Stellen hinweisen, wo Marx selbst feststellt, daß auf die Dauer der Lohn nicht hinreicht, um die Arbeitskraft in ihrem Bestande zu erhalten, ${ }^{2}$ ) d. h. daß der Kapitalist sie unter ihrem Werte kauft; wohlverstanden nicht von den zufälligen Schwankangen des Marktes ist hier die Rede, sondern von länger dauernden Zuständen! Ich will auch nicht auf die Aufschlüsse des dritten Bandes eingehen, nicht untersuchen, ob und wie weit Marx selbst gezwungen gewesen ist, den Wein seiner

1) Vyl. Marx, „Elend der Philosophie“, 3. Luflage, Stuttgart 1895, p. 19.

D Kapital I. 228, 229, 490. 
reinen Wertheorie mit dem Wasser der Kostentheorie zu rerdünnen.')

Sondern ich will hier die Wertlehre annehmen, wie sie geboten ist, und mich begnügen, zu zeigen, dal.b sie im System des „Kapital" nur eine Prümisse der Mehrwertlehre ist, und daR das Gesetz der Akkumulation ihre zweite Prämisse darstellt.

Varx war nämlich in späterer Zeit ein entschiedener Gegner des ,ehernen Lohngesetzes", wie es Malthus anf Grund seines Bevölkerungsgesetzes und nach ihm - zu Agitationszwecken Ferdiuand Lassalle aufstellte. Daß der Lohn anf das absolute Minimum an Subsistenzmitteln naturnotwendig hingravitiere, liat er zwar zuerst ebenfalls geglaubt, aher später bestritten.") Nach ihm gravitiert der Lohn gegen das Minimum der sogenannten notwendigen Bediirfnisse"; und deren „T'mfang, wie die Art ihrer Befriedigung is selbst ein historisches Produkt und hängt daher großenteils vou der. Kulturstafe eines landes, unter anderem auch wesentlich davon $a b$, unter welchen Bedingungen und daher , mit welchen Gewohnheiten und Lebensansprüchen die Klasse der freien Arbeiter sich gebildet hat. Im Gegensatz zu den anderen Wareu enthält also die Wertbestimmung der Arbeitskraft ein historisches und moralisches Element." ${ }^{3}$ )

Daraus ergibt sich, dab der Fall mindestens denkbar ist eines Landes, in dem die Gewohnheiten und Lebensansprüche der freien Arbeiter eine so große Menge ron Sulssisteuzmitteln konsumieren, daß der gesamte physisch mögliche Arbeitstag durch "notwendige Arbeit" absorbiert wird, sodaß keine Mehrarbeit geleistet, und kein Mehrwert geschaffen wird. Eine solche Gesellschaft wiire nun freilich keine „kapitalistische" ${ }^{* 4}$ ): aber es ist ja nicht der Nachweis zu führen, daß Mehrwert

") Vgl. z. B. Slonimski, „harl Marx' national-ökonomische Irrlebreu.* Berlin. 1897, p. 89 ff. und Herkuer, „Arbeiterfragex, 3. Auflage. Berlin. 1902 , p. $883 \mathrm{ff}$.

2) Vgl. Engels, Anm. zu Pliil. des Elends, p. 24, und Berustein, "Lur Geschichte und Theorite des Suzialisums". Berlin. 1901. p. 80, i.l. a. p. 88.

3) Kapital I. 184, vgl. a. I, 193.

t) Kapital I. 577. 
(und durch ihn Kapitalismus) möglich, sondern daß el notwendig ist.

Fs ist ferner, wenn man nur von der Wẹrttheorie ausgeht, auch der andere Fall denkbar, dab, wenn der Lohn unter gürnstigen Cmständen immer inehr, und zwar nicht nur nominell, sondern auf Rosten des Profits steigt, noue Gewohnheiten und Lebensansprtiche landesüblich werden, d. h. daß die Mehrwertlate fortwährend fällt, ') bis sie sich dem Nullpunkt mindestens sehr nahe einstellt, sodali clie "Ausbeutung" praktisch irrelevant wird. Marx meint, "der Stachel des (kewiuns“. würde in solchen

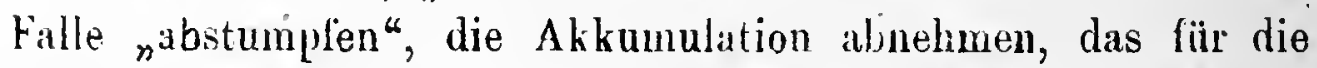
kapitalistische Exploitation notwendige Verhältnis zwischen Kapital und exploitabler Arbeitskraft sich autnmatisch wiederherstellen. ${ }^{2}$-- Er kann aber nicht angeben, bei welcher Rate des Mehrwerta diese Abstufung des Stachels eintreten würde; theoreiach ist wahrscheinlich, daß ter Kapitalist nur um so eifriger „spart", wenn sein Kapital sieh stat mit $10 \%$. nur noch mit $0,001 \%$ verzinst. Und doch wäre dann offenbal von praktischer Ausbentnng kaum nuch, und von der Notwendigkeit einer lievolution der Wirtschalt garnicht meh: die Redé.

Marx selbst milbt übrigens dieser Argumentation - auf die noch zurüchzukommen sein wird - nur geringe Bedeutung bei.

Sondern seine entscheideude A uffassung geht ausgesprochenermaken dahin, daß die Produktion von "Mehrwert" nur solange aus dem Wertgesetze folyt, wie das "Kapitalverbültnis" als solches existiert. Dies Kapitalverhältuis seinerseits ist aber, unabhängrig vom Wertgesetz, durch die historische Entwicklung geschuffen worden und erhält sich, reproduziert sich automatisch; ebenfalk muabhängig vom Wertgesetz, durch den Mechanismus der "kapitalistischen Akkumulation". Würde diese Reproduktion nicht stattfindcn, so wïrde anch die Produktion vou Mehrwert aufhören. Demnach steht und fällt also auch die Melı'werttheorie mit de: Behauptung, dab kraft des Gesetzes der kapitalistischen Alkurnulation die Reproduktion des Kapitalvor-

1) Kispicial I. 17\%.

2) Kapital 1. is 83. 
laälnisses solange stattfimden mug, bis die Produktionskrätte das Produktionsverhältnis sprengen, bis "die Stunde des Kapitalismus ischlägt und die Expropriatenre expropriiert werden", kraft der immanenten Lialaktik ler Fintuicklung.

Die Wertlehre aher ist für das System als logisches (refuige von durchaus untergeordncter Beileutung: Inan kann sie annehmen und dennoch von ibr aus, wie gezeigt, eine nichtkapitalistische Wirtschaft obue Mehrwert konstruieren man kann aher auch umgekehrt die bxploitation der Arbeiter vom Standpunkte der Kostenwertheorie, und sogar olme jede Wertheorie ableiten. Bernstein satgr: "(ib die Marxiche TVertheorie richtig ist oder nicht ia fiir den Nachweis der Neh rarbeit ganz und gar gleichgültig. Sie ist in dieser Hinsicht keine Beweisthese, sonden nur Vittel der Analyse und der Verauschaulichnngr".

Genau dieselbe Aullassung von der Bedentung dieser Lehre fuir das System finden wir in andern Laiger der Narxistein. Kautsky schreibt:")

"In Wirklichkeit hat jedoch die Marssche Werttheorie mit dem sozialismus nichts zu tun. . Die Lehre vom Wert ist nicht die Grumblage des Sozialismns, sondern die Grundlage der heutigen kapitalistischen Ökonomie. Mit der Widerlegung der Marxschen. Werttheorie wäre der Sozialismus noch lange nicht widerlegt; liese Theorie lehrt uns nicht den Sozialismus, sondern das Getriebe des hapitalismus verstehen." Und an anderer Stelle: ${ }^{3}$ )

„Marx hat das Wesen des Meluwerts nicht entdeckt. Seit Smith weiß jeder, der sich enstlich mit Nationalökonomie boschäftigt, dab ein solcher existiert. Aber Marx walr der erste, der gezeigt hat, wie ler Mehwert entsteht, wie er produzint wird. J)amit erst wurde der Mehrwert zum Schlüssel der kipilalistischen Produktionsweise."

1) Berustein, Voraussetzungian etc. 1. 42.

2) K. Kautsky ïher Gustar Groß' .. Karl Marx", Leipzig. N. Z. III. 282.

3) K. Kautsky: N. Z. 1886 p. 55. Vol. a. folgente Stelle: „Dats dis Marxsche Wertheorie zum Nachwcis der Ansbeutung der Arbeiter überflüssig ist", ist „unanfechtbar". Kantsì: "Problematische! gegen wissenschaftlichen Sozialismus". (N. Z. 1900/01, Il. p. 361.) 
Ganz ebenso schreibt Fr. Engels:

nMarx hat daher seine kommunistischen Forderungen nie hierauf (den Mehrwert) begründet, sondern auf den notwendigen, sich vor unseren Augen täglich mehr und mehr vollzielienden Zusammeubruch der kapitalistischen Produktiousweise." ${ }^{\text {1) }}$

Und noch vor wenigen Monaten schrieb das Zentralorgan der sozialdemokratischen Partei in einem angenscheinlich aus berufeuster Feder stammenden Aufsatze zum 20. Todestage des Meisters:

„Die Basis der heutigen sozialdemokratischen Arbeiterpolitik, das ist nämlich die materialistische Geschichtsauffassung im allgemeinen und die Marxsche Theorie der kapitalistischen Entwicklung im besonderen. ${ }^{2}$ )

Auch ein nicht-marxistischer Sozialist wie Paul Weisengrün ${ }^{3}$ ) kommt zu demselben Ergebnis, das die einstimmige Überzeugung aller nicht-bürgerlichen Ökonomisten sein würde, welın nicht ein ungenannter Russe ") anderer Meinung wäre. Er hält gerade die Arbeitswerttheorie für eine Hauptsäule des Marxschen Systems, namentlich der materialistischen Geschichtsauffassung. ¿Die Zerstörung dieser Theorie wäre gleichbedeutend mit der Zerstörung des ganzen von Marx errichteten Gebäudes." Seine recht verworrene Beweisführung beruht auf lauter Mißverständnissen.

Die übrigen stehen, wie gesagt, auf dem Standpunkt, daß die Werttheorie für den Gesamtaufbau der Marxschen Lehre von geringer Bedeutung ist. Ich kann mich dieser Auffassung nach dem Gesagten nur völlig anschließen, und so darf ich mir im wesentlichen die folgenden Ausführungen zu eigen machen:

nDie gesamte bürgerliche Ökonomie - und die klerikalen Autoritäten wie Kämpfe, Hitze, Hertling, Cathrein u. a. haben in diesem Punkte nichts andres getan, als die liberalen Ökonomen ausgeschrieben - geht in ihrer Kritik des Sozialismus von der p. IX/X.

1) Fr. Engels, Vorwort nur 3. Aufl. von Karx' "Elend der Philosophie“

3) "Karl Marx." Gedächtnisartikel zum 14. Marz 1908 in "Vorwärts".

3) "Das Ende des Marxismus" (Leipzig 1899) p. 11 und "Der Marxismus etc." (Leipzig 1900) p. 221.

†) N. Z. $1900 / 1$ p. 337. 
Marxschen Werttheorie aus. Man gibt za, da $\mathrm{B}$ die sozialistischen Forderungen Marx' durchaus zutreffen, wenn seine Wertheorie richtig sei. Marx jedoch ebenso wie Engels und mit ibnen der ganze Sozialismus der Gegenwart haben ihre sozialistischen Forderungen niemals auf die Wertheorie aufgebaut; sie erkennen in der Werttheorie lediglich ein Mittel, den Zersetzungsprozeß der kapitalistischen Gesellschaft zu begreifen, ein Gesetz, das zur Erklärung der gegenwärtigen Erscheinungen dient, and das falsch oder richtig sein kann, ohne daß dadurch die aus den ökonomischen Tatsachen gezogenen sozialistischen Folgerungen irgendwie berührt werden. Während also die bürgerliche Ökonomie die Folgerichtigkeit der sozialistischen Dialektik zuzugeben genöthigt ist, richtet sie ihren Angriff in vollstem Mißverständnis des gesamten morlernen Sozialismus gegon einen Punkt des Marxschen „Kapitals", der gar nicht als Ausgangspunkt des Sozialismus anzusehen ist, den Marx selber nicht als den Ausgangspunkt seiner Theorien angesehen wissen wollte. Die ganze angeblich ${ }$ wissenschaftliche ${ }^{\alpha}$ Vernichtung der Sozialdemokraten ist also nichts als ein vollendeter Selbstwiderspruch. ${ }^{\text {") }}$

Damit scheint mir dieser Punkt erledigt. Fs hat sich also eine in großen gedachte, nicht kleinlich an Einzelheiten nörgelnde Kritik des Marxschen Gedankenbaus ausschließlich gegen sein "Gesetz der Akkumulation" zu richten; und das System wird als im ganzen widerlegt gelten müssen, wenn es gelingt, diese seine 'itadelle zu erobern.

1) „Vorwārts" rom 6. Mai 1903. 



\section{ZWEITER TEIL.}

\section{DER MARXSCHE BEWEIS.}




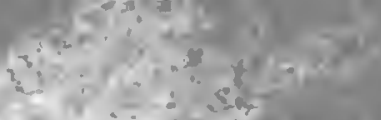

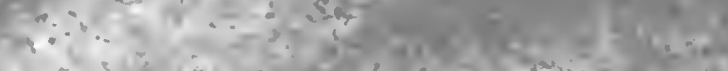

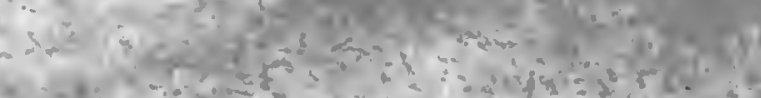

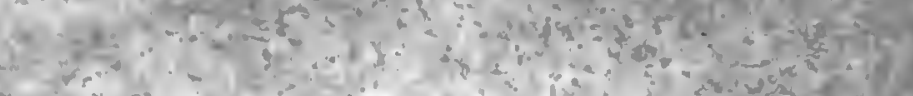

a

51,

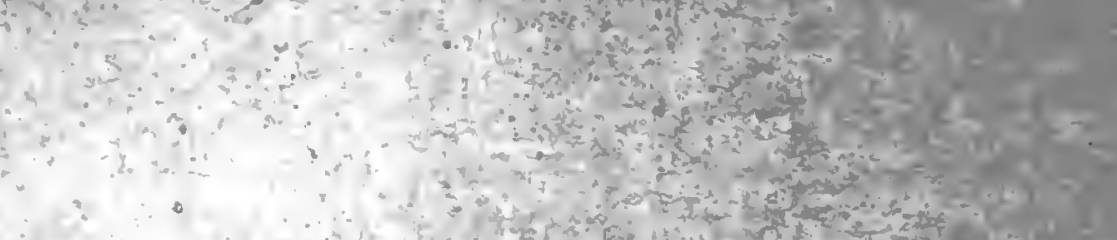

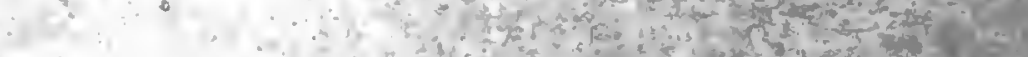

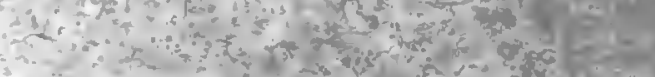

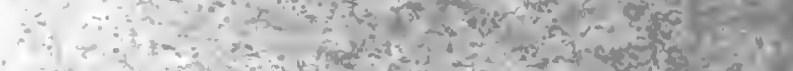

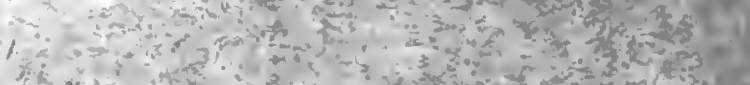
a

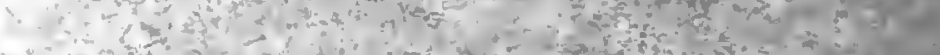

i

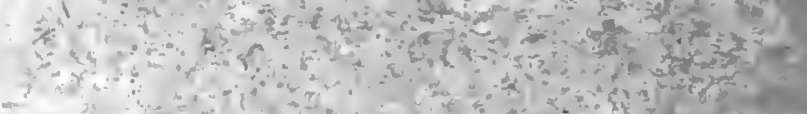

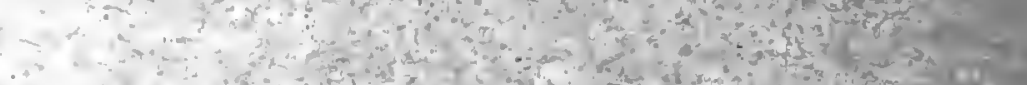

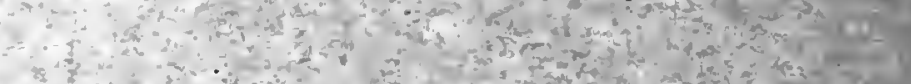
of yet $\therefore$ a

(a) 40

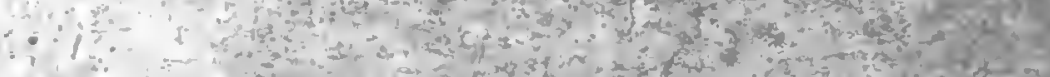

$-120$

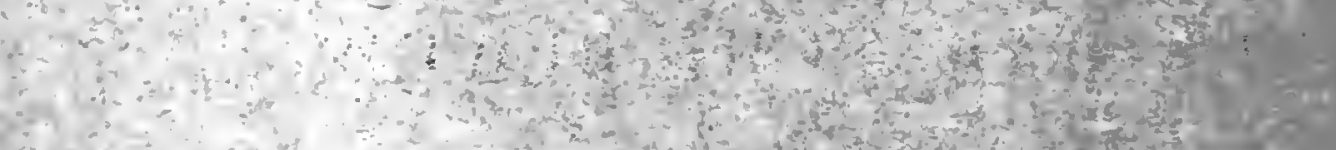

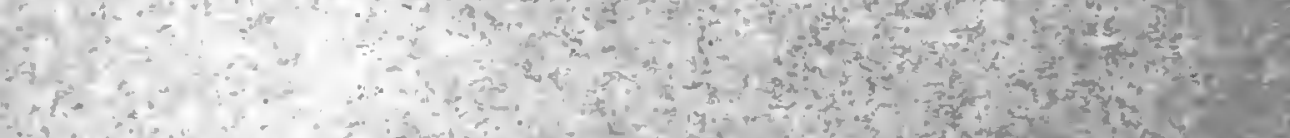
3.

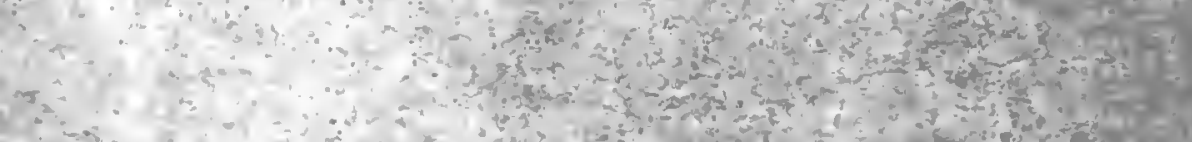
$\because T^{\circ}$ i $\because$ b

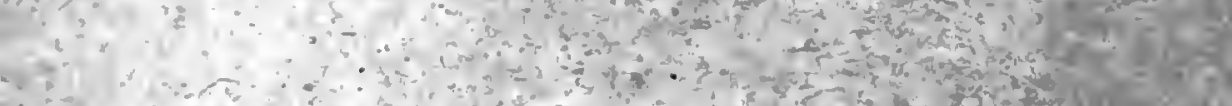

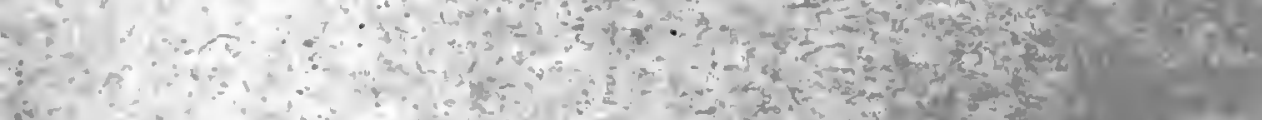

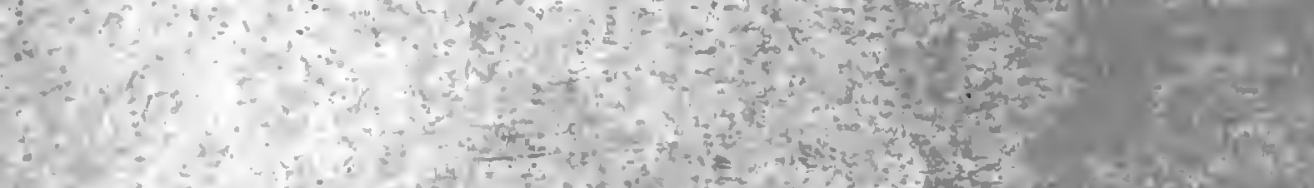
1.1.

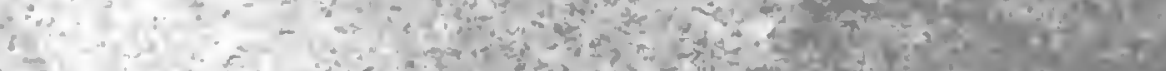

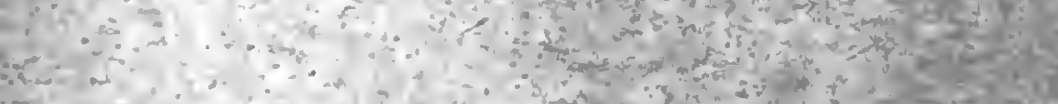

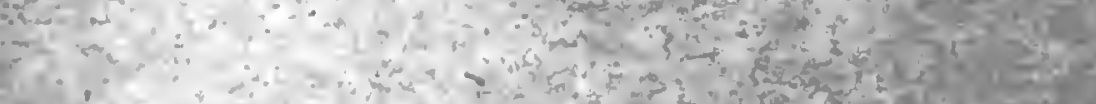

$\therefore$ : :

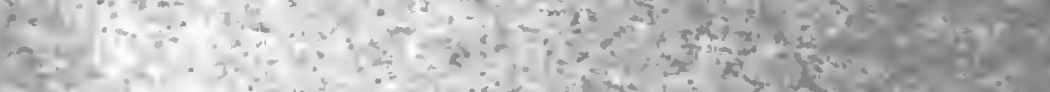

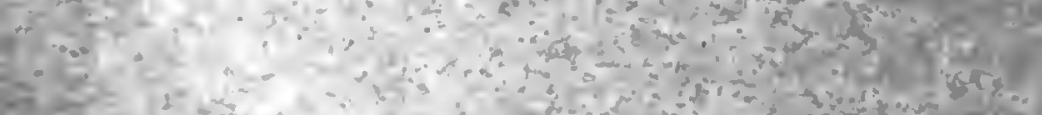

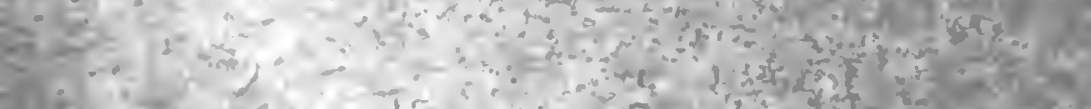

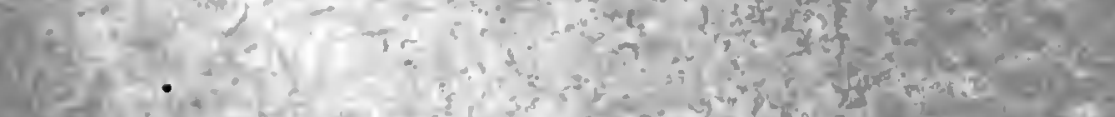

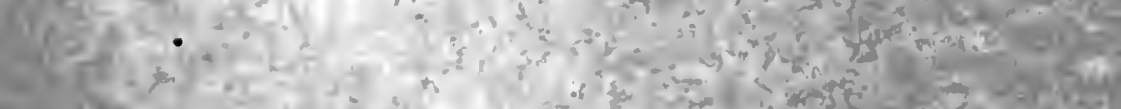

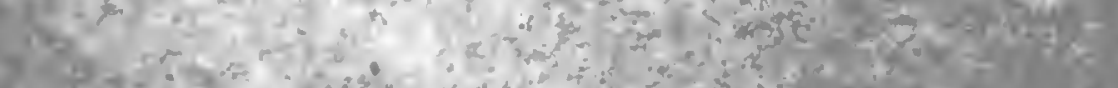




\section{Kapitel. \\ Die Entstehung des, Kapitalverhältulsses“.}

(Die ursprüngliche Akkumulatiou.)

Die Erklärung, die Mars von der Entstehung des Kapital verhältuisses gibt, gehört nicht eigentlich zu unserem Themader Erklärung für die dauernde Reproduktion des Kapitalverhïltnisses. Es ist jedoch nötig, auch jene Darstellung hier kurz wiederzugeben, da es auf andere Weise kaum möglich sein Jürfte, in đen entscheidenden Gedankengang des Meisters einzuführen.

Kapital ist „Wehrwert heckender Wert". „Geld und Ware sind nicht von vornherein Kapital, so wenig wie Produktionsund Lebensmittel. Sie bedürfen der Verwandlung in Kapital. ") Diese Verwandlung kann nur erfolgen auf Grundlage einer schon bestehenden Klassenscheidung: „Das Kapitalverhältnis während des Produktionsprozesses kommt nur heraus, weil es an sich schon im Zirkulationsakt existiert, in den unterschiedenen ökonomischen Grundbedingungen, worin Käufer and Verkäufer sich gegeniibertreten, in ihrem Klassenverbältnis. Es ist nicht das Geld, mit dessen Natur das Verhältnis gegeben ist; es ist vielmehr das Dasein dieses Verbältnisses, das eine bloße Geldfunktion in eine Kapitalsfunktion verwandeln kann. " )

Welches ist dieses Klassenverbältnis? „Zur Verwandlung von Geld in Kapital muß der Geldbesitzer den freien Arbeiter auf dem Warenmarkt rorfinden, frei in dem Doppelsinn, daß er als freie Person über seine Arbeitskraft als stine Ware verfügt, daß

b) Lapital I. 680.

2) Kapital II. 8. 
er audererseits amlere Waren nicht zu rerkanfen hat, los und ledig, frei ist von allen zom Verwirklichung scince Arbeitskraft nötignn sachen." ${ }^{\prime \prime}$, Lnd diese eine historische Bedingung umschllupht eine Weltgeschichte." $?$ )

11 ir wurde also geschichtlich der ,freje Arbipiter" "geschaften? Das stellt Yarx alusfümlich im Kapitel XXIV Irs ersten Bandes scines "Kapital" dar, das den 'litel trägt: "Die sogenannte ursprüugliche Akkumulation“. Nach der „Kindertils!l “ der BourgeoisOKonomie stanmt das Kapital aus der eigenen Arueit der hentigen Besitzer selbst und ihrer Torfihren, die es durch „previous accumulation" (A. Smith) aus ibrem Eiukommen erspart haben. Dem gregenüler zeigt Marx korrekt, da $B$, wenn ich mich der T'erminologie moiner ${ }_{n}$ sozialökonomischen Geschichtsătuffassung ${ }^{*}$ hedicnen darf, das ursprüngliche Kapital, mit dem der ${ }$ Verwertungsproze!., seiner"zeit beganu, nicht dem „ökonomischen", sondern dem „politischen Mittel" seine Entstehung verdankt. „In der Tat sind die Methoden der ursprünglichen Akkumnlation alles andre, nur nicht idyllisch. ... Die ökonomische Struktur der kapitalistischen Gesellschift ist hervorgegangen aus der ökonomischen Struktur der fendalen Gesellschaft. Die Auflösung dieser hat die Elemente jener lreigesetıt. ${ }^{\circ 3}$ ) „Diese Neubefreiten werien erst Terkäufer ihrer selbst, nachrlem ihnen alle ihre Produktionsmittel und alle durch die alten feudalen Einrichtungen gebotenen Garantien ilirer Existenz reraubt sind. Ind die Geschichte dieser Expropriation ist in die Annalen der Menschheit eingeschrieben mit Zügen ron Blut und Feuer."4) . : „Der Ausgangspunkt der Entwicklung, die sowohl den Lohnarbeiter wie den Kapitalisten erzeugt, war die Knechtschaft des Arbeiters. Der Fortgang bestand in einem Formwechsel dieser Knechtung, in der Verwandlung der feudalen in kapitalistische Exploitatiou. ... Historisch epochemachend in der Geschichte der ursprünglichen Akkumulation sind alle Cmwiilzungen, dic der sich bildendon Kapitalistenklasso

1) Kapital 1. 131.

2) Kapital I. 133 .

3) Kapital I. 680.

1) Kipjital 1. 681. (Die gesperrten Stellen săıntlich im Origiual ungespert. 
als Hebel dienen; vor allem aber die Momente, worin große Menschenmassen plötzlich und gewalts a m von ihren Subsistenzmitteln losgerissen und als rogelfreie Proletarier auf den Arbeitsmarkt geschlendert warden. Die Expropriation der lïndlichen Produzenten, der Bauern, ron Gruml nud Buden bildet die Grundlige des ganzen Prozesses. ")

Diese Expropriation schildert Marx nun in seiner meisterhaften Weise an der Hand der englischen Wirtschaftsgeschichte: die Auflösung der fendalen Gefolgschaften, die Säkularisation der Klöster und ihre Cinschalfung in Rittergüter, die "Einhegungen“ und das Clearing-System. 'Sie schufen die ,freien Arbeiter", und eine im Interesse der Kapitalisten, d. h. hier der Großgrundbesitzer und industriellen Unternehmer, erlansene und hart durchgeführte drakonische "Blutgesetzgebung" sorgte dann dafür, daß ihr Lohn genügend herabgedrückt wurde, um die gewiinschte Profitmarge übrig zu lassen nnd die Akkumulation des Kapitals genügend schnell zn fördern. Was hier wirkt, ist durcilaus die nackte Gewalttat und der kaum verschleierte Rechtsbruch nnter dem Schntze deś Klassenstaates!

Ebonso entsteht das zweite der "Elemente" der „kipitalistischen Gesellschaft" , das Kapital selbst in seiner Belleutung als eine Geldsumme, die für den ersten Produktionsprozeß ausreicht: hier ist es namentlich der offene, kriegerische Raub an den Eingeborenen der Kolonien, der wie ersten großen Vermögen in Privathänden aufhäuft, ferner Sklavenjagd und Sklavenliandel. Der Klassenstaat wird gleichfalls im Interesse der herrsclienden Minderheit zur Bildung der ersten Kapitalstämme herangezogen: durch Führung von Kolonial- und Handelskriegen zu Gunsten der Herren, aber mittels der Steuern und des Blutes der Volksmasse, wobei jene sich noch einmal an der Frucht dieses Syrstems, den Staatsschulden, bel eichern; - ferner durch das Schutzzoilsystem, das nichts anderes ist als eine Besteuerung der Masse zü Gunsten der Herren - durch unmittelbare Steuerverwendung für ilhre Interessen -; und schlieblich durch die Einführung der kaum noch formell verschleierten Kindersklaverci zu Gunsten der

1) Kapital I p. 681/2. 
Iniernehmer. "Wenu das Geld, nach Augier, mit natürlichen Blutflecken anf einer Backe zur Welt kommt, so das Kapital von Kopf bis Zeh, aus allen Poren blut- und schmntztriefend. ${ }^{\text {(1) }}$ ) lch habe grundsätzlich dieser Darstellung nichts hinzuzufügen. Sie ist geschichtsphilosophisch vollkommen einwandfrei, und auch in der Dirstellnug so exakt, wie sie zu Marx' Zeit sein kounte. Wir würden heute die Datierung des Anfangs der kapitalistischen Aera etwas früher ansetzen, weil wir auf umfangreicherem historischen Material bauen können: aber im wesentlichen hat auch die allerneueste barstellung, die von Sombart, ${ }^{2}$ ) keinen neven Zug in das Bild zeichnen können. Nur eben, daß die koloniale Raubwirtschaft in der Ievante schon mit den Krenzzügen einsetzt, noch vor der Periode der großen Seeschifffahrt der Kolumbus und Vasco de Gama.

Aber eins möchte ich bemerken, weil es mir eine Wurzel des Hauptirrtums zu sein scheint, den ich sogleich angreifen werde, daß Marx diesen riesenhaften Geschichtsprozeß durchaus nur als Historiker gewürdigt und dargestellt hat: in welcher ökonomischen Umwälzung er gipfelte, hat er aber nicht erkannit, hat, un es scharf zu bezeichnen, seine ökonomisch-theo"etische Quintessenz nicht festgehalten. Daß durch diesen ganzen Yrozeß eine wirtschaftliche Einrichtung entstand oder vielmehr wiedererstand, die das spätere Mittelalter nicht mehr kannte, das Großgrundeigentum, als Bezieher einer stetig wachseuden Grundrente, des ninearhed increment", im Gegensatz zur mittelalterlichen Grundherrschaft, hat er nicht erkaunt, und konnte er wohl auch bei dem damaligen Zustande der geschichtlichen Überlieferung kaum erkennen. Denn das beweisende Material hat erst die dertsche „historische Schule" zu 'Tage gefördert.

Jedoch hat dieser Mangel keinen Einfluß anf die Schlüssigkeit der Theorie, insofern sie zeigt, wie die kapitalistiseho Wirtschaft zum erstenmale entstand als ein „durch Sachen vermittoltes gesellschaftliches Verhältnis zwischen Personen. ${ }^{\text {u3 }}$ ) Wir

1) Kapital I. $725 / 0$.

3) Der moderne Kapitalismus. 2 Bände. Ltipzig 1902.

3) Kapital I. 731. 
haben erfuhren, wie die Geldsummen des Kaufmanns- und Wucherkapitals entstanden sind, die zur Einleitung der ersten Verwertungsprozesse nötig waren, und wir haben ebenso erfahren, woher die "freien Arbeiter" stammen, ohne deren Anwesenheit auf dem Markte als notgedrungene Verkäufer der Ware „Arbeits-

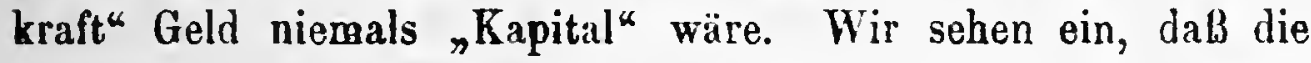
"Gewohnheiten und Lebensanspräche" dieser Expropriierten stark herabgedrückt sein müssen. Sie werden sich also mit einem. Lohn begnügen, der ihreen Anwender „Nehrwert" ïbrigi läßt, oder, in Marx' Auffassung: ,die für einen bestinmten Zeirraun verkaufte Arbeitskraft besitzt weniger Wert, als ihr Gebranch während dieser Zeit schafft". Hier besteht keine Lnklarheit, keine xhwierigheit.

\section{Kapitel.}

\section{Die Reproduktion des Kapitalverhältnisses.}

\section{(l)as Gesetz der kapitalistischen Akkumulation.)}

Das derart durch ursprüngliche Akkumulation, d. h. durch „außerökonomische Gewalt" entstandene Kapitalverhältnis wird nun nach Marx - und damit kommen wir zu unserem eigentlichen Thema - inmer wieder reproduziert durch einen von ihn entdeckten Mechanismus, den er als "das Gesetz del hapitalistischen Akkumulation" bezeichnet.

Durch diesen Prozef entsteht automatisch immer von neuem die Existenzbedingung des Kapitalismus, der "freie Arbeiter" in Marx' Sinne.

Wie nämlich Gold nur Kapital werden konnte, sobald aus irgend welchen Lrsachen "freie Arbeiter" in genügender Anzahl auf lem Markte zu finden waren, so kaun Kapital nur Kapital bleiben, wenn jederzeit "freie Arbeiter" in genügender Anzahl auf lem Markte sich anbieten. Denn wenn jene erste freie Arbeiterschaft sich nicht als solche reproduzierte, so wïrde der 
Lohn auf Kosten der Profitrate steigen und sie zuletzt ganz aufzelren, womit Kapital wieder in einfaches Geld zurückverwandelt wäre. Das ..gesellschaftliche historische Produktionsverhältnis ${ }^{\text {1 }}$ ) wäre verschwunden. Der dem Kapitalverhältnis nzu grunde liegende Tatbestand, die Verteilung der Elemente der Produktion sellsst, von denen die gegenstänllichen laktoren auf der einen Seite kouzentriert sind, die Arbeitskraft daron isoliert auf der anderen "), wäre nicht mehr gegeben.

Fin solcher ginustiger Ausigang ist aber nach Marx ausgeschlossen. Denn nach seiner Behauptung ist „Arbeitshraft auf Basis der kapitalistischen Produktion immer vorrätig“; es kann sogar nweun nötig, ohne Vergrößerung der beschäftigten Auzahl Arbeiter oder Masse Arbeitskraft melır Arbeit flüssig gemacht werden. *33)

Er stellt den Tatbestand, wie er ihn sieht, am ansführlichsten in den folgenden Sätzen dar:

"In Fortgang der kapitalistischen Produktion entwickelt sich eine Mrbeiterklasse, die ans Erzielıung, Tradition, Gewolınheit, die Anforderungen jener Produktionsweise als selbstverständliche Naturgesetze anerkennt. Die Organisation des ausgebildeten kapitalistischen Produktionsprozesses bricht jeden Widerstand, die beständige Erzeugung einer relativen Übervölkerung hält das Gesetz der Zufuhr von und Nachfrage nach Arbeit; und daher den Arbeitslohn, in einem den Verwertungsbedürfnissen des Kapitals entsprechenden Gleise, der stumme Zwang der ökonomischen Verhältnisse besiegelt die Herrschalt des Kapitalisten über die Arbeiter. Außerökonomische, unmittelbare Gewalt wird zwar noch immer angewandt, aber nur ausualunsweise. Für den gewöhnlichen Gang der Dinge kanr der Arheiter den „Naturgesetzen der Produktion“ überlassen bleiben.

. Anders während der historischen Genesis der kapitalistischen P'roduktion. Die aufkommende Bourgeoisie brancht und verwendet die Stalatsgewalt, um den Arbeitslolın zn reguliereu, d. h. innerhalb der Plusinacherei zusagender Sclıranken $\mathbf{z a}$ zwängen,

') Kapital J. 7:\% $\mathbf{l n m}$.

2) Kippitial II. 9.

3) Kapital II. 503. 
uın den Arbeitstag zu verlängen'n, und den Artueiter selbst in normalem Abhängigkeitsgrad zu erhalten. Es ist dies ein weseutliches Noment der sog. ursprü̈nglichen Akkumulation. ${ }^{\text {(1) }}$ )

„Was aber Anfangs- und Ausgangspunkt war, wird vermittelst der hloßen Kontinuitït des Prozesses .... stets aufs neue produziert and verewigt als eigenes Resultat der kapitalistiechen Produktion. Einerseits rerwandelt der Produktionsprozeß fortwährend den stofllichen Reichtum in Kapital .... andererseits kommt der Arbeiter beständig aus dem Prozeß lieraus, wie el in ihn cintrat, - persönliche Quelle des Reichtums, aler entblübt von allen Mitteln, diesen Reichtum für sich zu verwirklichen. “ ${ }^{2}$ ) „Der kapitalistische Produktionsprozeß, im Zusimmenhang betrachtet, oder als Reproduktionsprozeb, produziert also nicht nur Ware, nicht nur Mehrwert, el produziert und reproduziert das Kapitalverhältnis selbst, auf der einen Seite den Kapiralisten, auf der auderen den Arbeiter. ${ }^{3}$ )

Die gleiche Behauptung tindet sich noch an den verschiedensten Stellen in venschiedener Formulierung, aber immer gleicher Bestimmtheit: "Die kapitalistische $\Lambda$ kkumulation prodnziert..., und zwar im Verhältnis zu ihrer Energie nnd ihrem Lmfang, beständig eine relative, $d . h$. für die mittleren Verwertungsbedürfuisse des Kiapitals überschïssige, daher überfliissige oder Zuschuf,-Arbeiterbevölkerung. ${ }^{*}$ ) - - „Durch den einfachen Prozeß, der einen Teil der Arbeiter beständig ,freisetzt“, durch Iethoden, velche die Anzahl der beschäftigten Arbeiter in Ver-

1) Kapital I. 703.

3 Kapital I. 533 .

3) Kapital 1. 541. Vgl. auch JII. 2, prag. 353: ,Wir hal,en geselien. dab der kapitalistische Produktionsprozeß eine gesehichtlich bestimnte Form des gesellschaftlichen Produbtiousprozesses überhaupt ist. Dieser letztere ist sowohl Prodnlitiunsprozef der materiollen Existenzhedingungen des materiellen Lebens, wie ein in spezitischen, historisch-ökonomischen Proditktionsverhăltuissen von sich gehender, diese Produktionsverhältnisse selbst, nud damit die Trïger dieses Prozesses, ihre materielleu Existemzliedingungen und ibre gegenseitigen Verhätnisse, d. h. ihre bestimmle ükonomische Gesellschaftsforn produziereader und reproduzicrender Proze B." (In Orio. nicht gesperit).

b) Kapital I. 594: rgl. auch III. 1, pag. 217. 
hältnis zur vermehrten Produktion verminderin, wird geschaffen jenes , ilisponible Menschemnaterial“, jene „vom alısoluten Wachstun der Bevölkerung unabhängige Vernichrung vou Arheitern." "1) „)iese C̈bervölkerung wird. . . zum Hehel der kapitalistischen Akkumulation, ja zu einer Existenzberlingung der kapitalistischen Produktionsweise. ${ }^{\text {(2) }}$ )

Diese inhaltsschweren Sätze sind das Ergebnis einer langen, mühevollen Derluktion, die den wichtigsten Inbalt des ersten Bandes des „Kapjtal" ausmacht. Ich glaube, heinen Widerspruch erwarten zu dürfen, wenn ich diese Jeeinktion als den folgenlen fünfyliederigen Kettenschlufs larstelle:

I. Wo Kapital akkumuliert wird, da (wächst verhältuismäßßig der konstante und) fïllt verhältnismäbig i variahle Kapitalbestandteil. ${ }^{3}$ )

II. Wo das variable Kapital im Verhältnís zum Gesaintkapital fällt, da fällt im gleichen Verhïltn:s (Lolin und Länge des Arbeitstages als gleich gesetzt) die Zahl der heschäftigten Arbeiter, der "Stellen", wie ich diese 7ahl im folgenden nennen werde.

III. Wo die Zahl der „Stellen" im Verhältnis zum Gesamtkapital fällt, da fällt sie auch im Verhältnis zur Ziahl der arbeitsfähigen und arbeitswilligen Mitglieder des Proletariats, der naktiven Arbeiterarmee".")

IV. Wo die Ziahl der ${ }_{n}^{\text {Stellen }}{ }^{\alpha}$ im Yerhältnis zum ... Proletariat fällt, da wächst die Surplusbevïlkerung. ${ }^{5}$ )

V. Wo die Surplusbevölkerung wächst, da wäclsst auf Seite des Proletariats „Elend, Arbeitsqual, Sklaverei, Unwissenlseit, Brutalisierung und moralische J)egtadation".6)

1) Kapital I. 598.

2) Kitpital I. $596 / 7$.

3) Kapital I. p. 585-593.

t) Kapital I. 593-600.

5) Kapital I. 600-605. „Die Produktion einer relativen C̈berväkerung oder die Freisetzung ron Arbeitern geht daher noch ruscher voran als die olınehin mit dem Fortschritt der Akkumulation beschleunigte techuische linwälzung des Produktionsprozesses und die entsprechende proportionelle Abnalune des variablen Kapitalteils gegen den konstanten “ (l. c. I. 600).

6) Kapital 1. 611. 
Folglich (I-V):

„Wo Kapital akkumuliert, wird, da wächst auf Scite des Proletariats „Elend, Arbeitsqual“ u. s. w.

Gibt man sämtliche Prämissen zu, so ist dẹ SchluR unwiderleglich: in allen diesen allgemeiu-bejahenden Siitzen ist das Prädikat des rorhergehenden das Subjekt des folgenden Satzes.

Ich werde jetzt die Begründung der einzelnen Hauptsätze, wie sie von Marx selbst gegeben ist, in möglichster Kürze wiedergeben, nm daran den Beweis zu schliefen, daß der gesante Kettensciluf einer logischen Prüfung nicht stand halten kam.

\section{Kapitel. \\ Der Marxsche Kettenschluß.}

\section{A. Darstellung.}

\section{a) Hanptsatz I.}

Wo Kapital akkumuliert wird, (wächst verhältnismäßig der konstante und) fällt verhältnismäßig der variable Kapitalbestand teil.

Kapital, insofern es Wert, "Mehrwert heckender Wert" ist, besteht aus "konstantem Kapital oder Wert der Produhtionsmittel, und variablem Kapital oder Wert der Arbeitskraft, (iesamtsumme der Arbeitsiöhne". Dies Verhältuis nenut Marx die "Wertzusammensetzung des Kapitals". „Nach der Seite des Stoffs (aber), wie er im Produktionsprozeß fungiert, teilt sich jedes Kapital in Produktionsmittel und Arbeitskraft; diese Z11summensetzung bestimmt sich durch das Verhältuis awischeu der Masse del angewandten Produktionsmittel einerseits und der za ihrer Anwendung erforderlichen Arbeitsmenge anter'rseits." Dies Verhältnis nennt or die "technische" Zusammensetzung des Kapitals. „Zwischen beiden besteht eine enge Wechselbeziehung. Um diese auszudrücken, nenne ich die Wertzusammensctzung des Kapitals, insofern sie durch seine technische Zusammen- 
setzung bestimmt wird ...: dic organische Zusammensetzung des Kapitals." $)$

Diese organiscise Zusammensetzung $m u ß$ sich nun nach Marx mit der Akkumulation fortwährend ändern, und zwar derart, daf das variable Kapital fortwährend ahnimmt im Verhältnis zum koustanten Kapital. In dem Yaße, wie das Kapital sich durch Akkumulation vermehrt, wird ein immer gröferer Teil desselhen in konstantem Kapital angelogt, also in Arbeitsmitteln: Creoüuden, Maschinen etr.; dem "fixen Kapital ${ }^{\star}$ der älterely Ökon unih; ur:d denienigen Teile des ron jener sogenimten ,zikialierenden Lapitals ${ }^{*}$, der in Arheitsgegenständen bestel:i, ilericn lie Arbeitskruft Wert zusetzt. Ein immer kleinerer T'eil aber wind als rariables hapital reransgabt, d. h. zu Arbeitslöhnen, zur besoldung von Arbeitern verwendet.

MLux widmet den Crsachen und dem Fortgange dieser Veränderming in der cryanischen Zusarnmensetzung des individuellen und damit ies fiesamtkapitals eine schr ausführliche Darstellung. Er zcigt, wie schon im Prozeß der einfachen Kouzentration des Kapitals anf dem Wege der Akkumulation die technische Úmwälzung eilitreten $n u \beta$, weil die ans Mehrwert neu gebildeten Zusatzkapitalien regelmäßig in den neuesten und besten Arbeitsmittel"s alugelegt werden und durch ihre Konkurrenz das alte Kapital zwingeu, den technischen Fortschritten zu folgen; und wie namentlich der Prozeß der Zentralisation, d. h. Bildung eines größeren Kajpitals aus vielen kleineren, sei es durch Vergesellschafturg, sei es durch Aufsaugung der schwachen Kapitalisten duich die starken, die technische V'mwälzung beschleunigt.

\section{b) Hauptsatz II.}

Ifo las variable Kapital in Verhältois $20 \mathrm{~m} \mathrm{Ge-}$ santiapital fält, fällt im gleichen Perhältnis (Lohn und Lïuce des Arbeitstages gleich gesetzt) die Zahl der ,Stellen".

ग) Kay.itial 1. 576. Rekapituliert III. 1, pag. 183/4. 
Dieser Hauptsatz ist kein ,synthetischer" Satz, der etwas Neues vom Subjekt iussagt, sondern ein "inalytischer Satz", der ein konstitnierendes Nerkmal iles Subjekts noch eimmal im Prädikat heraushebt.

Variables Kapital ist nämlich definiert als "(iesamtsuinme der Arbeitslöhne". Nemne ich den Durchschnittslohn zu einer gegebenen Zeit $l$, die Zahl der Beschläftigten („Stellen" ${ }^{*}$ ) $s$, und das variable Kapital $v$, so ist $v=l \cdot s$. Dann ist also $s=v: l$; oder in Worten ausgedriickt: die Kahl der „Stellen" fäll, wenn der Loln konstant bleibt, mit dem rariablen hapital. „Wo früher ein Kapitalzuwachs von $20 \%$ genügt hätte, die Nachfrage nach Arbeit un $20 \%$ zu steigern, . . . $\left.;^{\prime}\right)$ - „Bisher wurde angenommen, daß der Zu- oder Abnihne des variablen Kapitals genau die $\mathrm{Zu}$ - oder Abnalime der beschäftigten Arbeiterzahl entspricht. ${ }^{2}$ )

Diese Formel gilt also ausdrücklich nur unter der Toraussetzung ${ }_{n}$ sonst gleicher Verhältnisse" des Lohnes und der Jänge des Arbeitstages. Wie und wie weit sie sich nach Marx ändert, wenn Lobn und Arbeitstag variieren, wird uns unteu noch des näheren beschäftigen. Hier genügt uns, mit Marx vorläufig festzustellen, daß ceteris paribus die Zahll der Arbeiter im gleichen Verhältnis wie das variable Kapital steigen und fallen muß.

\section{c) Hauptsatz III.}

Wo die Zahl der "stellen "im Verhältnis zum Gesamtkapital fällt, da fällt sie auch im Verbältnis zur Zahl der arbeitsfähigen und arbeitswilligen Mitgliedor des Proletariats, der aktiven Arbeiterarmee.

Ich führe die entscheidenden Sätze wörtlich an: ${ }^{3}$ )

„Die spezifisch kapitalistische Produktionsw eise, die ibr ontsprechende Entwicklung der Produktivkraft der Arbeit, der

1) Kapital I. 587/8.

2) Kapital I. 600.

2) Kapital I. 593/4. 
dadurch verursachte Wechsel in der organischen Zusamunensetzung des Kapitals halten nicht nur Schritt mit dem Fortschritt ler Akkumulation oder dem Wachstum des gesellschaftlichen Reichtums. Sie schreiten ungleich schneller, weil die einfache Akkumulation: oder die absolute Ausdehnung des Gesamtkapitals von der 'Zentralisation seiner individuellen Elemente, und die technische Imwälzung des Zusatzkapitals von technischer Lmwälzung des Originalkapitals begleitet sind. Mit dem Fortgang der Akkumulation wandelt sich also das Verhältnis von konstantem zu variablem Kapitalteil, wenn ursprünglich $1: 1$, in $2: 1,3: 1$, $4: 1,5: 1,7: 1$, soda $\beta$, wie das Kapital wächst, statt $1 / 2$ seines Gesantwerts progressiv nur $1 / 5,1 / 4,1 / 5,1 / 6,1 / 5$ u. s. w. in Arbeitskraft, dagegen $3 / 3,3 / 4,4 / 5,5 / 6,7 / 8$ u. s. w. in Produktionsmittel ungesetzt wird. Da die Nachfrage nach Arbeit nicht durch den Umfang des Gesamtkapitals, sondern durch den seines variablen Bestariteils bestimmt ist, fällt sie also progressiv mit dem Wachstum des Gesamtkapitals und in beschleunigtel Progression mit dem Wachstum dieser Größe. Mit dem Wachstum des Gesamtkapitals wächst zwar auch sein variabler Bestandteil, oder die ihm einverleibte Arbeitskraft, aber in beständig abnehmender Progression. Die $Z$ wischenpausen, worin die Akkumulation als bloße Erweiterung der Produktion auf gegebener technischer Grundlage wirkt, verkürzen sich. Nicht nur wird eine in wachsender Progression beschleunigte Akkumulation des Gesamtkapitals erheischt, um ine zusät/liche Arbeiterzahl von gegebener Größe zu absorbieren. oder sellst, wegen der beständigen Metamorphose des alten Kapitals, die bereits funktionierende zu beschäftigen. Ihrerseits schlägt diese wachsende Akkumulation und Zentralisation selbst wieder um in eine Qnelle neuer Wechsel der Zusammensetzang des Kapitals oder abermaliger beschleunigter Abnahme seines variablen Bestandteils verglichen mit dem konstanten. Diese mit dem Wachstum des Gesamtkapitals beschleunigte relative Abnahme seines variableu Bestandteils scheint auf der anderen Seite stets rascheres absolutes Wachstum der Arbeiterbevölkerung als das des variablen Kapitals oder ihres Arbeitsmittel. Die kapitalistische Akkumulation produziert vielnehr, und zwar im Verhältnis zu ihrer Energie und ihrem Lin- 
fang, ') beständig eine relative, d. h. für die mittleren Verwertungsbedürfnisse des Kapitals überschüssige, daher überflüssige oder Znschuß-Arbeiterbevölkerung. " )

\section{d) Hauptsatz IV und V.}

IV. Wo die Zahl dei Stellen im Verhältuis zum ... Proletariat fällt, da wächst die Surplusbevöllerung.

V. Wo die Surplusbevölkerung wäcbst, da wächstauf Seite des Proletariats Elend, Arbeitsqual, Shlaverei, Tnwissenheit, Brutalisierung und moralische Degradation.

Die beiden Sätze finden keine ausführliche Darstellang und bedürfen einer solchen auch nicht. Sie sind unlengbare Konsequenzen aus Satz III. Wo die Zahl der Stellen im Verhältnis zur. Zahl der arbeitsfähigen und arbeitswilligen Mitglieder des. Proletariats sich vermindert, da wïclst natïrlich die Zahl der Unbeschäftigten, und mit jhr der Druck auf den Arbeitsmarkt, und es mul3 sich der Lohn, d. h. die materielle Lage der Arbeiterschaft, ebenso verschlechtern, wie ihre physische. Ausnützung (Arbeitsqual) und ibre Behandlung innerhalb und außerhalb des Arbeitsprozesses, d. h. ihre soziale Lage.

\section{B. Kritik.}

Ich lasse Satz I, II, IV und $V$ gelten. Was aber Hauptsatz III anlangt, sq kann ich mich nicht davon überzeugen, dals der ron Marx für ihn heigebrachte Beweis ausreicht.

"Wo die Zahl der "Stellen" im "erhältnis zum Gesantkapital fällt, da fällt sie auch im Verhältnis zur Zahl der arieitsfähigeu und arbeitswilligen Mitglieder dez Proletariats." So lautet der Sati in unserer Formulierung.

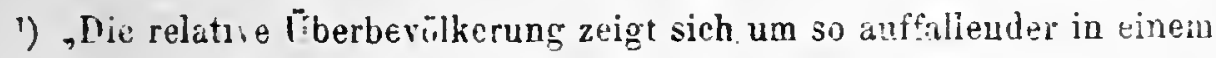
Laude, je mehr die kapitalistische Produktionsweise in ihm entwickelt. ist." Kapituil. III. 1, p. $21 \%$.

$?$ Äinlich Kapital III. 1, p. 19S1f., namentlich 204.

us penui iner, Marx' Gesellschaftslebre. 
Nenue ich die Zahl der Stellen $s$, das Gesamtlapital li; dio Zahi der arbeitsfahigen ... Proletarier $p$, so lantet der Satz: Wo die Propoltion $s: k$ fällt, da fällt auch die Proportion $s: p$. Da $v=l \cdot s$, ( $c$ : das gesellschaftliche variable Kapital, $l$ : der John) $l$ aber in dieser ganzen Betrachtung als konstant gesetzt ist (vol. oben S. 31), so kann man deu Satz auch folgendermaßen formulieren: „Wo $v: k$ fällt, fällt auch $\because: p$. “

1)ieser Satz ist der kurz ausgedrückte Inhalt der oben unter „Hauptsarz III" wörtlich angefïhrten Stelle. Der arste Teil. bis zu den Wocten: , verglichen mit dem konstanten " boschäftigt sich mit dem Fallen der Proportion $r: k$; die beiden letzten Sät $z$ :

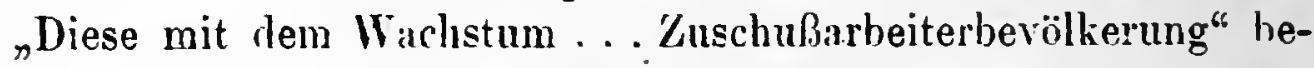
haupten das entsprechende Fallen der Proportion $v: p$.

Marx ist also der Meinung, daß $k$ und $p$ Größen sind. zwischen denen eine Ahhängigkcit besteht derart, daß das Wachstum ron $k$ eng an dasjenige ron $p$ gebunden ist: „Es ist also heineswegs das Verhältnis zweier von einander unabhängiger Frößen, einerseits der Größe des Kapitals, andrerseits del Zahl der Arbeiterbevölkernng. " $)$

Wenn eine derartige Abhängigkeit zwischen $k$ und $p$ in der Tat existiert, so ist es jedenfalls eine solche, welche nicht ohne weiteres erkanut werden kann. Denn $k$ und $r$ wachsen auf verschiedene Weise: $k$ wächst mit der Stufenleiter des Produktionsprozesses und der Größe des ahsoluten und relativen Mehrwertes und umgekehrt proportional dem persönlichen Verbrauch der Kapitalistenklasse. $p$ aber wächst mit der Bevölkerung je nach dem C̈berschuß der Geburten plus der Einwanderung über die Sterbeziffer plus der Auswanderung und nit dem prozentualen Viachstum der Erwerbstätigen. Das sind Dinge, die auf den ersten Blick voneinander unabhängig zu sein scheinen.

Varx rersucht unn, eine tiefere, soznsagen dynamische $A b-$ hängigkeit zwischen $k$ und $p$ aufzudecken. Er stellt folgende Betrachtung an: „Interstellen wir, daß, nebst sonst gleichbleibenden Lmständen, die Zusammensetzung des Kapitals unverïndert bleibt, d. h. eine bestimmte Masse Produktionsmittel

1) Kapital I. 584 . 
oder konstantes Kapial stets dieselbe Ylasse Arbeitskraft erheischt, um in Bewegung gesetzt zu werden, so wächst offenbar die Nachfrage nach Arbeit und der Subsistenzfonds der Arbeiter verhältnismäßig mit dem hapital und um so rascher, je rascher das Kapital wächst. Da das liapital jührlich einen Mehrwert produziert, woron ein Teil jährlich zum Originalkapital geschlagen wird, da dies Increment selbst jähr'ich wächst mit dem zunehmenden Linfang des bereits in Funktion berriffenen Kapitals, und da endlich unter besonderem Sporn des Bereicherungstriebs, wie z. B. Öfinung neuer Märkte, neuer Sphären der Kapitalanlage infolge neuentwickelter gesellschaftlicher Bedürfnisse, usw, die Stufenleiter del Akkumulation plötzlich auscichnbaj ist durch blob veränderte Teilung des Mehrwerts ofer Mehrprodukts in Kapital und Kerenue, können die Akkumulationsberlürnisse des Kapitals das Wachstum der Arbeitskraft orlel Arbeiteranzihl, die Nachfrage nach Arbeitern ihre 'Zufuhr überflügeln, und daher die Arbeitslöhne steigen. Dies mus sogar schließich der Fall sein bei unveränderter Fortdauer der oligen Voraussetzung. Da in jedem Jahre mehr Arbeiter beschäitigrt werden, so mub früher oder später der Punkt eintreten, wo die Bedürfnisse der Akkumulation anfangen, über die gewöbnliche Zufuhr von Arbeit hiniuszuwachsen, wo also Lohusteigerung eintritt. “')

Hier wird also der Fall untersucht, daß k zeitweilig schneller wächst als $p$, und daß, weil die Proportion $v: k$ hier als konstant unterstellt wird, auch $v$ entsprechend schneller wächst. In diesem Falle wächst also der Bruch $n: p$, und die liehrwertrate sinkt, wäbrend der Lohn steigt. 'Bliebe die Voriussetzung so gïnstiger Umstïnle gegeben, so wäre auf die Länge der Zeit das kapitalistische System in seiner Wurzel bedroht; denn die zu Anfang reer l.ohnsteigerung noch vorhandene Surpinsbevölkerung "freier" Arbeiter, die Grundvoraussetzung aller kapitalistischen Akkumulation, würde sich dauernd vermindern, der John würde auf Kosten der Mehrwertrate dauernd steigell, der dem Kapitalverhältnis zugrunde liegende Klassengegensatz würde sich mohn und mehr ausgleichen, statt sich zu verschärfen, kurz, die

1) Kapital I. $\mathbf{3 7 7 .}$ 
kapitalistische Wirtschaft würde mehr und mehr verschwinden; und, wenn vielleicht auch das „Kapitalverhältnis“ immer wieder reprodnziert würde (obgleich bei so hohen Löhnen auch der Arbeitel" würde ,akkuınulieren" könuen), so wäre doch jedenfalls von der Reproduktion von "Elend, Arbeitsqual" usw. keine Rede mehr.

Dieser günstige Ausgang kann aber nach Marx nicht eintreten. Er schreibt: ${ }^{1}$ )

„Das Steigen des Arbeitslohues besagt im besten Fall nur 'quautitative Abnahme der unbezallten Arbeit, die der Arbeiter leisten muß. Diese Abnahme kann vie bis zum Punkt fortgehen. wo sie das System selbst bedrohen würde ... Ein aus Akkumulation des Kapitals entspringendes Steigen des Arbeitspreises stellt folgende Alternative:

"Entweder führt der Preis der Arbeit fort zu steigen, weil seine Erhöhnug den Fortschritt der Akkumulation nicht stört; es liegt darin nichts wunderbares, denn, sagt A. Smith ... nein großes Kapital wächst selbst bei kleinerem Profit im allgemeinen rascher als ein kleines Kapital bei großem Profit. "... Oder die Akkumulation erschlafft infolge des steigenden Arheitspreises, weil der Stachel des Gewinns abstumpft. Die Akkumulation nimmit ab. Aber mit ihrer Abnahme verschwindet die Irsache ihrer Abnahme, nämlich die Disproportion zwischen Kapital und exploitabler Arbeitskraft. Dè Mechanismus des kapitalistischen Produktionsprozesśes beseitigt also selbst die Hindernisse. die er vorübergelsend schafft. Der Arbeitspreis fällt wieder auf ein den V'erwertungsbedürfnissen des Kapitals entsprechendes Niveau." :)

Marx rekapituliert seinen Schluß noch einmal auf der folgenden Seite: ${ }^{3}$ ) "Wächst die Menge der von der Arbeiterklasse gelieferten und rou der Kapitalistenklasse akkumulierten, unbezahlten Arbeit" (i. e. des Mebrwerts) "rasch genug, um nur

1) Kaprite1 1. $383 / 4$.

$\Rightarrow$ Kiure Rekapitulation 111. 1, 343: „Dic Ninimalgrenze des Zinses ist "gauz, und gar unıestimıbar. Er kann zu jeder beliebigen Tiefe fallen. ladesson treteu dacu immer nieder gegenwirkende Uustände ein und beben ihn über dies relative llinimum."

" hapilal 1. 585 . 
durch einen außergewöhnlichen Zuschuß bezahlter Arbeit sich in Kapital verwandeln zu können, so steigt der Lohn und ... nimmt die unbezahlte Arbeit iın Verhältnis ab. Sobald aber diese Abnalıme den Punkt berülırt, wo die das Kapital ernährende Mehrarbeit nicht mehr in genïgender Menge angeboten wird, so tritt eine Reaktion ein: ein geringerer Teil der Revenüe wird kapitalisiert, die Akkunulation erlahmt, und die steigende Lohnbewegung empfängt einen Gegenschlag. Die Erhöhung des Arbeitspreises bleibt also eingebannt in Grenzen, die die Grundlagen des kapitalistischen Sisstems nicht nur unaugetastet lassen, sourlern auch seine Reproduktion auf wachsender Stufenleiter sichern. Das in ein Naturgesetz mystifizierte Gesetz der kapitalistischen Akkumulation drückt also in der 'Tat nur aus, dat inre Natur jede solche Abnahme in Exploitationsgrad der Arbeit oder jede solche Steigerung des Arbeitspreises ausschließt, welche die stetige Reproduktion des Kapitalverhältnisses und seine Reproduktion auf stets erweiterter Stufenleiter ernsthaft gefährden könnte."

Hier ist also der Nachweis zn führen gesucht, daB $k$ auch unter den günstigsten Cmständen, die man erdenken kann, niemals auf die Dauer wesentlich schueller wachsen kann als $p$, oder, m. a. W., daß der Bruch $k: p$ nicht wesentlich wachsen kann. Da hier unterstellt wird, das variable Kapital $v$.wachse pari passu mit dem Gesamtkapital $k$, so kamn danach auch der Bruch $v: p$ nicht wesentlich steigen, der Arbeitslohn bleibt in Grenzen gebannt, die „die Grundlagen des kapitalistischen Systems unangetastet lassen."

Nnn bestehen abei in Wirklichkeit noch viel ungünstigere Verhältnisse. Nach unserem Hauptsatz II wächst in Fortgang der Akkumulation $v$ nicht gleichen Schritts mit $k$, sondern die Proportion $v: k$ sinkt fortwährend. Wenn also sehon die Proportion $\bar{k}: p$ nicht wesentlich wachsen konnte, so muk die Proportion $v: p$ mit ungefïhr derselben Geschwindigkeit sinken, mit der die Proportion $v: k$ sinkt.

Diese Gesch windigkeit abər ist eine ungeheure, weil sie durch einen fatalen Prozeß, in dem die Wirkung immer wiecler zur Ursache wird, fortwährend beschleunigt wird. Denn der größere 
Kapitalist expropriiert durch Lnterbietung dein kleineren, oder kleinere Kapitale assoziieren sich zu einem großen (Aktiengesellschaften): Zentralisation der individuellen Elemente des Gesamtkapitals; ${ }^{\text {) }}$ "viele kleinere werden in wenige große Kapitale yerwanclelt", ein Prozeß, dessen "Spielraun also durch das absolute Wachstum des gesellschaftlichen Reichtums oder die absoluten Gren\%en der Akkumulation nicht beschränkt ist. "2) Diese Zentralisation großei Kapitale in einem Betriebe drückt sich technisch naturgemäß aus in einer Erhölıng der Stufenleiter des Produktionsprozesses, d. h. in einem beschleunigten Wechsel der organischen Kapitalszusammensetzung. Dasselle, wie diese n.ttriktion" der individueilen Tapitale bewirkt aber auch ihre "Repulsion", d.h. die Bildung neuer, nach neuer Anlage, nach "Verwertung" in neuen Betrieben verlangender "7usatzkapitale“. Es „reifen sich Ableger von den Originalkapitalen los und funktionieren als neue selbständige Kapitale. Eine große Rolle spielt dabei unter anderm die Teilung des Vermögens iu Kapitalistenfamilien. ${ }^{3}$ ) Diese neuen Kapitale bewaftinen sich naturgemäß mit deı vollkummensten zur Zeit vorhandenen Waschinen etc., und zwingen daher die schon länger funktio-

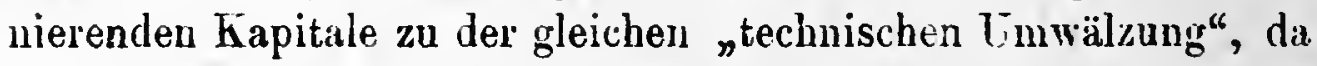
sie anderś den Konkurrenzkampf nicht bestehen könuten. Nadurch wird aber wieder der Prozeß der Zentralisation und .:Attraktion" beschleunigt, da schwächere Kapitalisten die technische $L$ mwälzung aus Mangel in Mitteln nicht mitmachen können und infolgedessen expropriiert wercien; nit der Zentralisation beschleunigt sich bei den Siegern im Konkurrenzkampfe die Akkumulation und mit ihr die "Repulsion" von Zusatzkapitalen, und so fort in infinitum: eime Beschleunigung der Bewegung, älsulich wie beim fallenden Körper.

Es fillt also $v: k$ in fortwährend beschleunigter Progression, und so muß auch $v: p$ in älnlicher Progression sinken, kraft des dargestellten engen Zusammenhangs zwischen $k$ und $p$. Es

i) Kapital I. 594.

\%) Kupital I. 590 .

3 Kilpital I. 589. 
drängen sich, mit andern Worten, immer mehr Arbeiter zur Anteilnahme an einem variablen gesellschaftlichen Kapital von gegebener Gröbe, das ihren "Subsistenzfonds" darstellt. "Einerseits attrahiert das im Fortgang der Akkumulation gebildete Zuschußkapital, verhältnismäßig zu seinte Grïlie, weniger und weniger Arbeiter, andrerseits repelliert das periodisch in inmer neuer Zusammensetzung reproduzierte alte Kapital mehr und mehr früher von ihm beschäftigte Arbeiter". ${ }^{1}$ ) Jie Folge ist, daß nicht nur der auf den einzeluen Beschïftigten entfillende Anteil I die Tendenz hat, zu sinken ("dis Elend stets waclisender Schichten der aktiven Arbeiterarmee ${ }^{2}$ ) - sondern daP auch eine wachsende 7ahl Linheschäftigter iibrig bleibt, „freigesetzt" wird. ${ }^{3}$ ) Cnd so folgt der Schlußsatz der oben angeführten Stelle richtig aus den Prïmissen: „Die kapitalistische Produktionsweise produziert vielmehr, und zwar in Verhältnis zu ilırer Euergie und ihrem Ymfang, bestïndig eine relative, d. h. für die mittleren Verwertungsbedürfnisse ïherschüssige, daher überflüssige oder Zuschuß-Arbeiterbevölkerung.".

Das ist der Marxsche Beweis für das Gesetz der Akkumulatiou. Er steht und fällt mit der Stringenz der Schlüsse, die Marx aus seiner oben dargestellten Alternative gezogen hat. Ich kann mich nicht überzeugen, daß diesen Schlüssen zwingende Kraft innewohnt.

Zunächst könnte man schon gegen die Formulierung der Alternative Bedenken geltend machen. Sie ist nach dem :Ifuster der obertlächlichsten Konstruktionen der klassischen Schule und ihrer "vulgär-ökonomischen" Nachfolger" gebaut und m. E. durchaus nicht erschöpfend. Es ist z. B. die Möglichkeit gar nicht ins Auge gefaßt, dal der Preis der Arbeit, ohne "den liortschritt der Akkumulation (seitens der Kapitalistenklasse) zu stören", so hoch steigt, daß auch die Arbeiter in geringerem oder

1) Kapital I. 610 .

2) Kapital I. \$93.

3) Kupita! I. 598. 
größerem laße akkumuliereti können. Dann sind sie nicht mehr "freie" Arheiter im strengsten Sinne und haben vielleicht in größerer Anzahl sogar die Nittel, ihre Arbeitskraft zu ihrem eigenen Natzen zu rerwerten. Aber lassen wir die Alternative eiumal gelten! Nehmen wir also mit Marx an, die Akbumulation werde in der Tat erschlaften. wenn der Profit einen gewissen Iinimalsatz unterschitten habe, und dann werde sich der Gewinnsatz, weil die Bevölkerung weiter wächst, oder Kapital verzehrt wird, wieder auf jenes Minimum eriöhen, an dem der ${ }_{n}$. itachel des Gewinus abstumplt". Sobald dieser Minimalsatz des Profits erreicht ist, sollen also wirklich $k$ resp. $v$ und $p$ eng aneinander gebundene Größen sein.

Daraus kann man folgern, daß der Bruch $k: p$ resp. $v: p$, und daher der Arbeitspreis, nicht über ein völlig unbestimmtes Maximum wachsen kann. Marx zieht aber Scblüsse, dic nur richtig wären, wenu er bewiesen hätte, daß diese Proportion nicht über ein ganz bestimmtes Maximum wachsen kann, nämlich über denjenigen Arbeitspreis, der dem Proletariat eben gerade die Befriedigung, seires standesgemäBen, allenfalls eines etwas gehobenen Standard gestattet, der ihn aber durchaus nicht gestattet, an den höheren Kulturgütern teilzunehmen, geschweige denn selbst Kapital zu akkumulieren: kurz, über ein Maximum, bei dem das „Kapitalverhältuis" kaum gemildert bestehen bleibt.

Yarx hat aber auch nicht den Schatten eines Beweises dafür erbracht, daß jenes unüberschreitbare unbestimmte Maximum (ies Arbeitspreises mit dem von ihm behaupteten bestimnten Vaximum zusammenfallen muß. Er hat den ersten Fall seiner eigenen Alternative nicht zu Eude gedacht.

Ilier dreht sich alles um ein psychologisches Problem: wie lange kann der Preis der Arbeit fortfahren zu steigen, ohue daß seine Erhöhung den Fortschritt der Akkumulation stört? Oder m. a. II.: wo liegt jener Minimalsatz des Gewinns, der nicht unterschritten werden-darf, ohne daß der Stachel des Gewinns abstumpft?

Diese Frage kann niemand beantworten. Marx selbst sagt präzis: „Die Minimalgrenze des Zinses ist nnbestimmbar; er 
kann $7 u$ jeder beliebigen. Tiefe fallen:"1) Lnd der Zins ist zwar nicht der Profit, aber doch ein Indikator des Profits!

El nimmt aber, das geht aus seinen Schlïssen deutlich hervor, augenscheinlich an, $\mathrm{da} B$ die Grenze nicht sehr tief unter dem heutigen ïblichen Profitsatz liegen kann. Diese Auschauung erscheint mir grundfalsch. Man ist vielmehr wohl berechtigrt, anzunehmen, daß die Grenze außerordentlich tief liegen wird. Es ist mehr als wahrscheinlich, daß die Kapitalsbesitzer, je mehr der Arbeitspreis stejgt und dio Mehrwertrate sinkt, um so ängstlicher "entsagen ", d. h. um so weniger aus ihrer Revenüe konsumieren und unn so inehr kapitalisieren werden. Der "Stachel des Gewinns" wird nur um so schärfer, statt sich abzustumpfen. Die Angst des Bourgeois fïr sich und seine Erben, das "Kapitall" angreifen und dann von der Handarbeit leben zu müssen, würde ihn gerade bei sinkender Profitrate spornen, möglichst viel zu ahkunulieren, um ein für standesgemäße Lebensweise ausreichendes Vermögen zu erlangen. Adam Smith, der gewiß kein schlechter Psycholog war; ist derselben Meinung und belegt sic durch ein interessantes Beispiel.') Und auch wir beobachten yoch heute, daf die kleinen Sparer beim dreiprozentigen Kurse der Staatsanleihen sich bemühen, entsprechend mehr zurückzulegen, als seinerzeit beim fünfprozentigen Kurse. Die Akkunulation würde also bei steigendem Arbeitspreise nar noch stärker wachsen, und der Lohn weiter steigen, bis endlich der psychologische Reiz nicht mehr wirkte, und der Bourgeois in heller Verzweilluing auf weitere Akkumulation Verzicht leisten und vielleicht sogar scin geliehtes Kapital aufznzehren begänne. Wenn wir uns vorstellen, diese Grenze läge bei $0,01 \%$ Profit, so wäre die "Nehrarbeit" vielleicht auf wenige Miuuten täglich, und die Rate des Mehrwertes a uf $1 / \tau$ g gesunken; es gäbe viélleicht Trillionäre mit einem trotz alledem ungeheureu Finkommen, das immer noch starke Akkumulation gestattete: aber daun wäre von der ...1kkumulation von Elend, Sklaverei,

') ill, 1,343 .

$\Rightarrow$ Völkerwohlstand, 1. Buch, 9. Kap. p. 103 der Löwenthalschen C̈bersetzung. 
Unwisseuheit, Brutalisierung und moralischer Degradation auf dem (Gegenpol "') doch augenscheinfich kine Rede mehr. Denn der Lohn der Arbeiter wäre nahezu gleich den von ihnen den Produktionsmitteln zugesetzten Werte, und diesel Wert wäre enor'm.

1)ieser psychologische Punkt einmal erreicht, wïrle del Arleitspreis allerdings sein Maximum erlangt haven, weil von jetzt an das Wachstum ron $k$ resp. $v$ eng an dasjenige ron $p$ geknüpft bleibt: aber dieser Arbeitspreis kann dann so hoch sein, daß las , hapitalverhältnis" selbst längst verschwanden ist, das jai an ein bestimmtes Maximum des Arbeitspreises geknüpft ist. Damit ist also nichts gewonnen.

Yarx hätte richtig gesclulossen, wemn er hätio heweisen könuen, daß das Wachstam von $v$ immer eng an dasienige von $p$ gebunden war, ist und bleiht: aber er hat allenfalls nur beweisen können, daß einmal ein Zeitpunkt eintreten wird, von dem an gerechnet das Wachstum von $v$ eng an dasjenige von $p$ gebunden ist und bleibt. Dabei bleibt aber die Mioglichkeit, daß $v$ bis dahin sehr viel schneiler wächst als $p$, so daß der Bruch $v: p$ (und mit ihm der Arbeitspreis) weit über das Maximum hinauswä/hst, bei clem das Kapitalrerhältnis noch bestehen kann. ${ }^{2}$ )

Es ist nach alledem, wie ich glaube, Marx nicht gelungen, die ion ihm behauptete enge Abhängigkeit der Größe $k$ von der Größe $p$ zu erweisen. Dann ist aber auch der aus dieser $\mathrm{Ab}$ -

1) Kapital I. 611.

2) Mlarx bekämpft gerade mit àieseu Erörterungen die gedautenlose Bevölkerungtheorie des Yalthus und seiner Auhänger. Er macht aber einen āhnlichen Fehler, wie eine der Richtungen dieser Schnle, nāmlich wie der . Yalthusiauisuus, der unit Zahlen jongliert", meiner Terminolegie (vgl. meinen, Malthus", p. 132 ff.). Anc.. diese Lehre zeigr, daß, wenn die Bevölkerung. als danernd wachsend angenommen wird, schlieblich einmal ein Zeitpunkt eintreten $m u \beta$, wo die Frile nicht mehr Nahrung genug für sie hervorzubringen instiude ist; und sie faßt gleichfalls den reitlich bedingten Satz als absolut und yelangt so zu dem Quiproquo, das klend der Vergausenheit und Gegenwart aus einem erst in Zukunft erwarteten Vißverhäituis zu erklären. Der Jarxsche Bereis kommt ungefähr auf dasselbe hinaus. 
hängigkeit gezogene Schluß ohne Stlitze, daß die Proportion $v: p$ mit ungefähr derselben Geschwindigkeit fallen muB, wio die Proportion $v: k$.

Demnach ist für Hauptsatz III:

"wo die Zahl der. "Stellen" im Verhältnis zum Gesamtkapital fällt, da fällt sie auch im Verhältnis zur Zahl der arbeitsfähigen und arbeitswilligen Mitglieder des Proletariats" -

ein genügender Beweis nicht erbracht.

Somit bricht der Marxsche Kettenschlub in der Mitte auseinander, und sein SchluBergebnis, das Gesetz der kapitalistischen Aktumulation, ist nicht bewiesen.

Die Widerlegung eines Beweises ist noch nicht die Widerlegung einer Behauptung. Ein Beweis kann logisch unhaltbar, und dennoch die Behauptung richtig sein. Damit das Marxsche Gesetz der Akkumulation als völlig widerlegt gelten könne, ist daher noch zu zeigen, dab es nicht nur die Tatsachen der Erfahrung nicht erklärt, sondern daß sogar die Bildung der Surplusbevölkerung nicht derart erfolgt, wie der Fall sein müBte, wenn das Gesetz wirklich existierte. 
3. a

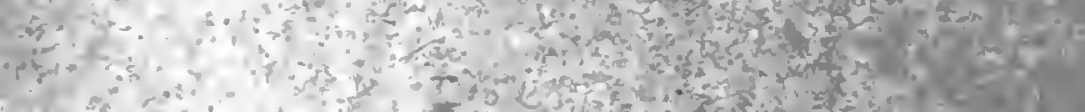

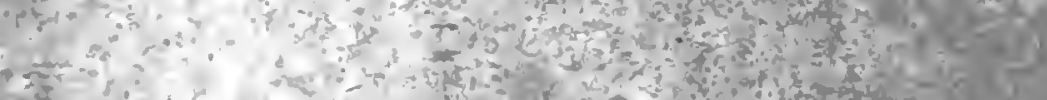
Xat (2)

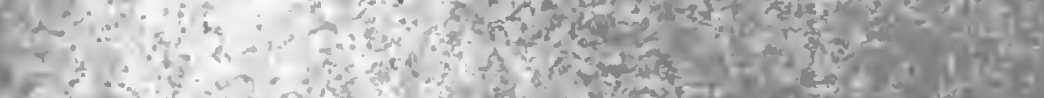

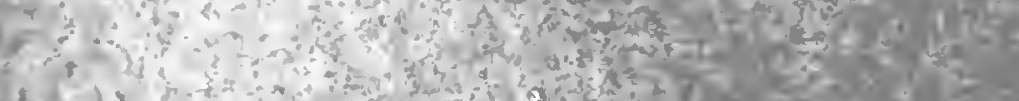

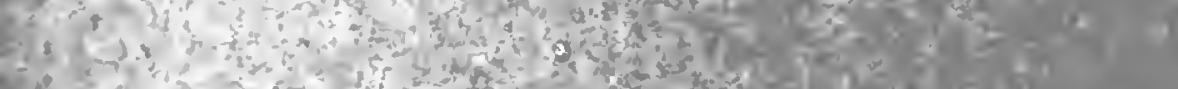
2.

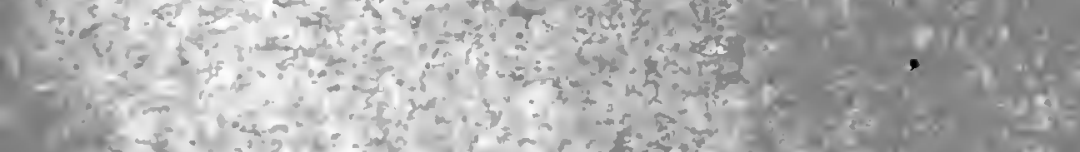
(7)

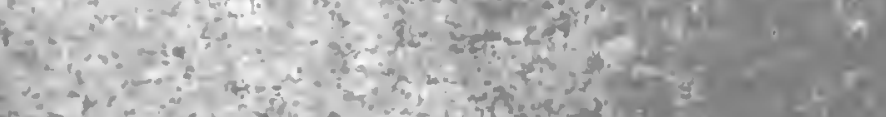




\section{DRITTER TEIL.}

\section{DIE MARXSCHE BEHAUPTUNG}

[N LICHTE DER TATSACHEN. 


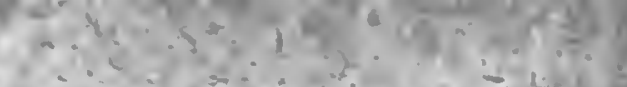

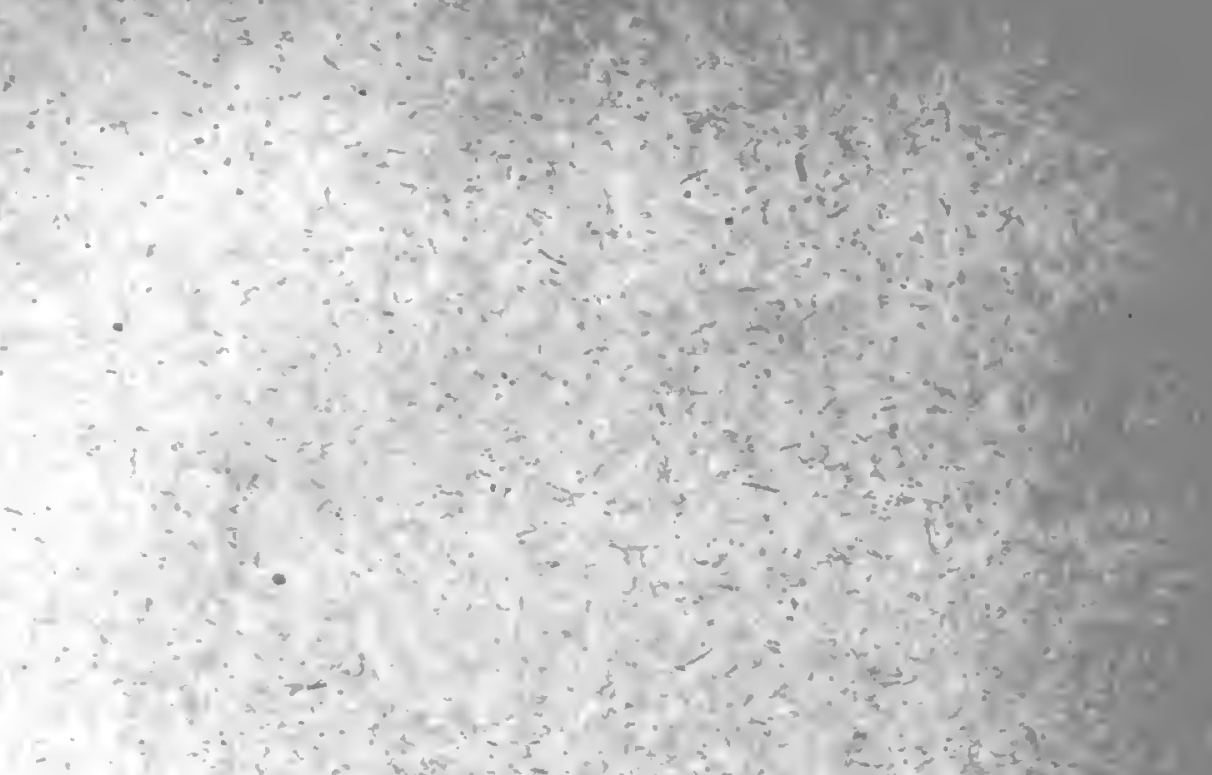

(x)

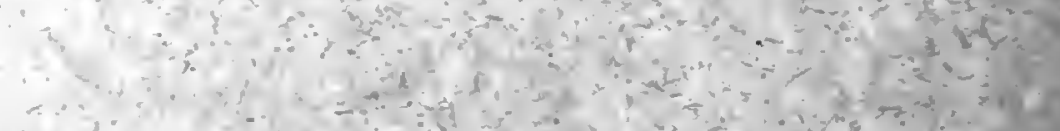

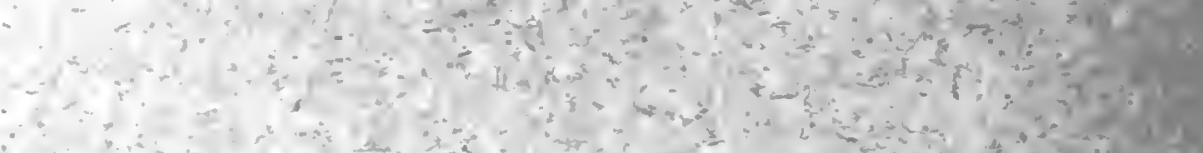
Cand a

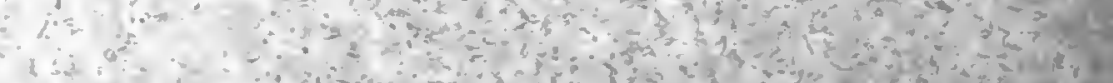

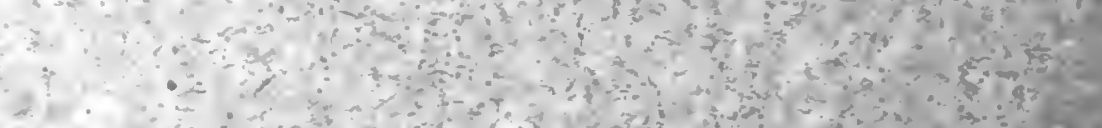

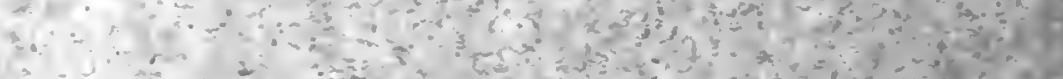

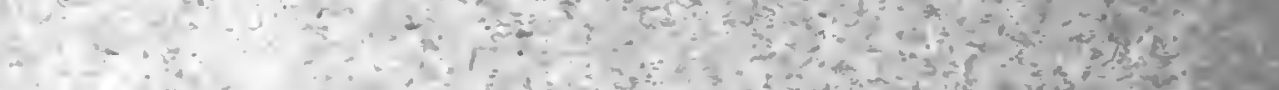
$\because \therefore 3$

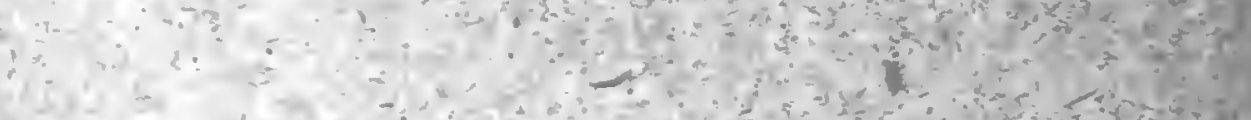

4 $=0$

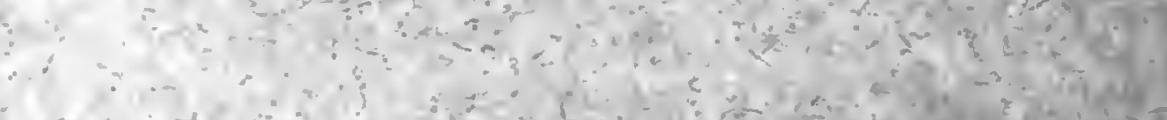

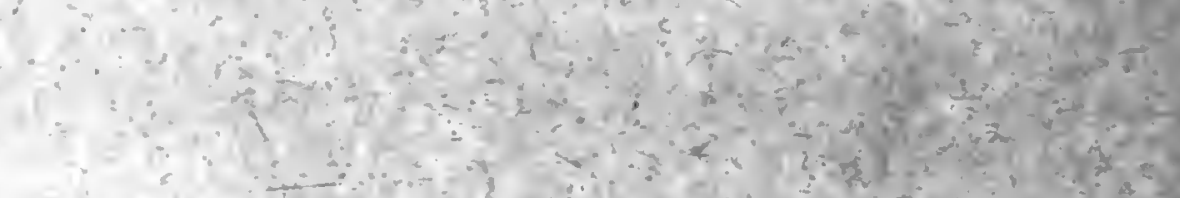

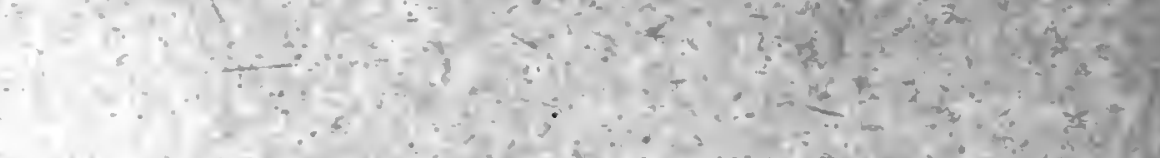

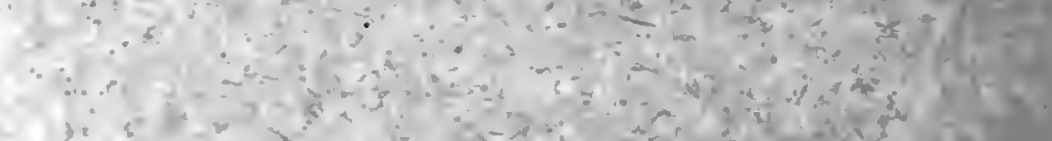

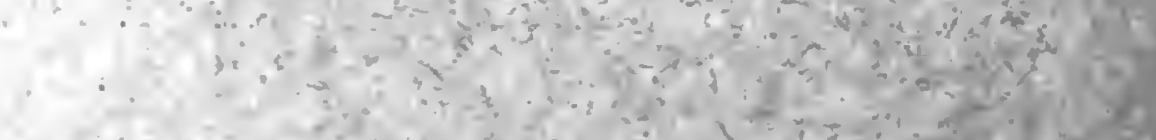

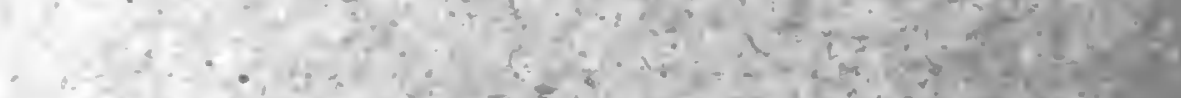

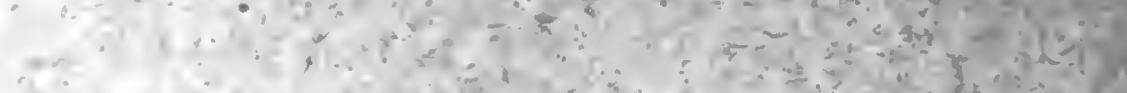

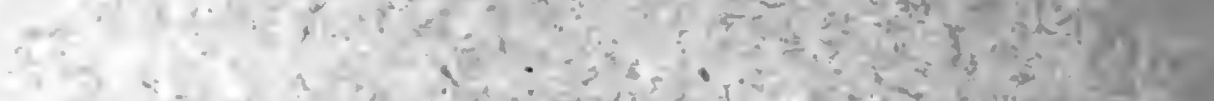

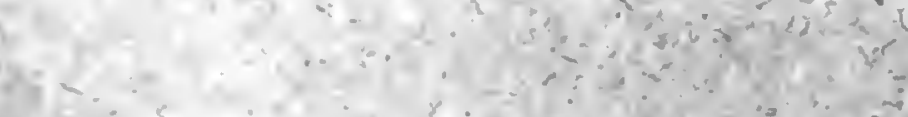

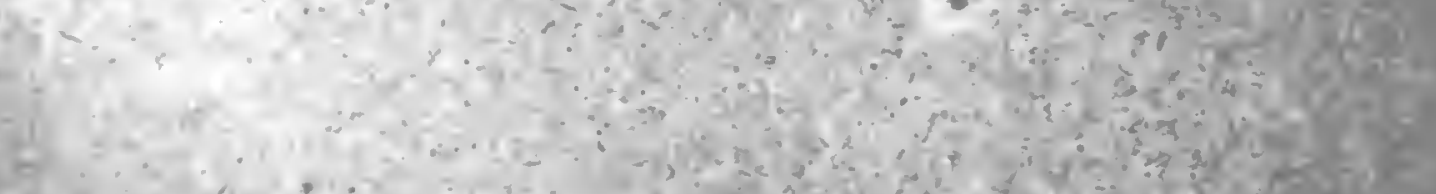
5.t.

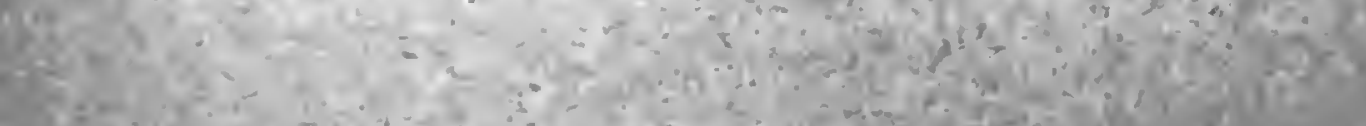
(1) 
lis ist der wesentliche Inhalt der "revisionistischen " Kritik des marxistischen Gedankengangs, zu zeigen, daß das Gesetz der Akkumulation die Priffnng an den Tatsachen nicht aushält. Es wird geleuguet, daß die Konzentration der Kapitale und die Zentralisation der Betriebe überhaupt in dem Maße und rol allem in dem Tempo erfolgt, wie Marx das angenommen hatte; ${ }^{1}$ ) und numentlich sind es die Ziffern der landwirtschaftlichen Berufs- und Betriebsstatistik, die gergen das Gesetz ins Feld geführt werden.

Die niachsten Tiipitel stellen sich die gleiche Aufg.be, wollen sio aber mit hisher nicht angerrandten Mitteln zu lösen rersuchen. Das von Bernstein, Hertz, Jaurès u. s. w. und auch ron David'y gebrauchte Beweisverfahliren erscheint mir aus mehreren Gründen nicht recht ïberzeugend.

Erstens durch die von ihnen angewandte Methode. Sie ist fast durchans statistisch. Die Statistik ist aber, wie die literarisuhe Fehde Bernstein-Kautsky zeigt, eine auferordentlich plastische Yasse.- Man kam mit ein wenig dialektischer Jonglierkunst so ziemlich allos statistisch beweisen, sodaf der Yersuch einer Finigung aui Grund dieses Materials wenig Aussicht hat. Aber anch daron abgeselien, ist sie in diesem Kampfe wenig empfehlenswert. Marx kamn uur durch Marx' Yerborle üherwundeu werden. Diese Ylethode ist aber nichts weniger als statistisch. Marx braucht für den eigentlichen Beweis grund-

1) Der erste, der diesen W'er beschritten ha!, scineint, wie schon ansgeführt, Jul. Wolf zu sein. Diesc: hedentende Yer.lienst konin ihı nicht bestritten werden. Das üher die revisionistische liampfmethocie zu bemerkende gilt auch für ihn.

3) In scinem trefflichen Werice "Sozialismus und landwirtschaft". Berlin 1903. 
sïtzlich nur die Deduktion; und wo er seinen Beweis an den Tatsachen pruift, da sind es immer nur die großen, auch ohne statistische Subtilitäten zugänglichen, die jedermann bekannten Tatsachenmassen. $W_{0}$ er Zahlen bringt, bringt er sie rein illustrativ, nie aber als Beweis. Dafür ist bezeichnend, daß häufig die wichtigsten statistischen Tatsachen als Anmerkungen unter dem Strich gebracht werden.

Den zweiten Mangel der revisionistischen Kampfart erblicke ich im folgenden:

Man betrachtet hier die Marxsche Behauptung von der Tendenz der kapitalistischen Akkumulation durchaus nur als eine Prophezeihung in die Zukunft hinein. Daher stellt sich als kritische Aufgabe der Nachweis, daß die Entwicklung anders verlaufen ist, als Marx voraussah. Dieser Nachweis läßt sich aber kamin anders als mit statistischen Argumenten führen.

Die Zukunftsprophezeihung ist jedoch nuir ein 'Teil der Narxschen Behauptung; und sie ist zwar für dic Führung und Schürung des proletarischen Klassenkampfes die wichtigere, aber theoretisch-wissenschaftlich weitaus die unwichtigere Hälfte. Denn Marx gewann das Recht, die „Tendenz der kapitalistischen Produktionsweise ${ }^{u}$ in die Zukunft hincin $7 . u$ projizieren, nur daraus, daB er die gleiche Tendenz als von Anfang der kapitalistischen Ära an wirksam nachwies: die Akkumulation des Kapitals am einen und des Proletariats am anderu Pole und die fortschreitende Simplifiziernng der Volkswirtschaft.

Das haben die revisionistischen Kritiker nie genügend beachtet. Sie haben das verhängnisvolle Wort "Tendenz" ungefähr so falsch verstanden wie die heutigen Malthusianer die berühmte "tendency of all animated life to increase beyond the nourishment prepared for it": als eine Zukunftsprophezeihung statt als eine wissenschaftliche Erklärung der Tatsachen von Vergangenheit und Gegenwart, die dann allerdings gewisse Schlüsse auch für die Zukunft erlaubt.

Lnd dieser Irrtum hat Bernstein und die Seinen daran verhindert, das Nächstliegende und, wie sich hoffentlich zeigon wird, Wirksamste gegen die Marxsche Theoretik zu unternehmen, nämlich dic von Marx selbst herangezogenen Tatsachen 
zu untersuchen, an denen el sein ${ }_{x}$ Gesetz der Akknmulation" erhärtete, die Tatsachen, durch die er beweisen wollte, dab die Tendenz der kapitalistischen Produktionsweise in der Vergangenheit und Gegenwart in Übereinstimmung mit seiner Deduktion sich durchsetzte.

Diese Untersuchung bildet den wesentlichen Inhalt der nächsten Kapitel.

\section{Kapitel.}

\section{Die Tatsachen der industriellen Entwicklung.}

(Die "Feisetzung" des Arbeiters und die

foupensationstheorie.)

Das Gesetz der Alkumulation lantet, aus der wissenschaftlichen Terminologie ins Volkstümliche übersetzt: "Die Maschine setzt den Arbeiter frei".

Die ersten drei Hauptsätze des von uns dargestellten und widerlegten Kefterschlusses ergehen nämlich folgenden Satz: „Wo das konstante Kapital im Verhälnis zum Gesamtkapital wächst, da fallt ceteris paribus im gleichen Verhältnis die Zahl der .Stellen!" Das konstante Kapitai aber ist im wesentlichen die Maschine samt den für sie erforderlichen firundstïcken und Gebäuden.

Daß die Maschine den Arbeiter freisetzt, wir zuerst unr die naive Über\%eugung der Fiandwerker and Yanufakturarhoiter, die sich von den neu erfundenen arbeitsparendn Maschinen in ihrer Existenz bedroht glaubten - zaweiten nicht mit Inrecht und sich mit allen Mitteln dos Rechtes und der Gewalt gegen ihre Einführung sträubten. In die Wissenschaft aufgenormen wurde diese Meinung nach Marx') zuerst ron John Barton; dann nahm sie Ricardo in dem nachíräglich seinen (ntersuchungen einverleibtei XXXI. Fapitei in die offizielle Theorie auf. Seitdem gehört sie zum gemeinsamien Besitzstande der manchester-

¿) Kapita! I. 596, Anm. 79.

Oppenheine'r, Marx' Gesellschaftslehre. 
liberalen und sozialistischen Doktrin. Sie hat, verq́uickt mit dern Malthusschen "Berölkerunggesetz" zur sogenannten "Berölkerungtheorie", alle bürgerliche Wissenschaft auf dürrer Haide im Kreis herumgeführt, ') und hat, wie ich hoffe, zeigeu zu können, auch das großartige System der proletarischen Öhonomik in seinen letzten Konsequenzen abgelenkt.

Auch für Marx stand es außer Zweifel, daB „die Maschine deu Arbeiter erschlägt ".") Er akzeptiert die naire Auffassung der beteiligten Arbeiter, deren Kämpfe gegen den neu erstcheuden Feind er mehrfach darstellt, ${ }^{3}$ ) im Prinzip, nur daß ihm natürlich die Maschine nicht als Ding von Stahl, Eisen und Holz, sondern als Werkzeug der kapitalistischen Exploitation die rerhängnisvolle Wirkung auf Markt und Kurs der Arbeit ausübt. „Es bedarf Zeit und Erfahrung, bevor der Arbeiter die Maschinerie von ihrer kapitalistischen Anwendung unterscheiden und daher seine Angriffe rom materiellen Produktionsmittel selbst auf dessen gesellschaftliche Exploitationsform übertragen lernt. " Aber in dieser Form "setzt sie frei". "Der Dampfwebstulll hat 800000 Weber aufs Pflaster geworfen "4) (inkl. der "von innen selbst beschäftigten Familien ${ }^{*}$. $^{5}$ ) „Die Maschiné wirft unaufhörlich Arbeiter aus der Fabrik heraus" (Citat nach (re). ${ }^{\circ}$ ) In der großbritannischen Baumwollindustrie ist von 1861 bis 1868 die Anzahl der Fabriken um 338 gesunken, die Zahl der Spindeln

1) Vgl. mein „Berölkerungrsest? des T. R. Malthus" (Berlin 1900) namentlich in III. und IV. Kapital.

${ }^{2}$ Kanital 1. 397. Vgl. Fr. Engels, Herrn Eugen Dihrings [mwälzung". Hottingen 1886 p. 245.

3) Kapital I. $392 \mathrm{fi}$.

†) Kapital I. 394. „DaB es aber keine "C̈bertreibung" war, zu sagen, dab der Dampfwebstuhl 800000 Weber auf das Pflaster geworfen habe, daron kann sich Berr Bertheau durch den Bericht des Committee ou Handloomweavers, 1834 und 1835, überzengen, wo die Gesantzahl aller Handweber Englands auf eine Million angegeben wird. 1861 waren diese so gut wie verschwunden und betrug die Zabl der Dampfstuhlweber rund 230000." (Ed. Bernstein, "Drachentōtung in fünf Briefen", N. Z. 1894/5. II. p. 117.)

5) Kapital I. 415.

6) Kapital I. 398. 
um 1612541 gestiegen, die der Arbeiter aber um 50505 gefallen. Und Anm. $78 \mathrm{zu}$ Seite 595 bringt eine ganze Anzahl von I'roduktionszweigen, in deren Mehrzahl der Zensus von 1861 einen Rïckgang der Arbeiterzahl im Verbältnis zu 1 Sō1 nachweist.')

Indessen, wie gesagt, Marx legt auf Zahlen baum irgend ein frewicht. Sie dienen ihm zor gelegentlichen Illustration, abcr nicht zum Beweis. Daher tut Julius Wolf ihm entschieden unrecht, wenn er ihn liiderlicher Statistik oder gar absichtlicher Irrefïhrung anklagt. Er wollte keinen ankern Beweis als den durch Deduktion, die alle Tatsachen erklärt. Seine Deduktion aber erschien ihm als vollkommen schlüssig. So schliissig: dah er niemals nachgerechnet hat. Sonst hätte ihm allerdings auffallen müssen, was $\mathrm{W}$ olf $^{2}$ ) ihm aufmutzt, dal jene 14 ans den 431 Berufen des Zensus von 1861 heransgegriffenen Positionen (rund 3 Millionen ron rund 13\% Millionen Erwerbstätigen) zusammengezählt ein Plus beschäftigter Arbeiter ergeben. Dieselbe Gleichgültigkeit gegen statistische Induktion findet sich noch an mehreren Stellen. 7. B. stellt er neben die eben angefiihrten Daten aus der Baumwollindustrie von 1861/68 anch die von 1858, aus denen er hätte bere chnen können, daß trotz des enormen Kückgangs in der zweiten Hälfte des Jahrzehnts 1858/68 die Arbeiterschaft dieser Industrie in diesen zehn Jahren im ganzen demnoch ron rund 379000 auf rund 401000, also um fast $\left(i{ }^{\circ} ;\right.$ gewachsen war. Ferner gibt er selbst p. 595 Anm. 78 an, daf die britischen Bunnwollwebereien und -Spinnereien 185137177,1861 aber $\$ 56046$ Arbeiter beschäftigten. (Eine lerechnung hätte hier eine Vermehrung von ca. $23 \%$ ergeben, wïhrend sheichzeitig die Bevölkerung Großbritannicns nur um $\overline{5}, 6^{0} \%$ zunahm. $\left.j^{3}\right)$

1) a die Textilindustrie das Schulbeispiel für die "Freisetzmng der Arbeiter durch die Maschine" ist, so sei es gestattet, hie: einige spätere Zahlen anzuführen. Der Rückgang zwischen 1:11

1) Writere ctatistische Details p. 413.

$\Rightarrow$ „Socinlismus u. kippital. Gesellschaftsordnung", Sruttgart 1892. 11.261.

) Die Berülkeruu berechuet nach Yulhall. Dict. of Stat. 4. Artif. p. 444 . 
und 1868 war eine Folge der „Baumwollteurung“ (cotton-famine), die sich während des amerikanischen Sezessionskrieges einstellte. Nach der Beseitigung dieser. Störung, die mit der kapitalistischen Entwicklung Großbritanniens nicht viel zu tun hatte, wuchs die Arbeiterschaft der Baumwollindustric regelmäfig weiter und regelmäßig, trotz aller Konkurrenz des Auslandes, weit stärker als die Bevölkerung. Sie betrug 1880: 487000, 1885: 504000, ${ }^{1}$ ) 1890: 530000. ${ }^{2}$ ) Während die Bevölkerung insgesamt 1851/89 um $31 \%$ zunahn, wuchs die Arbeiterzahl der Baumwollindustrie um nicht weniger als $43 \%{ }^{3}$ )

Man sieht, sogar die-Zahlen dieses Schulbeispiels stimmen nicht mit der 'Theorie. Ich habe aber erklärt, auf alle statistischen Subtilitäten verzichten zu wollen und will diher unterstellen, Marx habe in der Tat nachgewiesen, dafi in mehreren bedeutenden Zweigen der Volkswirtschaft viele Arbeiter durch die Maschine freigesetzt worden sind.

Mit diesem Zugeständnis ist zunächst für das Gesetz der Akknmulation nichts erreicht. Denn es spricht nicht von einzelneu Zweigen der Volkswirtschaft, sondern von ihrer Gesamtheit: es ist "allgemeines, absolutes Gesetz der kapitalistischen Akkumulation", und es kann anch nur als solches als Prämisse der uns bekannten wichtigen Folgerungen dienen. Beschränkte sich die Freisetzung z. B. auf die Handweber, so wäre die üble Lage z. B. der Maschinenbauer niclit erklärt.

Es ist aber oflenbar nicht ohne weiteres gestattet, vom Einzelzweig einen generalisierenden Schluß auf die Gesamtwirtschaft zu machen. Es muß erst Umschan gehalten werden, ab nicht vielleicht in einigen andern Zweigen der Wirtschaft die Zahl der beschäftigten Arbeiter im Verhäitnis zur-Bevölkerung gewachsen ist. Nur wenu sich ein solcher Fall von "Konıpensation“ nicht

1) Nulhal! 1. c. 159 .

3) Wulhall 1. c. 678.

3) Kautsky 'Karr Marx' ök. Lehreu, p. 234) fülurt die Baumwollindustrie als ,ein Beispiel absoluter Abuabue der Zabl der beschäftirten Arbeiter" an. Lir vergleicht 1861 und 1871, wo er 456 resp. 450 Tausend zählt. Seia Buch erschien 1887; 1880 aber batte es wiesler 487000 und 1885 504000 gegreben. „Kautskys statistische Fabeln:.: 
nachweisen läßt, ist die Generalisierung mindestens vorläufig erlanbt.

Narx wußte aber, daß viele lälle derartiger Kompensation bestehen, daß die kapitalistische Wirtschaft eine sebr bedeuteude Mehreinstellung von Arheitern in vielen Zweigen mit sich bringt. Er stell ctwa folgende Betraching an:

Es kam in einzelnen Zweigen der Volkswirtschaft die Afleiterzahi wachsen, "enu zwei Bedingungen erfült sind. Erstens non! das rariable Kapital absolnt gewachsen sein, was nit seinem relativen Sinken im Torbät tiis zum konstanten sehr wohl vereinbar ist, wie wir wissen. Und zweitens mub der Markt des Produkts sich entsprechend erweitert haben. Das liegt alier, wie Marx zeist, in Beglife des Maschinemprodukts, das ja nur konkurreuzfathig ist, wenn es wohlfeiler ist, und das, weil es wohlfeiler ist. größeren Absatz findet, d. h. in viel größerer Masse hergestellt wirl,') und daher auch einer, wenn auch ,.im Verhältnis zur Produktionsleiter" verminderten, so doch unter Lmständen absolut rermehrten Arbeiterzahl zu seiner Herstellung bedarf, nämlich dann, wenn der Absatz stärker gewachsen ist, als die Produktionskratt des Gewerbes.

So kann Marx zu dem Schlusse gelangen:

„.Man - begreift, trotz der vom Maschinenbetrieb faktisch verdrängten und virtuell ersetzten Arbeitermasse, wie mit seinem eigenen Wachstum, ausgedriickt in Fabriken derselben Art oder den erweiterten bimensionen vorhandener Fabriken, die Fabrikarbeiter schließlich zahlreicher sein köunen, als die von ihnen verdlängten Manufakturarbeiter oder Handwerker. ${ }^{\text {“ }}{ }^{2}$ )

Eine solche Entwicklung des einen $\mathbf{Z}$ weiges wirkt aber auf viele andere $\mathrm{Zweige} \mathrm{zurück:}$

Vermehrter Absatz nämlich ist erstens nicht möglich ohne vermehrte Prorluktion der A rbeitsgegenstände und Arbeitsmittel der einzelnen Zweige. Die Baumwollpflanzungen, die Metall- und $\mathbf{h}$ ohlenbergwerke u. s. w. ha? eine "ungeheuer schwellende ${ }^{{ }^{3}}$ ) Arbeiterzahl beschäftigt. "Eine neue Arbeiterart

1) hapital I. 408.

3) Kapital I. 414.

3) Kapital 1. 408 
springt mit der Maschine ins Leben, ihr Produzent. Wir wissen bereits, da $B$ de: Maschinenbetrieb sich dieses Produktionszweiges auf stets massenhafterer Stufenleiter bemichtigt. "') . . „Ergreift die Maschinerie Tor- oder Zwischenstufen, welche ein Arbeitsgegenstand bis zu seiner letzten Form zu durchlaufen hat, so vermehrt sich mit dem Arbeitsmaterial die Arbeitsnachfrage in den noch handwerks- oder manufakturmäßig betriebenen Gewerken, worin das Maschinenfabrikat eingeht. Die Maschinenspinnerei \%. B. liclerte das Garn so wohlfeil und reichlich, daß die Handweber zunächst, ohne vermehrte Auslage, volle Zeit arbeiten konnten." Ferner mächst mit der Mehrwertmasse die Luxusproduktion und die Klasse der "unproduktiven Diener", und es entstehen ganz nene Zweige der Produktion: llerstellung ron „Karälun, Warendocks, Tmmels, Brücken“."2) Schlieflich "sind Wohlfeilheit des Iaschinenprodukts und das umgewäizte Transportund Komminikationswesen Waffen zur Eroherung fremder Märkte", ${ }^{3}$ ) und damit ist natürlich wieder die Möglichkeit zur Beschäftigung neuer, ainsolut rermehrter Arbeiter in der Gesamtindustrie des iudustriell entfalteten Landes gegeben.

Marx entwickelt also selbst, daß die ,Freisetzung von Arbeitern in einzelnen Zweigen in bedeutendem Maße durch Mehreinstellung von Arheitern in ạderen $Z$ weigen kompensiert wird. Dann ist der rerallomemende schluß ron jenen ersten 'Wreigen auf die Gesamtwirtschuft also nicht erlaubt, sondern es sind drei lälle möglich:

1. Vie Freicet\%ung in den einen $Z$ reigen überwiegt die Mehreinstelinug in den anderen: teilweise kompensation;

2. Freisetzung und Nehreinstellung gleichen sich aus: volle Komperisition;

3. die Mehreinstellung überwiegt die Freisetzung: Überkompensation. bewiesen.

Ist Fall 1 wirklich, so ist das Gesetz der Akkumulation
3) Kapital I. 409.
S Kapital I. p. $\$ 11$.
3) Kapital I. p. 416. 
Ist fall 2 wirklich, so ist es noch immer teilweise richtig. Nur läßt sich dann die ,absolute" Verelendung nicht meh" daraus ableiten, sondern nur allenfalls eine relative.

Ist aber Fall 3 wirklich, übersteigt die Mehreinstellung in einzelnen $Z$ weigen die Freisetzung in anderen, so stellt sich folgende Alternative:

Entweder sind die in einzelnen $\mathrm{Zweigen} \mathrm{freigesetzten} \mathrm{Arbeiter}$ nach Kraft und Vorbildung fähig, ohne weiteres in diejenigen Zveige überzutreten, die ein überstarkes Bedürfnis nach neuen Arbeitskräften haben, die also, um auf Marx' Bolen zu bleiben, einen sehr großen Zuwachs an rariablem Kapital haben: dann wird, statt Drucks auf die Löhne, ganz allgemein ein Steigen der Löhne eintreten. - Oder: jene "Freigesetzten" sind nicht fähig, überzutreten: daun wird das Lohnnivean aller anderen Zweige absolut nur um so stärker steigen, da die fonkurrenz jener Klasse nicht eingreift. In den notleidenden $Z$ weigen wird in diesem Falle allerdings ein relativer Pauperismus sich einstellen, der aber erstens streng auf den ergriffenen Personenkreis beschränkt bleibt ( $d_{a}$ der ron den prosperierenden $Z w$ eigen so stark angezogene Nachwuchs sich natürlich den notleidenden Zweigen nicht zuwenden wird), und der zweitens keinen gefährlichen Grad erreichen kann. Demn die Handweber z. B. hätten nicht mit Maschinen honkurrieren müssen, die von jämmerlich bezahlten, überanstrengten Arbeitern bedient wareu, somlem mit solchen, die von hoch entlohnten Arbeitern in kurzem Werktage bedient waren. So hätte ihnen der Preis ihrer Handarbeit immer noch eine, wenn auch beschränkte, so doch auskömmliche Existenz gesichert, und das Gewerbe wäre friedlich mit seinen Veteranen ausgestorben. Hier hätte also eine Ausgle ınn der Lebenshaltung erst allmählich stattfinden köunen.

Aber in beiden Fällen unserer Alternative würde das durchschnittliche Lohnniveau sich beträchtlich erhöhen. und würde weiter steigen, so lange unsere Bedingung erfüllt bleibt (also bis „der Stachel des Gewinns abstumpft" ${ }^{*}$ ). Der Lohn wi de, un ganz korrekt zu. sein, nicht nur steigen durch Vermehrung seiner Kaufkraft, sondern wirklich durch Vermindernng der Mohrwertrate. Er stiege stärker als die Produktivkraft „einfacher 
gesellschaftlicher Arbeit", während er nach Marx bestenfalls nur weniger steigen kann. Lnd natïrlich wäre bei einem so ungeheuren Ilunger des verwertungsbedürftigen Kapitals nach Arbeitskraft auch binmen kurzem jene mit Beginn der kapitalistischen Ära "durch außerökonomische Gewalt" geschaffene Armee vogelfreier Proletarier aufgesiugt, und mit ihl wäre die „Existenzbedingung" der kipitalistischen Wirtschaft, das „Kapitalverhältnis": sellust, verschwunden.

Welcher dieser drei Tälle ist nun Wirklichkeit?

Das Problem ist durch Deduktion nicht lösbar; es ist eine Gleichung mit mehreren Unbekannten. Es wäre unmittelbar nur lösbar durch Zählung: man nüßte die Zahl der Arbeitlosen zu verschiedenen Zeitpunkten vergleichen: zeigt sich eine regelmäßige Znnahme, so hat nur teilweise Kompensation, zeigt sich regelmäBige Abnahme, so hat Überkompensation stattgefunden.

Diese Methode ist aber ans mehrfachen Gründen nicht anwendbar.

Erstens reichte das statistische Material zu Marx' Zeit entschieden nicht hin, um diese Frage zu beantworten. Er konnte zu der Zeit, als er die britische Wirtschaftsentwicklung beobachtete, zu dem Eindruck gelangen, dal. die Reservearmee regelmäfig wachse. Wir wissen heute, daß diese Erscheinung, wenn sie überhaupt bestand, sicherlich nur eine vorüborgeheude, akzessorische Erscheinung war; wir wissen, daß die Prozentzahl der offiziellen Pauper's sehr bedentend gefallen, ') daß die Durchschnittszahl del Arbeitlosen mindestens im Verhältnis zur Gesamtbevölkerung stark gesunken ist, soda $\beta$ sich also $s$ schneller vermehrt hat als $p$. Und wir wissen anßerdem, daß ein großer T'eil des noch heute bestehenden Pauperismus in England in den Kreisen der Eingewanderten herrscht, namentlich der osteuropäischen Juden, ron denen es zum wenigsteu noch unbewiesen ist, daß ihr Elend dem Kapitalismus überhaupt, geschweige denn dem britischen Kapitalismus zur Last gelegt werden muf.

Alle diese Tatsachen der neueren Wirtschaftsentwicklung dürfen wir unserer programmatischen Erklärung gemäß nicht

3) Jul. Wolf I. c. p. 270. 
gegen Marx verwenden, sondern haben uns an das zu halten, was er selbst im ., Kapital“ von Tatsachen anführt.

Vor allem aber ist folgendes gegen diese Methode $z u$ bemerken, das Verhältnis $s: p$ aus der Zahl del: Arbeitlosen zu erkennen:

Es würde zwar gegen Marx entscheiden, wenn sich herausstellte, daß s schneller gewachsen ist, als p; aber es würde selbst. dann nicht für ihn entscheiden, wenn er nachgewiesen hätte, daß das umgekehrte Verhältnis Platz gegriffen hat. Wollte man diesen Schluß ziohen, so würde man einen Fehlschluß begehen. Denn es wird ja nicht bestritten, daß sich eine "Reservearmee" auf irgend eine Weise und in irgend einem Maße bildet, sondern es wird bestritten, daß sie durch den ron Marx angeklagten Mechanismus zustande kommt, durch "Freisetzung“.

Wir müssen also versuchen, dem Problem von einer anderen Seite näher zu kommen.

Da bietet sich uns als bequemes Mittel die Ziffer der „Lrbanisierung“, der zunehmenden Verstadtlichung der Bevölkerung in allen kapitalistisch sich entfaltenden Ländern. und namentlich in dem Marx vor allem interessierenden Lande, in Großbritannien. Er kannte die Tatsachen, die einem Beohachter von solcher Größe natürlich nicht entgehen konnten. Um uur einen Beleg anzuführen, so schreibt er $^{1}$ ) in bezug auf die Periode 1851-61: „781 Städte sind aufgezählt im Zensus ron 1861 für England und Wales mit 10960998 Einwohnern, während die Dörfer und Landkirchspiele nur 9105226 zählen. . . Im Jahre 1551 figurierten 580 Städte im Zensus, deren Bevölkerung ungefähr gleich der Bevölkerung der sie umgebenden Landdistrikte war. Während abel in den letzteren die Bevölkerung nur um eine lalbe Million wuchs, wuchs sio in den 580 Städten um 1554067. Der Bevölkerungszuwachs in den Landkirchspielen ist $6,5 \%$, in den Städten 17,3\%. Der Cnterschied in der Rate des Wachstums ist der Wanderung vom land in die Stadt geschuldet. Drei Viertel des Gesamtwachstums der Bevölkerung gehört den Städten."

1) Kappital I. 607 Anm. 86 . 
El wubte auch, daß diese Wandernug vom Lande keine vorïbergchende, auf das eine Jahrzehnt beschränkte Erscheinung war, sondern daß es sich um eine danernde Tendenz handelie: „Ein Teil der Lindbevölkerung befindet sich daher immer auf dẹm Sprunơ, in städtisches oder Manufakturproletariat überzugehen.:" )

IIir sind berechtigt, in unserer auf alle statistischen Subtilitäten verzichtenden summarischen Betrachtung der großen Tartsachenmassen städtische Beröllieruny und stältisches Industrieproletariat gleich zu setzen. Wenigstens ist ein Anhängẹ Marxens der letzte, der behaupten dïrfe, da\& die eingewanderten Landproletarier etwas anderes geworden seien als Industrieproletarier; und außerdem beweist die eben angefïhrte Stelle, daß Marx selbst diese Auffassung hatte: "Die Landberölkerung geht in städtisches oder Manufakturproletariat über." Er setzt also ebenfalls beide Begriffe gleich: denn „Manufaktur" heißt hier, wie ausdriicklich beigefügt, ralle nicht-agrikole Industrie".

Was bedeutet die Tatsache eines solchen Stromes von Landarbeitern in die Industriestätten für das Problem der Freisetzung oder Kompensation?

Die Gesamtindustrie, alle Stoffiveredelung zusammengenommen, also Marxens „Manufaktur", hat nicht nur die Zahl ihrer Arbeitsstellen nicht vermindert, sie hat nicht nur für den gesanten Zuwachs der Industriearbeiterbevölkerung und für die neu „Expropriierten" der übrigen Stadtbevölkerung zu jeder Zeit ausreichend neue „Stellen" erschlossen, sondern sie hat auch noch darüber hinaus eine ungeheure Zithl neuer Stellen geschaffen, die von eingewanderten Landproletariern besetzt worden sind.

In der Gesamtindustrie besteht also Ūberkompensation der "Freisetzung" durch Mehreinstellung!

Das ist noch kein Beweis gegen das Gesetz der Akkumulation salbst. Denn das ist aufgestellt nicht für die Gesamtindustrie, sondern für die Gesami wirtschaft der kapitalistischen Epache. Es könnte ja sein, daß alle jene in die Stälte einwandernden

1) Kapital I 607. 
Landarbeiter durch das landwirtschaftliche Kapital freigesetzt worden sind.

Aber es ist ein Beweis ad hominem gegen Marx! Er dürtte diesen Einwand nicht erheben. Wenn er zugeben muk, daß in der Gesamtindustrie Überkompensation stattfindet, so hat er die Partie verloren. Demn er hat die ganze Theorie von der Freisetzung der Arbeiter durch die Maschinerie gewonnen aus der Analyse der Industrie. Erst nachträglich hat er die derart erİaltenen Kategorien auf die Landwirtschaft übertragen.

Er spricht dem auch regelmäBig von den durch "grobe Industrie und Agrikultur" freigesetzten Arbeiter"n. Daß nur die Agrikultur freisetzt, während in der Industrie Überkompensation stattfindet, hat er nicht gesehen; sonst hätte er seine Theorie nicht aufrecht erhalten können. Er hätte also den Einwand nicht erlueben dürfen, daß das landwirtschaftliche Fapital allein den Arbeiter freisetzt. Nithin ist die Tatsache der Überkompensation in der Gesamtindustrie ein schlagendes Argumentum ad hominem segen Marx.

In der Tat zieht auch ein früher als berufener Exeget gepriesener, jetzt allerdings von den Marx-Orthodosen mit Heftigkeit befehdeter Schüler des Meisters diesen Schluß. Ed. Bernstein sagt: ')

"Wenn sich, wie in den Hauptindustriestanten, die industrielle Berölkerung stärker rermehrt wie die Gesamtberölkerung, ohne daß die Prozentzahl der Arbeitslosen steigt, so läßt sich die bisherige Erkiärung jener Tatsache (der industriellen Reservearmee), nämlich, dafi es das „Kapital“ ist, das sie beständig von neuem schalit, nicht aufrecht "erbalten. " 2 )

1) Zur Geschichte und Theorie etc. p. 97.

$\Rightarrow$ Berustein kritisiert in ciner Ammerknng nu dieser Stelle Marx einschlägige lehre mit anfälligel Schärfe (ovrquicknug ganz heterugener Gesichtsprinkte", sinnlose Redefloskei"). Es ist schwer zu begrnifen, was er an dem ökonomischen Marxisuns noch nufrecht erhalten will, wenn er dieses sein Fundament preisgibt. Ind ehenso schmer ist zu verstehen, daf er gar kein Bertünis empltindet, die him entstaudene Lüche durch eine neue Erliärung , jener Tatsacile" zu schließen, wenn er schon meine eigene ablehnen 211 müsseu glaubt. Es ist einigermaßen betrüblich, daß sich selbst 
Indessen: so leicht ist Marx nicht zu fassen! Daß ein Beobachter ron sulcher Größe an so. wichtigen Tatsachen gänzlich rorleeisihe, ist natülich ausgeschlossen.

Er erkennt an, daß die Zahl der ron der Gesamtindustrie liesetzten "Stellen “ nicht sinkt, sondern wächst:') „In den Zentren der monternen Industrie - Fabriken, Manufakturen, Hütten und Bergwerken usw. - werden Arbeiter bald repelliert, bald in größerem Lmfang wieder attrahiert, sodaß im großen und ganzen die Zahl der Beschäftigten zunimmt, wenn auch in stets al)nehmendem Yerhältnis zur Produktionsleiter. Die C̈bervölkerung existiert hier in fließender Form."

Diese Sätze sind roll - man ist fast versucht anzunehmen, absichtsvoller - Dunkellieit. Sie enthalten zwei hier gar nicht hergehörige Bestimmungen, lassen aher dafür die wichtigste Bestimmung im dunkeln.

Da: die Kurve der Stellenzahl ..im sroßen und ganzer:" nicht eine aufsteigende Gerade, sondern eine stark bewegte Wellenlinie darstellt, je nachdem Repulsion und Attraktion auf sie einwirken, gehört nicht hierher, sobald zugegeben werden muß, daß lie Atraktion „ill größerem Limfange“ erfolgt. Dann mulf auf die Dauer und im Durclisebnitt trotz aller temporären liückschläge eben Lohnsteigerung eintreten. Ebensorrenig grehört hierher, dil. die Arbeiter\%ahl rur „in stets abnehmendem Verhïltuis zur Produktionsleiter" zunimmt. Denn nicht der

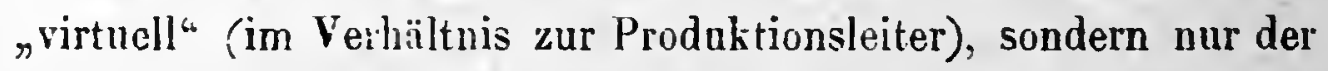

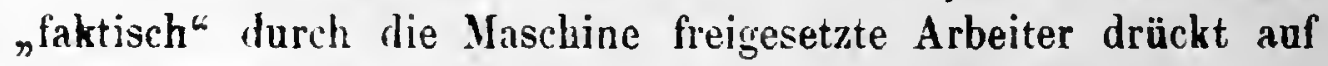
den Arbeitsmarkt.

Andererseits feblt die wichtigste Bestimmung, die der Quantität. Mit der Feststellung, daß die Arbeiterzahl, im großen und ganzen" wächst, ist keine Förderung des Kompensationsproblems möglich. Die entscheidende Frage lautet klipp und klar: Ist $s$ schneller oder langsamer gewachsen als $p$ ? Haben

eiu Bernstein mit der Redensart abfindet, es grehe keine einheitliche Lohnarbeiterklasse und laber auch beine einheitliche Lohnbewegung etc. (p. $9 \mathrm{Sff}$.). [iese Lehre ist ein Verweif lungsakt nuserer delsadentesten Vulgärökonoinik. (Davon mehr in 11. Kapitel).

b) Kapital I. 606. 
prozentual mehr oder weniger Mitgliede: des Prolctariats "Stellen" gefunden? Die unbestimmte (quantitätsangabe „iun großen und ganzen" gestattet beide Auslegungen, führt also nicht einen Schritt weiter. ${ }^{1}$ )

Marx, in seiner Deduktion befangen, stellt das quantitative Problem nicht, fühlt aber doch heraus, daß ein so starkes Anwachsen des Industrieproletariats schwer mit dem Gesetz der Akkamulation, mit ler" „Freisetzungtheorie", vereinbar ist, and versucht, sie durch folgende Argumentation zn retten:

Es kann zwar ein in Veriälnis zur Bevölkermugahl sinkendes variables hapital bei gleichem Lohn nur relativ weniger Arbeiter beschäftigen. Wohl aber ist das müglich bei sinkendem Lohn! Tnd Marx ist ja der festen Überzeugung, daß es in der Teudenz der kapitalistischen Entwicklung liegt, den John zu senken.

Erstens sinkt nämlich mit dem Fortschritt der Akkumulation der Wert der in kilpitalistischen Betrieben hergestellten Subsistenzmittel dos Arbeiters, daher auch der Wert seiner Arbeitskraft, und, nach der Theorie, d:amit ihr Preis, der Lohn, wenn auch nicht immer genau proportional. Kräftiger Widerstand der urganisierten Arbeiterschaft, namentlich der gewerkschaftliche Lohukampf, kann unter Umstinden einen Teil der gesellschaftlichen Errungenschaften für den Arbeiter sichern.") Ferner aber findet das Kapital auch Ylittel und Wege, um mit denselben variablen Kapital mehr Arbeitshraft flüssig zu machen, und mit einem größeren variablen Kapital melur Arbeit zn erwerben, ohne neue Arbeiter einzustellen:

„Der kapitalistischen Produktion genügt keineswegs das Quantum disponibler Arbeitskraft, welches der natüliche Znwachs der Bevölkerung liefert. Sie bedarf zu ihrem freien Spiel

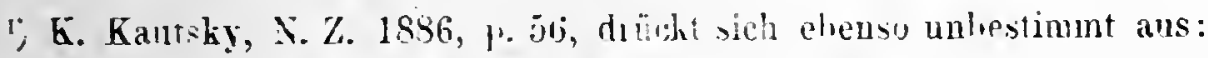
„Deun die Akkumulation und die sie begleitendo honz'ntration des Kapitals bedingen die Abnahın: der Zahl der beschïftigten Irbciter iu lerhältuis: zur Ausdehnung des ancewasten Gesanthapitals, eint relative Alinahme, die mitunter so reit geht, dab sie a:! abojuten rind; sic bedingen das Anwachsen, einer industriellen C̈hervölkerung, ciner Reservearmec." --

2) Kanital I. $485,6.605$. 
einer ron diser Viturschranke unablä jigen industriellen Reservannce. Bishel wuide unterstellt, laß der Zu- oder Abnahme des varialien Kapitals genati dic Zu--oder Abnahme der beschïfrigten Ar! witerzahl entspricht."

[A]so wie in unserer Darstellung die rorläufige Annahme honstanter Löhne!]

„Bei gleichbleibender oder selbst verminderter Zahl der von ihı kommandierten Arbeiter wächst jedoch das variable Kapital, "enn der individnole Arbeiter mehr Arbeit liefert und daher sein Arbeitslohn wänst, obgleich der A rbeitspreis gleich bleibt, nder selhst sinkt, nur langsamer, als die Arbeitsmasse steigt." 17. B. hei angestrengterer Akkordarheit.] „Der Zuwachs des variablen Kapitals wird dann Index ron mehr Arbeit, aber nicht ron mehr beschäftigten Arbeitern. Jeder Kapitalist hat las absolute lnteresse, ein bestimmtes Arheitsquantum aus kleincrer, statt ebenso wohlfeil oder selbst wohlfeiler ans größerer Arbeiterzahl auszupressen. ${ }^{1}$ ) In dem letzten Fall wächst die Auslage ron konstantem hapital verhälnismäBig zur Masse der in FluB ytsetrten Arbeit, im erstel Falle viel langsamer. Te größer die stufenleiter der Produktion, desto entscheirlender dies Motir. reine Wucht wächst mit der Akkumultition des Kapitals.

„Man hat gesehen, dab die Entwicklung der kapitalistischon I'roduktionsweise und Produktionskraft der Arbeit . . . denselben Kapitalisten befähigt, mit derselben Auslage ron variabiem hapital melır Arbeit durch größere extensive oder intensive Exploitation der individuellen Arbeitskräfte flüssig zu marhen. lian hat ferner gesehen, dafis er mit demselben Kapitalwert meh. Arbeitskräfte kiuft, indem er progressir geschicktere Arbeiter lurch ungeschicktere, reife durch unreife, männliche durch weibliche, erwachsene Arbeitskraft durch jugendliche oder kindliche verilrängt.

,Einerseits macht also, im Fortgang der Akkumulation, größeres variables Kapital mehr Arbeit flüssig, ohne mehr Arbeiter zu werben, andrerseits macht variables Kapital ron derselben Größe mehr Arbeit mit derseiben Masse Arbeitskraft

1) Vol. dazu Kaprual I. 492 Anm. 15. I 511. 
flüssig und endlich mehr niedere Arbeitskräfte durch Verdrïngung höherer." ")

Auch das letzte liegt nach Marx offenbar in der 'Tendenz der kapitalistischen Entwicklung selbst; denn da es sich je länger je mehr nur nech um die Bedienung immer vollkommenerer Maschinen handelt, so ist auch die Möglichkeit gegeben, in steigendem Maße gelerute erwachsene Männer durch Ungelernte, Weiber und Kinder zu erseizen. ${ }^{2}$ )

Wenn aber der Durchschnittspreis der Arbeit sinkt, dann kann ein gegebenes variables Kapital mehr Arbeiter beschäftigen; es kann also auch ein relativ zur Kopfahl der Bevöllerung gesunkenes rariables Kapital rerhältnismäßig ebensoviel, ja hei starker Lolndepression sogar verhältnismäßig mehr Mitglieder der Industriebevölkerung beschäftigen als vorher. Waren beispielsweise von je hundert Angehörigen der industriellen Proletarierklasse in einem gegebenen Zeitpunkte zwanzig, sämtlich erwachsene Männer, im Dienste des Kapitals beschäftigt, so waren es in einem späteren Zeitpunkte, sage: vierzig, wovon, sage: 15) Männer, 10 Frawen und 15 Kinder. Es sind also fünf Männer freigesetzt, in die Reservearmee hinabgeschleuder, und dennoch hat sich die Arbeiterzahl verdoppelt, und zwar nicht nur absolut, sondern sogar im Verhältnis zur gewachsenen Bevölkerung.

Diese Argumentation ist außerordentlich scharfsinnig, aber unhaltbar.

Sie geht erstens ron einer falschen Prämisse aus. Wenn das Kapital mehr Arbeiter braucht, als ihm. der Bevölkerungszuwachs stelleu kann, so hann es unmöglich Männeratheit durch Frauen- und Kinderarbeit ersetzen. Der Arbeiter schleudert Weib und Kind, nuter das Juggernautrad des Kapita!s"33) nur dann, wenn Sklavenvogt Hunger die Peitsche üher ihm schwingt. Und das ist nur der Fall, wenn ein Überangebot ron Händen

1) Kapital I. 600 .

2) Dazu Ed. Bernstein, Zur Theorie etc. p. 99/100, der zeigt, daß diese Auffassung nicht allgemeingültig ist. Doch werden natürlich noch heute vielfach Gelernte durch Weiher etc. ersetzt. Vgl. Eulenburg (Conr. Jabrb. 3. F. XXIV, p. 327) am Beispiel der Porzellanfabrikation.

3) Kapital I. 610 . 
atuf den Preis der Ware „Arbeitskraft" drückt. Das aber widerstreitet der Voralussetzung, wonach das Kapital mehr Arbeiter braucht, als der Bevölkerungszuwachs liefern konnte.') Dann muß nach Marx' eigener oben wiedergegebener klarer Darstellung das Lolinnivealu steigen - und dann denkt der Arbeiter nicht darin, Weib und linind anf den Sklavenmarkt zu führen. Marx argumentiert hier, als wäre der Proletarier rechtlich robotpflichtig, statt, wie seine Grundroraussetzung, „freier ${ }^{\text {A Arbeiter. }}$

Aber es stimmen fernerhin die Konsequeizzen nicht mit den Tatsachen der Wirklichkeit ïberein:

Wäre nämlich die Marssche Argumentation richtig, so hätte der durchschnittlich pro Kopf des arbeitenden Proletariats, Gelernte, Ongelernte, Weiber und Kinder insgesamt, gezahlte Geldlohn mehr ils verhältnismäßig, in unserem Beispiél also um mehr als die Hälfte, gesunken sein mï̈sen. Denn nach der durehgehenden Voraussetzung ist der Lohn $l$ bestimmt als Quotient des Bruches $\frac{v}{s}$ (variables Gesamtkapital dividiert durch die Zahl der Beschäftigten): $l=\frac{v}{s}$. Steigt. $s$ auf das doppelte, während $v$ sinkt, so wird $l$ kleiner als $1 / 2$.

Nun ist aber notorisch, dafs der Geldlohn der Artheiter in regelın̈̈Bigem Steigen begriffen ist. Giffens Arbeiten haben für Grobbritimnien erwiesen, R. E. Mays, Julius Wolfs, Ed. Bernsteins Intersuchnnge! ${ }^{2}$ ) fïr Deutschland so gnt wie zur Evidenz erloben, daß sogia der Reallohn steigt,- und die Wuclut ihrer Argumente ist so groß, dal sellsst Kantsky ${ }^{3}$ ) und seine Anhïnger in Österreich, die das nene Parteiprogramm rerfaßt haben, nur

1) Das erktnut Marx in auderer Stelle atch an: ,Sobald also das Kapital gewachsen wäre in einem Verhältnis zur Arbeiterbevölkerung, daß weder die absolute Arbeitszeit, die di.se Borolkcrung liefert, insgedehut, noch die relative Ilelsarbeitszeit erweitert werden künte (das letztere ware obuehiu nicht tubar in einem Fill, wo die Nachfrage uach Arbeit so stark, also Tendenz zum Staigren der Lühue), etc." (Kapital IIl. 1, 233.) (Die gesperrte Stelle in Original niclst gesperrt.)

2) Vgl. Zur Theorie und Praxis $106 \mathrm{f}$.

3) „El. liernstein" etc. p. 116, 12S. 
noch von einer "relativen Verelendung“, rom "wachsenden Grado der Ausheutung " ${ }^{1}$ ) zu reden wagen. Wir haben dieses Fingeständnis nicht einmal nötig: uıß man zugeben, daß der Nominallohn durchschuittlich gestiegen ist - und niemand kann es bestreiteu -, dann ist es bewiesen, daß das überverlältnismäßige Wachstum der regelmäßig besetzten Arlueitsstellen in der. Industrie rom Standpunkte der Marxschen Theorie aus nur durch eiu (im Verhältnis zur Arbeiterhevölkeruug) wachsendes variables Kapital erklärt werden kaun. Nenue ich $s^{\prime}$ den Zulwachs der Arbeitsstellen während einer bestimmten Periode, $v^{\prime}$ den Zuwachs des rariablen hapitals in derselben Zeit, so ist der Lobn am Ende der Periode $=\frac{v+v^{\prime}}{s+s^{\prime}}$. Er kann größer sein ils ${ }_{s}^{v}$ nur dann, wenn $\frac{v^{\prime}}{s^{\prime}}$ größer ist als $\frac{v}{s}$, l. h. wenn das variable Gesamthapital stärker wuchs ats die Zahl der Arleitsstellen.

Indes wollen wir diese erst neuerlings festgestellten Tatsachen unserer Absicht gemäß nicht gegen Varx verwerten. Auch dann iürfen wir seine Erklïrung der Tatsache ablehnen. daß die Gesamtindustrie die Zahl der von ihr besetzten "Stellen" so überaus stark vermehrt hat. Denn, ganz abgesehen von der logischen Lnhaltbarkeit seiner einen Präimisse, ist er auch den Nachweis schuldig geblieben, dab der durchschnittliche Lohu im Verhältnis zum Zuwachs der Stellen gefallen ist, ein Nachweis. len er nie hätte erbringen künnen. Denn schon in den fünfzige: und sechziger Jahren des 19. Jahrhuuderts ist der Durchschnittslohn nach Giffen sehr betriichtlich gestiegen, eine Tatsache. dit Iarx nicht hätte entgehen können, wenn er nachgerechuet hüttc.

1) Vgl. Jaurès, Aus Theorie und Praxis, dentsch rou Südekın (190? 1. 32, und Em. Van der Velde, Vie kntwicklnug zım Sozialismus, deutseh ivn demselben (1902) p. 35. Die besten Ausfübrungen zur "relativen Ver

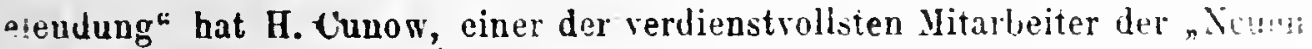
Zeit", gegehen. (,Zur Zusammenbruchsthenrie“, N. Z. 1898/9, II, H. 41: Vgl. uuch Engels, „Herru Eugen Dührings Lmwälzung" ofe. (Holtingen 1 agh) 1. i.j, und Kautsky in seiner Abbandlung über das neue osterreichishe Parteiprogramm, X. Z. XX, I, P. $75 \mathrm{ff}$.

Oppenheimer, Marx Gesellschaftslebre. 
Aber er hat eben nie nachgerechnet!

Ind su konmt er seiner entscheidenden Aufgalie, der Lösung des Problems, ol partielle, volle oder C̈herkompensation der "Ereisetzum: dusch Mehreinstellung stattfindet, auch nicht einen Sichritt näher.

Es kann mir wahrlich nicht einfallen, die Verfechter der bourgevis-ökonomischen „Kompensationstheorie" zu verteidigen gegen die schlagenden Einwände, die Marx in verachtungsvoller Bitterkeit gegen die Begründung ihrer Theorie erhebt, ${ }^{\prime}$ ) wonach „alle Maschinerie, die Arbeiter verdrängt, stets gleichzeitig und notwendig ein aläquates Kapital zur" Beschäftigung derselben identischen Arbeiter freisetzt. " ${ }^{2}$ )

Aber die Widerlegung einer Begründung ist noch nicht die Widerlegung einer Behauptung. Ind Marx hat ebensowenig bewiesen, daß nur eine teilweise Kompensation stattfindet, wie die Nill, MacCulloch, Torrens etc. bewiesen haben, daß volle Kompensation stattfindet. $\mathbf{Z u}$ diesem Beweise reichte die von beiclen Parteien angewaudte deduktive Methode nicht hin; hier nußte einmal gezählt werden!

Cind so kann denn auch Marx die bourgeois-ökonomische Kompensationstheorie nicht mit sachlichen Gründen überwinden, sondern fertigt sie nuit einigen gar nicht zur Sache gehörigen ethisch-humanen Redensarten ab:

'Alle zurechnungsfähigen . Repräsentanten der politischen Ölomomie greben zu, daß nene Einfülırung der Maschinerie pestartig wirkt auf die Arbeiter in den überlieferten Handwerken und Manufakturen, womit sie zunächst koukurriert. Fast alle beächzen die Sklaverei des Fabrikarbeiters. Ind was ist der grofie Trumpf, den sie ausspielen? Daß die Maschinerie, nach den Schrecken ihrer Einführungs- und Entwicklungsperiode, die Arleitssklaven in letzter Instanz vermehrt, statt sie schließlich zu rermindern! Ja, die politische ökonumic jubelt sich aus in lem abscheulichen Theorem ..., daf. selbst die bereits auf Maschinenbetrieb begründete Fabrik narh kürzerer oder längerer

1) Kapital I. 403 ก. 604.

$\Rightarrow$ Kapital I. 403. 
„Übergangszeit“ melu Arbeiter abplackt, ais sie ursprünglich aufs Pflaster warf. “ ${ }^{1}$ )

Das nennt Eduard Bernstein mit vollem Recht eine „sinnlose Redefloskel“ aud „Verquickung gauz heterogener Gesichtspunkte". ${ }^{2}$ )

Fassen wir zusammen:

Marx hat nirgend eine Tatsache für seine grundlegende These beigebracht, da $B$ in der fresamtwirtschaft eine nur particlle Kompensation dei "Freisetzung" durch Vehreinstellung vou Arbeitern stattfindet.

Dagegen führt er selbst die Tatsachen der „Lrbanisicrung“ an, die beweisen, dab mindestens in der Gesamtindustrie eine sehr starke Überkompensation stattíndet.

Sein Versuch, diese Tatsachen unit der Theorie in Übereinstimmung zu bringen, ist als mißlungen za bezeichnen.

Nithin ist das Argumentmon ad hominem gefülort: dis fesetz der Akkumulation, wie Marx es eutwickelt und rerstanden hat, ist widerlegt.

Es darf uns aber nicht genügen, Marx zu widerlegen, sondern es ist unsere Anfuabe, das von ihm anfgestellte Gesetz als nichtexistierend nachznweisen.

Zn dem Zwecke wenden wir uns der Prüfung der Frage zu, inwieweit das Gesetz der. Akkumulation fähig ist, die Erscheinungen in dem zweiten Hauptzweige der ,kapitalistischen Wirtschaft", in der Agrikultar, zu erklären. Dabei wird sich unter anderem ergeben, daß auch jener letzte Einwand mihatthar ist, auf den sich zwar nicht Marx selist, wohl aber ein anderer Verteiäiger des bestrittenen Gesetzes hätte zurückziehen kïmen. dab nämlich das landwirlschaltliche Kapital an der "Freisetzung" der Landproletarier die Schuld trägt.

:) Kapital I. 412.

?) Zur Geschichtc nad Theorie etc. p. 97. 


\section{Kapitel.}

\section{Die Tatsachen der landwirtschaftlichen Entwicklung.}

(Zentralisation, Expropriation nnd Freisetzung in der Agrikultur.)

Marx ist, wie nie bestritten, als Theoretiker Abkömmling der manchesterliberalen Schule, namentlich Ricardos. Wie ungemein er auch dasjenige verfeinert hat, was er von ihrem System beibehielt, die Aibeitwertheorie and die Theorie der „Freisetzung", braucht hier nicht dargestellt zu werden. Das gehört in eine Feschichte der nationalökonomischen Theorie. Genug, daß er nur abstreifte, was von jenen Gedanken der bürgerlichen Klassentheorie diente, und das übrige grundsätzlich beibehielt. Und darunter war der Kern aller Irrtiimer des Manchesterliberalismus, sein „Industriezentrismus “, wie ich es getauft habe.

${ }_{n}$ Schon die elementaiste Betrachtung mußte den Gemeinplatz ergeben, daß die Industrie nur ein sekundärer Trieb an dem Stamme der Urproduktion ist, $d ; B$ ihr Wesen nur aus der Urproduktion zu begreifen ist, daß, wie ihr Wachsen und Werden, so auch ihr Blühen and Vergehen nur zu verstehen ist, wenn man Wachsen und Werden, Blühen und Vergehen ihres Mutterbodens, der Landwirtschaft, versteht. “')

Von diesem einzig möglichen Grundstandpunkte, dem „Geozentrismus", hat sich zuerst der Manchesterliberalismus gali? losgelöst. Er hat immer versucht, aus den Erscheinungen der Industrie allein dicse selbst und die der Agrikultur zu begreifen und zu erklären. Das konnte auf die Dauer so wenig glücken, wie die ptolemäische Erklärung der Himmelserscheinungen. Nur pine „kopernikanische Umkehrung “ ${ }^{2}$ ) konnte Klarheit in die Ver-

1) Mein „GroBgrundeigentum und snziale Frage“, Berlin 1898, p. 59.

2) Ich wiederhole dicsen Ausdruck, den ich zuerst in einem Vortrage: Die soziale Bedeutung der Genossenschaft" gebrauchte (erschienen als Bro shüre Berlin 1899, Verlag der Sozialist. Youatshefte), weil er meinen inarx-orthodoxen Gegnern großes Vergnügen bereitet nat. 
wirrung bringen. Marx' Kapital aber stellt den letzi.n, mit gigantischer Kraft unternommenen I'ersuch dar, das verlorene System durch die Aufstellung einer geistvollen Epizyllentheorie zu retten. Er mulite scheitern.

Wie die kopemikanische Lehre, so hat anch der Geozentrismus in der politischen Ökonomie seine Vorläufer gehabt. Noch Adam Smith war, wenn anch bereits schwankend, Gouzentrist: er bezeichnet den Puukt, wo die sackgasse alzweigt. Aber sein größter Vorgänger, François Qhesuay, hat au den Anfang unserer Wissenschaft das monumentale Wort gestcllt: .. Il est évident que le g'uvernement n'a point d'autrés noycis pour faire fleurir le commerce et pour sontenir et étendre lindustrie que de veiller à l'accroissenent des reverius, (des Ackorbaus) ar ce sont les revenus qui appellent les marchiands et les artisans et qui payent leurs travaux. Il faut donc cultiver le pied de larbre et ne pas borner nos soins a gouverner les branches; laissuns les sarranger et s'étendre en liberté, mais ne négligeons pas la terre qui fournit les sucs nécessaires a leur vécgétation et a leur accroissement." " )

Marx ist "Industriezentrist" par excellence! Thm ist die Landwirtschaft ein "trade", ein Zweig der Gesamt-,Inrlustrie“, wie irgend ein anderer. Nichts kaun lür liese Auffassung bezeichneuder sein, als daß er in der schion einmal zitierten, von Jul. Wulf $^{\prime \prime}$ ) so hart beurteilten statistischen Anmerkung ${ }^{3}$ ) die Agrikultur ohne weiteres neben die wahrlich nicht sehr bedentenden Gewerbszweige der lichtgießer, Mälze:, Hutmacher usw, stellt.

So üherträgt er alle in der Betrachtung der Industrie gewonnenen Kategorien ohne Belenken auch auf die Landwirtschaft: $\left.{ }^{*}\right)$ Das "Gesetz der Akkumulation" wirkt hier in genau derselbea Weise wie dort:

1) Quesnay, Wuvres éd. Onchen 1). 208.

3) Sozialismus und kapitul. (Gestllschaftsordnung, Bd. I, Stuttgart 1896, p. $259 \mathrm{ff}$.

3) Kapital I p. 595.

\) Die zahlreichen gelegentlichen Seitenblicke, dis ur anf die LaLdwistscluaft wirft, tragen fast durchweg den Charakter der Exemplifizierung suf Gleichartiges" (David 1. c. p. 6i). 
Auch in der Landwirtschaft herrscht der Konkurrenzkampf; auch hier ist der kilpitalistisch ausgestattete große Betrieb dem kleinen Betriebe des neinfichen Warenproduzenten" überlegen und „expropriiert" ihn durch Unterbietung, and so akkumuliert und zentralisiert sich auch hier das Kapital. In lem Maße, wic das der Fall ist, tritt auch hier der uns bekaunte Wechsel, in der organischen Zasammensetzung des Kapitals ein, der koustante Bestandteil wächst nicht nur absolut, sondern auch relatir, der variable fällt mindestens relativ, und so werden immer mehr Arbeiter "freisesst/., die nun zusammen mit jenen „Expropriierten" auf den landwirtschaltlichen sowohl wie auf den industriellen Arbeitsmarkt drücken und das Elend des Proletariats $₫$ verewigen".

Fr. O. Hertz') verspottet diese Auffassungr in seiner burschikosen Art sehr lustig: "Die ältere sozialistische Theorie erklärt einfach, wie in der Industrie so ist auch in der Landwirtschaft der Großbetriel, üherlegen, konkurriert die kleinen Betriebe nieder, Thesis, Autithesis, Synthesis, Expropriation, Akkumulation, Assoziation, - fertig! !

Der spott ist wohlverdient. Denn. ron der ganzen, so plausibél kliugenden Darstellung ist auch nicht das mindeste in Cibeinstimmung mit den Tatsachen, und Marx hat anch nicht für eine einzige sciner Behautungen auch nur einen einzigen Beleg beigebracht, weder für den „Konkurrenzkampf" zwischen Groß- und Kleinbetrieb, noch für die Überlegenheit des ersteren und die „Expropriation" des letzteren durch lnterbietung im Preiskampf; und ebensowenig für die ${ }_{n}$ Freisetzlung" von Landproletariern durch das agrikole Kapital.

Es bestcht zwar eine enorme „Freisetzung" von Landproletaviern: aber nach den von Marx selbst beigebrachten Belegen ist. las Kapital daran gänzlich unschuldig;- - und es besteht zwar eine starke „Zentralisation" des landwirtschaftlichen Kapitals: aber nach den von Marx selbst beigebrachten Belegen ist die „Konkurrenz “ daran gänzlich unschuldig.

1) Die agrarischen Fragen usк., Wien 1899 , p. 60 
a) Die "honkurrenz" in der Landwirtschaft.

Als die Tiurzel aller dieser Irrtümer spreche ich die sonterbare Anschauung an, daB anch in ler Landwirtschaft große und kleine Wirte in „Konkurlenzkampf stehen: „Die kleineren und mittleren Pächter . . . werden progressiv in ganz auderem Grad als zuvor von der Konkurrenz des kapitalistisch betriebenen Ackerbáues erdriickt und liefern daher der Klasse der Lohnarbeiter beständig neue Rekruten." ") Diese stelle scheint der Herkunftort der Lehrmeinung zu sein, die, wie es scheint unausrottbar, die agrarpolitischen Anschauungen der marx-orthodoxen Theoretiker bestimmt, ${ }^{2}$ ) die natürlich als so viel kieinere Denker den Meister gerade in seinen Irrtümern übertrumplen und den "Industriezentrismus" zur liarikatur treiben.

Demgegenüber mul. als Ausgangspunkt aller ferneren leetrachtung festgestellt werden, dab ein Konkurrenzkampf im sinne des in den Gewerben herrschenden in der Landwirtschaft überhapt nicht existiert. Wenn man gewisse Erscheinungen überhaupt als" "Konkurrenz" bezeichnen will, so ist es ein Kimpi". der init völlig anderen Mitteln um völlig andere Ziele gestritten wird.

Der Konkurrenzkampf in der Industrie wird, abgesehen von ungesetzlichen und numoralischen Mitteln, allein gefülirt durch Unterbietung im Preise ${ }^{3}$ ) wobei es natürlich gleichyriltig ist, ob das gleiche Quantum gleicher Ware billiger, oder dis gleiche Quantum besserer Ware ebenso hillig angeboten wird, worauf Sombart großen Wert legt. Diese Enterbietang ist nur möglich

1) Kapital I. 671. Ebenso III. 2 1. 341. Älulich auch III. 2 p. 290.

2) Vgl. Kantsky, Die Agrarfrage, Stuttgart 1899, p. 107, 169, 176: rgi. anch David, „Ökon. Verschiedenheiten“, N. Z. 94/5, II, p. 450/4 Kautsí, „Die Konkurrenzfăhigkeit des Kleinbetriebs in der Iandwirtschafı" ebenda p. 481. p. 486: „Die Kleinhetriebe rerden ron dor Konkurrenz der grolin!n nicht in vollem Yaße getroffen." Eduard Adler 1. c. P. 717 ist der Jeinunu. $\mathrm{daB}$, der kapitalkräftige, intensire Großbetrieb linbedingt zunächst den Kleinbetriel, und später auch den Hittelbetrieb vernichtet.".

3) V.rl. Kapital I. 590: „Der Koukurrenzkawpf wird dureh Verwuhl. feilerung-der Waren geführt." 
anf dem Boden der Preisbildung, der die Gewerbe trägt. Auf die Daner wird hier der Preis bestinmt durch die Reproduktionskisten der Wareneinheit in dem bestausgestatteten Betriebe; der zu gleichen Bedingungen anf dem Markte zur Konkurrenz zugelissen ist, sei er nun der am günstigsten gestellte clurch seinen Standort (Marktnähe, billige Arbeitskräfte, billige Prodnktionsmittel, günstire Verbindungen) oder durch seine kapitalistische Ausstattung oder schlieklich durch Genie oder Energie seines Leiters. Hier also tendiert die Entwicklung regelmäßig auf Senkung des Preises mit dem Wachstum der Bevölkerung, nit dem Fortschritt der Arbeitsteilung, mit der Entwicklung der Technik. J)ie Preishilidung erfolgt mehr durch Angebot der Warenproduzenten als durch Nichfrage der. Kundschaft. Jamit soll resagt sein, daB die Kundschaft die niedrigeren Preise auf die Dauer - rom einzelnen Markte mit seinem Zufallsverhältnis von Angebot und Nichfrage ist nicht die Rede - weniger erzwingt als akzepticrt: das bestimmende Moment der Preisbilclung ist die Konkurrenz der Verkänfer, die sich unter-, nicht die der Käufer, die sich überbieten.

Ganz anders in der Landwirtschaft! Hier wird der Preis auf die Datuer bestimmt durch die Reproduktionskosten (Gestehungskosten am Erzengurgsorte zuzüglich der Transportkosten bis zum Markte) der Wareneinheit in dem schlechtest ausgestatteten. Betriebe, der zur Versorgung des Marktes unter den gegebenen Verhältnissen der Kaufkraft noch beitragen muß, sei er nun der ab ungünstigsten gestellte durch seinen Standort (höchste Transportkosten) oder durch die Qualität seines Bodens. Hier also tendiert die Entwicklung regelmäßig auf $\mathrm{Hebung}$ des Preises') mit dem Wachstum der Berölkerung, dem Anschwellen der städte, d. h. des Marktes für das Lrprodukt. Die Preishildung erfolgt hier mehr durch Nachfrage der Kundschaft als durch Angebot der Erzenger. Damit soll gesagt sein, daß auf die

') Dabei sind jokale Rückschlāge natürlich nicht iusgreschlosseu. Weun die Transportpreise plötzlich stark sinken, so können marktuahe liaduirte fust su viel Rente einbüBen, wie marktferne gerinnen. Das ist der Ylechanismus der "amerikauischen Lonkurreuz". Vgl. dazu mein "Grobgruudeigentum* p. 169 f. 
Dauer - rom einzelnen Markte mit seinem Zufallsverhältnis von Angebot und Nachfrage ist auch hier nicht die Rede - die Erzeuger die höheren Preise weniger erzwingen als akzeptieren; das bestimmende Moment der Preisbildung ist die Konkurrenz der Käufer. die sich über-, nicht die der Verkäufer, die sich unterbieten.')

Hier interessiert uns vor allem. wie sich das Verhalten der Verkäufer der industriellen Ware zueinander dort, der landwirtschaftlichen zueinander hier gestaltet.

In der Industrie erstrebt jeder kapitalistische Warenproduzent - für die „einfache $W$ arenprodultion“ bestehen andere Gesetze, wie sich zeigen wird - , seine Gegner ans dem Yarkte zu werfen. Seine $W$ affe ist die Unterbietung. Dvrch Unterbietung expropriiert der Manufakturenleiter den Handwerker, der Fabrikbesitzer beide, der große Kapitalist den kleinei. So wachsen die betriebe za immer größerer Stufenleiter, das Kapital akhumuliert und zentralisiert sich mehr und mehr.

Da in der Landwirtschaft von Lnterbietung im Preise abgesehen von einzelnen Konjunkturen auf vereinzelten Märkten - gar keine Rele ist, so fehlt dieser einzige Motor des Preiskampfes hier gäızlich. Der einzelne Besitzer', und sei er der größte Magnat, hat gar keine Möglichkeit, den Marktpreis für Korn und Fleisch auf der.Dauer zu erniedrigen $;^{2}$ ) demn seine Produktion verschwindet als ein Tropfen im Neere der Gesamternten. Verkauft er, was er hat, unter dem Marktpreise, so macht er lediglich dem Spekulanten oder Müller ein Geschenk und beeinflußt. allenfalls einen vereinzelten Lokalmarkt damit; aber an den Marktpreis selbst rührt er nicht auf die Dauer: dem den bestimmt das Terhältnis vom Gesamtnachtrage uni Gesamtangebot. Nur ein-Welt-Getreide-Trust könnte eine Zeitlang den Preis heeinflussen: und, auch ein solcher würde kaum auf Lnterbietung der Außenstehenden hinarbeiten; seine Veriuste stiuden in keinem Verhältnis zu deun möglichen Gewinn.

1) Natürlich weiß Marx das alles ganz genau ivgl. z. B. Ficnd der Philosophie p. 144-148), aber er wendet is hier nicht an.

$\Rightarrow$ Vgl. Sering, Die Agrarfrage und der Suzialismus. Sepr.-Al.dr. aus Schmollers Jahrb., p. $292 \mathrm{ff}$., rgl. auch Hertz 1. c. 81/82. 
Unter diesen limstänilen besteht auch gar nicht die Aisichi der Interbietung, besteht gar nicht die psyrhologische Stimmung zum Konkurrenzkampf unter den Laudwirten. Wo keiner des andern Konkurrent ist, wi) keiner hoffen kann, durch Niederzwingung seiner Genossen das Monopo! des Marktes zu erriugen und die Preishestimnung der Ware dadurch in die Hand zu bekommen, stehen sich die Menschen als Warenverkäufer ökonomisch mit ganz anderor fresinuung gegenüber. Wic sie sich sonial gegenüberstehen, ist eine andere Frage. Aber jeter @önnt delu ancrert den höchsten Marktpreis, weil er seller inn erbält und nur laun erhalten kaun, wenn der Nacbbir ilm erhäli.

Wo kein Preishampf, keine Unterbi nng besteht, dai wirft aber auch der Größere den Kileineren wicht aus dem llarkte. Da entstehen also auch nicht durch ökonomische Expropriatiou wenige größere Betriebe an Stelle vieler kleineren.. ${ }^{2}$ )

b) Akkumnlation und Zentralisation des AgrikulturKapitals.

Ind dennocli fand sich gerade zu Marx' Zeit in der britischen Agrikultur die starke Tendenz zur Akkumulation und Zentralisation vor. Seit Jahrhunderten war eine Bewegung. im Ginge und hatte sich seit Beginn der kapitalistischen Ära unverkeunbal sehr verstärkt, die darauf hinausiief, viele kleinere lindwirtschaftliche Betriebe durch wenige grobe zu ersetzen: scheinbar ein genaues Gegenstück zu der Bewegung in der Industrie!

Iarx läßt die kleinen Wirte im "Konkarrenzkampf $f^{\prime \prime}$ zugrunde gehen. Es beiryt ihn aber nicht, daß er zwei Seiten vor der oben (S. Z1) angefïhrten Stelle selbst konstatiert, ${ }^{3}$ ) daß zu derselben Zeit „der Geldwert des Produktes rasch stieg infolge der seit len letzien zwanzig und ganz besonder's seit den letzten zehn Jahren steigenden englischen Marktpreise für Fleisch, Wolle usw." Er ist von seinen industriellen Kategorien so geblendet, daß er den

1) „Lie Überlegenheit des Großbetriebes über den Kleinhetrieb genügt heutzutave, ... so riele Bauern und Handwerker zu expropriieren" ete. hisutsky. ,Erfurter Programm* (Stuttgart 92) p. 31.

$\Rightarrow$ Filpital I. 1,69 . 
Widerspruch gar nicht empfindet, der darin liegt, daß die kleinen Produzenten bei steigenden Preisen zugrunde gehen sollen. Ob wohl die Handweber bei steigenden Preisen ihrer Ware ebenfalls zogrunde gegangen wären?!

Was hat also den kleinen landwirtschaftlichen Produzenten vom Lande fortgefegt, wemn es nicht der Preiskanpf war? Hat ihn das durch die, ursprüngliche Akkumulation" vor langer Zeit einmal gebildete Grofkipital a usgekauft? Das ist gewiß in einzeluen Fällen geschehen. Aber Narx kann das nicht meinen. Dénill er himnts natürlich die Statistik der Eigestumsveränderungen und whlie, daß ihre Zahl viel zu klein war: un die Massenwanderung zn erklären.') Außerdem: wiiren die Banern rom Kapital in Zeiten steigender Prodnktenpreise ausuekiuft. worten, so wären sie ja nicht als ,vogelfreie Prolctariei", von allen l'roduktionsmitteln enthlülit, sondern als - behähige Kapitalisten in die Stinlte gewandert, und hätten gewiß, „lewohnheiten und Juhensansprii:he. gehabt, deren Befriedigung im Lohne den stältischen Kapitalisten keine grolje II hrwertmarge gelassen bätte. Lè Auskaul also könnte, wenn er inassenhaft vorgekommen wäre, was nicht der Fall, allenfalls eine bedentende Massẹnwanderung in tie Stadt erklüren, aber unmöglich eine Massenwanderung elender Proletarier.

Wir stehen ratlos. Jeer landwirtschaftliche ,einfache Waren-

1) Yarx in rler Inanguralaulesese der Iuternationalen Arbeiterassoziation von 1864: "Ihr werdet finden, daf die Zahl der Grundeigentüner in England ron 16934 Personen in Jahne $185 \mathrm{I}$ anf 15066 im Jahre 1861 zusammengeschmolzen ist." (zit. naeh Kautsky, "Pernstein“ etc., p. 68). Das ist 2 rar eine, "Zunahee der linzizentration" no $11 \%$ : uber es sind duch nur hïchstens. 1868 ,exproprierte Iandwirtsfamilien, sagen nir: loukn Abwanderer. Wober stammen die übrigen 59 no(r)?

Ïlrigens sind die \%ahlen falsch. Nach lirodrick waren 18if ion 33̈ Nillionen Acres im Domesday Book cingetrauenen Bodens in Englant ud Wales rund 14 Millionen Figentum ron zusammen 1704 Grunlbesitzeru mit je 3000 Aeres und darüber. Die restlichen 19 Yillionen Acres verteilten sich zuischen rund 150000 Eigentümer von 1 Acre und darüher und eiue Cinmasse Figentümer von kleinen Landfetzen. N!lhall gah 1892 für das ranze lereinigte Königreich die ZahI der kìcentüner von mehr als 10 Acres Boden auf 176520 an. (Bernstein, Voraussetzungen p. 63.) 
produzent" kann nicht nielertionkurriert worden sein - denn es giht keinen Preiskampl; - er kann auch nicht ausgekauft sein - denn dann gäbe es keine proletarische Abwanderung; er karm auch nicht gewaltsam rertrieben worden sein, - denn das wäre "ursprüngliche" und keine „kipitalistische* Akkumulition. End dennoch ist, er verschwurlen!

Nenden wir uns an Marx selbst, un das Rätsel zu löseu. Sucheu wir die Stellen auf, wo er den Prozeß der Aktiumulation auf. dcm Lande nicht im allgemeinen aus seinem Gesetz ableitet, sondern im einzelnen dilstellt. Hier muß sich die lösungr linden.

., In Irland wuchs 1\$51-1861 die Zahl der Pachthöfe von 15-30) Acres um 61000, die der Pachthöfe von über 30 Acres nn 109000 , während die Gesamtzahl aller Pachten um 120000 ahnahn, eine Abnahme, die also au-schließlich der Vernichtung wn Pachten unter 15 Acres, alias ihrer Zentralisation ses:'huldet ist. "')

Is können nicht viel weniger als eine halbe Million gauz k!einer Pächter verschwunden sein. Ich frase noch einmal: was hat sie "veruichtet" und die Zentralisation des Laudkapitals erzeugr? Bei steigunden Preisen des Produkts?

Ifarx schreibt: "V'or der IIungersnot hesal der Acherbauragelöhner ein Stückchen Land, worauf er Kartoffeln hante und schwëine and Geflügel zog. Hentzutige muB er nicht mux alle seine J,ebensmitiel kaufen, sondern es entgehen ihm auch die Einnahmen. ${ }^{2}$ ) Wie ist er tam das land gekommen?

„. Han konfisziert das ... Slüchchen Land“ ... „Der erste A kt dor Ackerbanrevolurion war; auf allerwy B̈Btem Maßstal und wie nach einem von oben gegchesen losungswort, die auf dem Arheitsfeld gelegenen i'ütten wegzufegen."

In England selbst das gleiche Bild! „Die Abnahme der mittleren Pächter ersieht man namentlich aus den Rubriken des Zensus: „Pächters Sohn, Enkel, Bruder, Neffe, Tochter, Enkelin,

3) Kapital I. 665.
$\because$ Kapital I. 672.
3) Kapital I. 673. 
Schwester, Nichte“, kurz die vom Pächter beschäftigten Gliedrr seiner eigenen Familie. Diese Rubriken zählten 1851: 216851 Personen, 1861 nur 176151 . Von 1851 bis 1871 haben in England die Pachthöfe von unter 20 Acres sich um mehr als 900 verringert; die $z$ wischen 50 und 75 Acres sind ron 8.25 auf 6370 gefallen, älnnlich bei allen andern. Pachthöfen unter 100 Acres. Dagegen hat sich während derselben 20 Jahre die Zahl der großen I'achthöfe vermehrt: dic von 300-500 Acres sind gestiegen von 7771 auf 8410 , die von mehr als 500 Acres voll 2755 auf 3914 , die ron mehr als 1000 Acres ron 492 auf 589." "

Es handelt sich also überall um Pächter! Was ist ein Pächter? Ein Pächter ist ein berufsmäßiger Landwirt, der gegen Eutrichtung eines bestimmten jährlichen, meist in Geld festgesetzten, meist in kurzen Fristen steigernugsfähigen, Betrages anf fremdem Lande, auf dem Eigentum eines andern Eigentümers, Landwirtschaft betreibt.

Hat der kleine Pächter Ähnlichkeit mit dem Handwerker der „einfachen Warenproduktion"? In seinem Betriebe: gewiß! Denn er arbeitet selbst, unterstiitzt von seiner Familie, allenfalls geringem Gesinde. $\mathrm{Er}$ ist nicht Kapitalist: denn ,zersplitterte Produktionsmittel sind nicht Kapital ${ }^{\prime} .^{2}$ ) Aber damit ist die Analogie auch erschöpft. Seine Eigentumsverhältnisse sind von denen des mittelalterlichen Ilandwerkers völlig verschieden.

Er ist gar niclit ,einfacher Warenproduzent"! Denn dessen charakteristische Eigenschaft ist nach Marx das Eigentum an den Produktionsmitteln: "I) einfache Warenproduktion ist lie ursprüngliche Form dieser Produktionsart. Sie wird dadurch gekenuzeichnet, daß die Produzenten einauder nicht nur als Freie und Gleiche gegenüberstehen, sondern auch im Besitz ihrer Produktionsmittel sind.."3) Der Päcliter ahcr ist nicht Besitzer der Produktionsmittel; das wichtigste. sein land, gehört einen Fremden, seinem Grundherrn!')

1) Kapital I. 643 Anm. 14 s.

$\Rightarrow$ Kapital I. 6099 .

3) Kautsky, Agrarfragre, VI. p. 60.

b) "Die Erde ist stlbst ein Arbcitsmittel." Kapital I, 142; ebenso III, 2 p. $309 ; 10$ und 360 . 
Der ,einfache Warenproduzent" auf dem Lande, das Gegenstück zu dem Handwerker der Stadt, ist der "selbstwirtschaftende Bauer, leın die Produktiousmittel gehören ${ }^{\alpha} ;^{1}$ ) nicht aber der l'ächter!

Wonn es Pächter waren, auf deren Kosten die „Akkumulation und Zentralisation des landwirtschaftlichen Kapitals" erfolgte, dann' schwindet jede Schwierigkeit. .Denn Pächter kann man im sogenannten ,Rechtsstiate sehr einfich "expropriieren": man ermeuert ihren Vortrag nicht und "setat" sie schlimmstenfills durch Polizei oder einen Zuy Militär "frei"! Das bedarf hoiner tiefsinnigen Ableitung aus dem Wechsel der organischen Zusanmensetzung des Kapitals.

Aber herleutet das ,lie Expropriation der inmitielbaren Produzenten, d. h. die Auflïsmng des anf cigener Arbeit beruhenden Privateigentums ${ }^{4}$ ? $^{2}$ ) Ist diese "Expropriation" von Pächtern etwas, das mit der geschichtlichen Tendenż der kepitalistischen Akkumulıtion" etwas zu tun hat, deren.Inhalt es angeblich ist, den einfachen Warenproduzenten, den selbstwirtschaftenden Eigentümer von Produktionsmitteln kleinen Imfangs, durch Lnterbietung im Preiskampf zn "expropriieren"?

Größere Unterschiede als zwischen ler Akkumulation in der Industrie einerseits und der Janndwirtschaft andererseits sind kaum denkbar. In der Industrie ist der leidende 'Thil Figeutümer, in der Iandwirtschaft Nichteigentiimer seiner Prodnktionsmittel; in der Industrie ist dei gewiniende 'leil der hürgerliche Emporkömmling, auf dem Lande dei juristische Inhaber fendaler Eigentumsrechte; in ier Industrie wächst das "hilpitil" zaerst neben dem. Ilandwerk empor, akkumnliert sich lingsim, und daron die Folge ist die "Expropriation" dis IIandwerhers, sein Entegang in ökonomischen Proiskanipi gegen die !nterbietung des Kapitals: auf dem Lande aber wirci zuerst der kleine

1) Kapital J. 680, 7, vgl. auch 727: "Wo der Arbeiter freier Privateigentümer seiner vou ihn selber gehaudbal,ten Articitsbedingungen ist. der lauce des Ackers, den er bestellt, der llaudwerker des . Instruments, worauf er als Virtuose spielt." Fbenso III. 1, 156, III. 2, 215, nameutiich aber III. $2,3+1$.

3) Kapital I. 726 . 
Pächter "expropriiert" und zwar nicht durch Lnterbietung, ökonomisch, sondern durch Exmission, juristisch: ${ }^{1}$ ) und damit ist der kapitalistischen Agrikultur überhaupt erst die „Grundbedingung" ihrer Existenz gege! ien. Was dort Folge ist, ist hier Ursache, was hier Folge ist, ist dort Ursache!

Wenn Marx hier Identität erblickte, weil er über diesen entscheidenden Gegensatz fortsalh, so ist las Schuld einer simplen quaternio terminorum. E! sah hicr und dort "Expropriation" lind beachtete nicht, labis er zwei ganz verschierlene Bedeutungen damit verknïpte, die öhonomische, von ihm sonst gebrauchte, und die übliche juristisch-legale. Was für eine - Verwirrung das ist, ist leicht erkennbar, wenn man sich vorstellt, daR ein durch die Konkurrenz der Warenhäuser ,expropriierter" Ladenbesitzer auf (irund der "Expropriations"-Gesetze Entschädigung verlangen wollte. Wer diese Unterschiede sieht Marx sah sie nicht -, aber für gleichgültig hält, weil beide Yethroden schließlich doch zur „Expropriation“ führen, maz ein guter Agitator sein, ist aber gewiß ein schlechter 'ilheoretiker: er moralisiert, wo er untersuchen und unterscheiden sollte!

Marx moralisierte im allgemeinen nicht; die „Verquickung der ganz heterogenen Gesichtspunkte" von wissenschaftlicher Entersuchung und sozialer Antipathie ist bei ihm sehr selten. Hitr :her schieben sich in der Tat fortwährend die industriellen Kateg rien in seine Betrachtung der Agrikultur hinein, bis er den ('ächter für einen Bauern ansieht ${ }^{2}$ ) und zum Gegenstück des städtischen Handwerkers macht, und bis ihm die durch juristische Exmission der Päcliter erfolgte Zentralisation der Betriebe erscheint als eine durch ökonomische Expropriation erfolgte Zentralisation des ländlichen Kapitaleigentums.

Von der ökonomischen Expropration eines Bauern ist aber im ganzen „Kap:tal" keine Rede.

Ich stelle somit fest, daß für die eine Hälfte der Behauptung, die das "Gesetz der Akkumulation" aufstellt, bei Marx kein Be-

') Vyl. Kitpital I, 39.;, wo der Prozel ganz richtig dargestellt ist -. aber nur in seinen Anfängen.

2) "In Jriand . . . ist der Pächter im Durchschnitt ein kleiner Banel." (Kapital III. 2 p: $16 j$. 
leg beigebracht ist, soweit die Landwirtschaft in Frage kommt: die Akkumulation des Kapitals am einen Pol der gesellschaftlichen Stufenleiter.

c) Grob- und Kleinbetrieb iu ler Landwirtschaft.

In dem Streit um den Revisionismus, ist unter Aufwand (ar ungeheuersten belesenheit und Gelehrtheit besmlers die Frase ventiliert worden, ob der landwirtschaftiche GroBbetrieb wler der Kleinhetrieb öhonomisch stärker sei. Namentlich Fr. O. Hertz and nelerdings Darid l!ahein ge:nll Kautsky ein unschätzbares Material zusammongetragen (a. a. 0.). Ind dem,och war der Liebe Müh' in dicsm streitiall sallz umsonst. IIan hätte sich nur Marx' Kapital anzusehen hrauchen, un zu findun, dab cr nirgend einen einzigen hewcis tür dic Überlegenhoit des Großbetriebes erbracht hat.') bitse C̈berlesenheit ist. ledigtich erochlossen durch einen 'Trugschlub, inlem man die Zentr ulisation der Betriebe - zustandeigekommen durch juristische Pxmi:sion von Pächtern -, gleichsetzte ler Zentralisation des ladus riekapitals, - zustandegekonmen durch ökmomische Expropriation von Handwerkern. Es war nichts als pin grober Analogieschlab, wenn man auch in der Agrikultur die ökononische Ohberlegenheit des Großbetriebes im Konkmrenzkampf siegen lieb, wie es in der Industrie der Fall ist.

Kantsky schreibt: $\left.{ }^{2}\right)$ „Wer unser Ziel als irrig erweisen will, ter mub nachweisen, daf unsere Lehre ron ler ükonomischen Entwicklung eine f:lsche ist. . . daß es keinen Fortschritt gribt rom Kleinbetrieb zum Großbetrieb." Verzeihung! Die Beweis-

1) Im Gegentcil! Er hat in spāterer Zeit augenseheinlich das Umgekehrte angenommen: „Die Moral von der Geschichte, die man anch durch soustige Betrachtung der Agrikultur gewinuen kanu, ist die, dali das kropitalistische System einer rationellen Agrikultur widerstrebt, , wer die rationelle Agrikultur unverträglich ist mit dem kapitalistischen System (obgleich dies ihre technische Eutwicklung befördert) und eutweder der Ifaud des selbst arbeitenden Kleinluauern oder der Kontrolle des assoziierten Produzenten vedarf" (Kapital III. 1 p. 98 ).

$\Rightarrow$ Erfurter Programm p. 131. 
last hat der Behanptende: und für die Landwirtschaft haben weder Marx noch seine Schüler einen einzigen Beweis für die Überlegenheit des Großbetriebes erbracht, sondern nur den Schein eines solchen durch doppeldentige Worte: „Expropriation“, Zentralisation etc.

Daß es auch in der Landwirtschaft ,einen Fortschritt gibt vom Kleinbetrieb zum Großbetrieb“, könnte nur anerkannt werden, wenn im allgemeinen der selbstwirtschaftende freie Eigentümer, der Baner, ror der „Konkurrenz" des Großbetriebes verschwände. Daß das nicht der Fall ist, hat selbst Kautsky trotz der wanderlichsten Manipulationen mit den statistischen Ziffern schließlich anerkennen müssen. ${ }^{1}$ ) Über die $\Lambda$ rt, wie er mit ihnen umspringt, mag man bei Fr: O. Hertz ${ }^{2}$ ) nachlesen. Ich habe hier keinen Raum, darauf näher einzugehen. Nur die allererstanulichste leistung sei angeführt: ${ }^{3}$ ) Cm die Akkumulation und Zeutralisation des landwirtschaftlichen "Kapitals ${ }^{\text {zu }}$ bew eisen, macht Kautsky erst den Hypothekengläubiger zum wahren Eigentiimer des belasteten Gutes - und zeigt dann, daß die Hypotheken sich in den Kassenschränken von immer wenigeren Zentral-Beleihungsinstituten zentralisieren ${ }^{\star}$. Daß diese ihr -Figentum sofort in Gestalt von Rentenbriefen wieder ,repellieren", die das Hypothekeneigentum über weiteste Schichten kleiner Sparer verteilen, macht ihm keine Skrupel: die Konzentration des Hypotheken maklergeschäftes rerwandelt sich ihm unter der Hand in eine Zentralisation des Hypothekenbesitzes, und diese in eine solche des Grundbesitzes! ")

lch setze gegen diese höchst gröbliche Analogiespielerei folgende Betrachtung:

Ich stelle mir auf der einen Seite einen freien Ilandweber im rollen unverschuldeten Eigentum seines Hauses, seiner Werkzellge und seinor Rohstofe, in Besitze eines genügenden Vorrats an Subsistenzmitteln vor, auf der andern Seite einen freien, spann-

1) Agrarfrage p. 132 fi.

2) A. a. 0. 2. B. p. 71 und vielfach passim.

3) Vgl. meine Auzeige in der Berliner "Zukunft" rom 12. dug. 1899.

4) Agrarfrage 1. 86 ff.

Oppouheimer, Marx' Gescllschaftslehre. 
fähigen Bauern im vollen, unantastbaren. Eigentum seines unverschuldeten Grundstücks und seines Inventars, und lasse nnn anf beide das "Großjkapital " loskonkurrieren. Nach Ablauf einer bestimmten Zeit ist der Handwerker ein jämmerlicher, verelendeter Proletarier, der Bauer aber hat ein Piano im Wohnzimmer ${ }^{1}$ ) und läßt einen Sohn studieren. Der Handwerker ist am Preissturz seiner Produkte zugrunde gegangen, der Bauer hat ron Epoche zu Epoche höhere Preise erhalten, wenn nicht regelmäßig steigend pro Zèntner Rohprodukt, so doch sicherlich pro Hektar Fläche!

Hier läßt sich regelmäßig der folgende Einwand vernehmen: "Ist es etwa nicht Tatsache, laß die, amerikanische Konkurrenz die Preise für Korn, Fleisch, Flachs, Wolle etc. geworfen hat? Und sind nicht viele Bauern an dieser Konkurrenz zugrunde gegangen? Existiert also Konkurrenz in der Landwirtschaft oder nicht?"

Ich kann unmöglich hier die ganze Agrarfrage und Agrartheorie aufrollen.') Nur so viel sei hier bemerkt:

Erstens ist die amerikanische Konkurrenz keine „kapitalistische", und keine Konkurrenz zwischen Grob- und Kleinbetrieb: ${ }^{2}$ ) Sie gelit aus von „einfachen Warenproduzenten", selbstwirtschaftenden, freien Bauern, deren „zersplitterte Produktionsmittel gar nicht Kapital sind “. ) Zweitens: diese „Konkurrenz" trifft das landwirtschaftliche Großkapital Europas anerkanntermaßen noclı schwerer als den europäischen Klein- und Mittelbaueru. Drittens: es handelt sich.nicht um einen Preissturz, wie in den Handwerken, sondern lediglich un einen Preisr ückschlag

‘ Vigl. Hecht, Drei Dörfe: der schwälischen IFard. Leipzig 1895.

“) Vgl. meine „Siedelungsgenossenschaft", Teil II, Kap. 1, mein·, GroBgrundeigentun“ etc., I. Buch, Kap. 1, und meine Aufsătze:" „Die Agrarfrage“, Seue l)eutsche Rundschan VIII (1897) Beft 4, sowie „Die dcutsche Wissenschaft und der Kornzoll', ebendaselbst XIV (1903) Heft 1.

3) „Diese (überseeische) Konkurrenz ... bemht im entscheidenden T'eil wicht auf kapitalistischer Grundlagre." Vavid, „Zur Frage der Konkurrenzfähigkeit des landwirtschaftlichen Kleinbetriebs, " N. Z. 1894/う, II, p. 679.

4) Kapital I. 669 . 
im Vergleich mit einer kurzen Periode sehr hoher Preise von Mitte der sechziger bis Mitte der siebziger Jahre des 19. Jahrhunderts. Die Preise selbst fül die Gewichtseinheit' des Urprodukts sind heute noch höher als vor dieser Hochperiode; und doch waren die damaligen Preise solche, bei denen der Vorfahr des heutigen Bauern in Behagen lebte und emporkam. Viertens: dieser Preisrückschlag ist in sehr bedentendem Maße kompensiert worden durch Steigerung der Erträge von der Flächeneinheit, durch Verbilligung der Produktionsmittel und der Transportkosten bis zum Markte. Fünftens: an diesem Preisrückschlage sind nur wenig Bavern zugrunde gegangen, und zwar einzelne! Die Klasse als solche, und nur darauf kommt es an, hat sich iiberall velmehrt!')

Die wenigen Einzelnen aber sind zugrunde gegangen - von Unwirtschaftlichkeit abgeseher - an ihrer Verschuldung, seltener an der Kauf-, meistens an Erb- und Aussteveryerschuldung. Sie hitten als bleibende Erben ihre Brüder und Schwestern nach dem Verkehrswerte ihres Eigentums abzufinden, einem Verkehrswerte, der häufig nach den hohen Preisen jener Ausnahmeperiode festgestellt war: und darnm, nur darnm warf sie der Rückschlag der Preise zu Boden. Belege darf ich mir für diese allyemein bekannten und anerkannten Tatsachen hier ersparen, wo es sich um eine Polenik mit Marx, nicht mit seinen Jüngel'n handelt.

Die Verschuldung aber ist eine Folge des geltenden Grundeigentumrec?tes. Wir stoßen also auch hier, soweit eine Zentralisation des Grundeigentums durch den Ruin einzelner Bauern zustande gekommen ist, auf dieselbe letzte Ursache, die auch in Grobbritaunien die Pächter vom Iande fegte: das geltende römisch-rechtliche Grundeigentum, ${ }^{2}$ ) das „quiritische ${ }^{u}$, „private „privative" Bodenrecht, das nicht nar den Usus, sondern auch

1) Hertz I. c. z. B. 28, 29, 35, 55. Bernstein, Zur Geschichte etc. 227 etc.

$\left.{ }^{2}\right)$ „Jede Kritik des kleinen Grundeigentums löst sich in letzter Instanz auf in Kritik des Privateigentums als Schranke und Hindernis der Produktion." (Kapital III. 2 p. 347.) 
den Abusus des Grundeigentums gewährleistet, wie an jeder beweglichen Sache.

d) Die "Freisetzung des Landproletariats".

Wir kommen jetzt zu dem wichtigsten Teile der Erörterungen, die dieses Kapitel zu erledigen hat. Wie erklärt sich die „Freisetzung" des ländlichen Proletariats, dessen Zuwanderung in die Städte und 'Industriezweige allein jenes Heer "freier" Arbeiter liefert, ohne die das „Kapitalverhältnis" in der Industrie verschwinden müßte. Daß das „Kapital“, soweit die Industrie in Frage kommt, an der Bildung der Surplusbevölkerung gänzlich unschuldig ist, hat uns das vorige Kapitel gelehrt: wir werden jetzt mit Marx' eigenen Worten den Nachweis liefern, daß es ebenso unschuldig an der Freisetzung des Landproletariats ist und werden damit das Gesetz der Akkumulation auch aus seinem letzten Zufluchtsorte vertrieben haben. -

In der Industrie sollte die „Reservearmee" aus zwei Quellen gespeist werden: die ölkonomische Expropriation früher selbständiger Produzenten - und die "Freisetzung" schon früher unselbständiger Arbeiter von seiten des Kapitals.

Daß in der Landwirtschaft die erste Quelle nicht fließt, haben wir soeben gezeigt: es gibt hier keine "ökonomische Expropriation" früher selbständiger Produzenten: wie steht es um die zweite Quelle?

Die Tatsachen, die Marx bringt, beweisen nichts für die Freisetzung früher unselbständiger Arbeiter durch den Prozeß der kapitalistischen Produktion in der Jandwirtschaft. Was in den von ihm angeführten Fällen die Landproletarier vom Lande gefegt hat, ist nicht das „Kapital“, sondern dasselbe Recht der Grundbesitzer, mit ihrem Eigentum zu tun, was sie wollen, ${ }^{1}$ ) das auch die Pächter „expropriiert" hat. „Große Grundeigentümer haben nur zu beschließen, daß keine Arbeiterwohnungen auf ihren Gütern stehen sollen, und sie befreien. sich sofort von ler Hälfte ihrer. Verantwortlichkeit für die Armen. “") „Eine

1) Kapital I. 648.

3) Kapital I. 649. 
Pachtung mag noch so groß sein, es existiert kein Gesetz, dâs auf ihr eine bestimmte Anzahl von Arbeiterwohnungen, und nun gar anständigen, stehen muß; obensowenig behält das Gesetz dem Arbeiter auch nur das geringste Recht auf den Boden vor. . . "1) „Den Umfang des Übels mag man ans dem letzten Zensus beurteilen, wonach die Zerstörung von Häusern, trotz vermehrter lokalei Nachfrage für dieselben, während der letzten zehn Jahre in 821 verschiedenen Distrikten ron England fortschritt, sodaB, abgesehen von den Personen, die gezwungen wurden, Nichtresidierende (nämlich in dem Kirchspiel, in dem sie arbiten) zu werden, 1861 verglichen mit 1851 eine um $5 \% \frac{1}{3} \%$ größere Bevölkerang in einen um $4 \% \%$ kleineren Hausraum gedrängt, wurde. ${ }^{2}$ ) (Es handelt sich hier um die Folgen der unsinnigen britischen Kirchspielarmengesetze.)

All das ist nicht im mindesten Folge einer kapitalistischen Akkumulation, sondern Ausfluß desselben Rechtes, das Wilhelm den Eroberer "berechtigte ${ }^{*}$, soundsoviele Dörfer zu rasieren, um für seine Jagdleidenschaft den New Forest zu schaffen, und dasselbe, was die Herzogin von Sutherland ${ }^{3}$ ) "berechtigte", ihre gaelischen Clanverwandten zu vertreiben.

Freilich: die dabei bestehende Absicht war ,kapitalistisch:" Die Grundherren wollten mehr "Mehrwert" aus ihrem Eigentum herausschlagen. Aber das ist es nicht, um was es sich hier handelt. Das "Gesetz der Akkumulation" spricht nicht von den Absichten wirtschaftender Menschen, Mehrwert zu ziehen, sondern von den Mitteln, ${ }^{4}$ ) mit denen sie ihn erpressen. Niemand hat schärfer und klarer als Marx selbst festgestellt, daB "Kapital" nur unter ganz bestimmten; historisch gewordenen Verhältnissen als solches funktioniert. Sind diese Verhältnisse

') Kapital I. 648.

2) Kapital I. 649 .

3) Kapital I. 695 ff.

4) Die Verwechslung von kapitalistischen $Z$ weck tau und kapitalistischen Mitteln ist die Grundlage der Engelsschen Kritik gegen Dïhring. Ygl. „Herrn Dührings L'mwălzung“ p. 135, $159 \mathrm{ff}$. Vgl. dazu meine bereits erwähnte geschichtsphilosophische Abhandlung in der Vierteljahrsschr. f. wiss. Phil. u. Soziologie. 
nicht gegeben, so bringt es der Besitzer von Prodaktionsmitteln auch roit der innigsten Absicht nicht fertig, Mehrwert zu orlangen. Die ganze Frage, um die es sich hier handelt, ist die, unter welchen historisch gegebenen Bedingungen das "Kapitalrerbältnis" sich antomatisch reproduziert, sodaß die Absicht der hajitalbesitzer, Mehrwert zu beziehen, sich verwirklichen läßt. Oder mit andern Worten, woher die „freien" Arbeiter stammen, ohue die das "Kapitalverhältnis" nicht existieren kann.

Die rou Marx beigebrachten Tatsachen beweisen also nicht für, sondern gegen seine Behauptung - - und auf der andern Seite bringt er nicht eine einzige Tatsache bei, die seine Behauptung beweist. Er sagt zwar entschieden genug: "Sobald sich die kapitalistische Produktion der Agrikultur, nnd in dem Maße, wie sie sich derselben beschäftigt, nimmt mit der Akkumulation des hier funktionierenden Kapitals die Nachfrage für die ländliche Arbeiterbevölkerung absolut $a b^{\text {( }} .^{1}$ ) Aber auch diese These ist wie die Zentralisation des landwirtschaftlichen Kapitals nur ein gröblicher Analogieschluß, abgezogen aus der Tatsache der „Freisetzung ${ }^{\text {“ }}$ von Landproletariern, die , industriezentrisch" $^{\star}$ erklärt wird, ohne daß die völlige Verschiedenheit der Zusammenhänge beachtet wird. Ein Beleg jedoch für die These wird nirgend beigebracht. Betrachten wir zum Beweise die einschlägigen Stellen:

Akkumulation, das bedeutet Vermehrung des konstanten Kipitals, also zunächst der Maschinerie. Marx ist der Meinung, daß die ,Maschinerie im Ackerbau .... noch intensiver und obne Gegenstoß auf die „Überzähligmachung" der Arbeiter wirkt", als in der Industrie.')

Die einzige Stelle, no Marx m. W. für diese allgemeine Behauptung Tatsachen anführt, ist die folgende: ${ }^{3}$ ) ${ }_{\text {Von }} 1849$ bis 18.09 z. B. stieg in England der Arbeitslohn der Ackerban-

') Kapital I. 607. Ganz im gleichen sinne 1. 65y,60. Ann. 170 und III. 1. 246, 111. 2.177.

") Kapital I. 469. V'gl. Kautsky: Karl Harx' ijkonomische Lehren p. 176 tis.

9) Kapital III. 2, 168. 
arbeiter .... Gleichzeitig fielen die Durchschnittspreise des Getreides um mehr als $16 \%$. Die Pächter schrien nach Herabsetzung der Renten. Es gelang ihnen in einzelnen Fällen. Im Durchschnitt scheiterten sie mit dieser Forderung. Sie nahmen Zuflucht zur Herabsetzung der Produktionskosten u. a. durch massenhafte Einfülirung des lokomobilen Dampfs und neuer Maschinerie, die zum Teil Pferde ersetzte,..., zum Teil aber auch durch Freisetzung von Ackerbautagelöhnern eine künstliche Überberölkerung und daher nenes Sinken des Lohnes hervorbrachte." Marx beruft sich hier auf die Privat-Enquête eines Jobn C. Morton, angestellt bei ca. 100 Pächtern aus 12 schottischen und 35 englischen Grafschaften.

Unmittelbar anschließend aber an die oben zitierte allgemeine Behauptung, daß die Maschinerie in der Agrikultur massenhaft Arbeiter freisetzt, berichtet er:

„In England und Wales betrug 1861 die Zahl der in der Fabrikation von Ackerbaumaschinen beteiligten Personen 1034, während die Zabl der an Dampf- und Arbeitsmaschinen beschäftigten Agrikulturarbeiter nur 1205 betrug. "') Es sind also 1861 in höchstens 1205 landwirtschaftlichen Betrieben höchstens 1205 Maschinen gleichzeitig in Betrieb gewesen, wenn man auf jeden Betrieb nur eine Maschine und auf jede Maschine nur einen Bediener unterstellt: eine winzige Anzahl im Verhältnis zur Zahl der landwirtschaftlichen Betriebe in England und Wales. $^{2}$ ) Nehmen wir selbst an,- alle diese Maschinen seien in der Zeit von 1851-1861 neu aufgestellt worden, so ist es doch eine geradezu skurrile Torstellung, daß diese paar Maschinen die ungefähr 600000 Landbewohner überzählig gemacht haben sollen, die in diesem Jahrzehnt nach Marx' eigener Angabe in die Städte strömten. Jede Maschine müßte in jedem der zwölfhundert höchstens beteiligten Betriebe rund fünfhundert Menschen,

1) Kapital I. $469 / 70$.

*) Hier, also ohne Schottland und Irland, gab es noch 1991 nach dem offiziellen Zensus 223610 Farmer (zit. nach Bernstein 1. c. p. 184). Für ganz Grofluritannien rechnet er (185) eine Million Farmer und Farmerssöbne. 
d. h. mindestens handert erwachsene Männer ersetzt haben. So viele beschäftigen aher kaum die größten britischen Betriebe; die Mehrzahl besteht bekanntlich aus Pachtungen mäßiger Größe ${ }^{3}$ ) mit verhältnismäßig geringem Arbeiterstamm.

Damit ist auch jene eine Tatsache, die im übrigen wenig Gewicht hat, da sie der Privat-Enquête eines vielleicht interessierten Fachmanns entstammt, entkräftet. Denn sie bezieht sich auf ungefähr die gleiche Periode, wie die letzt angeführten Angaben.

Bekanntlich ist es in unserem Europa allein die Dreschmaschine, die in größerem Maße Arbeiter ersetzt. Sie hat namentlich durch Fortfall des Winterdruschs mit dem Flegel darauf hingewirkt, die Landwirtschaft mehr und mehr zum Saisongewerbe zu machen, worauf Marx mit Recht großen Nachdruck legt, und hat sie derart von der Notwendigkeit, eine ständige Arbeiterbevölkerung zu halten, emanzipiert. Und gewiß ist auf diese Tatsache ein beträchtlicher Teil der Abwanderung zurückzuführen. Aber Marx' eigene Zahlen beweisen klar, daß ein ungehenrer, unerklärter Rest zurückbleibt. Die Abwanderang erfolgt zeitlich lange vor der Einbürgerung der Dreschmaschine und vollzieht sich ganz außer dem Verhältnis zu ihrer Verbreitung.

Die übrigen arbeitsparenden Maschinen aber sind ${ }^{2}$ ) im großen Mábstabe nur unter dên exzeptionellen Verhältnissen des amerikanischen Westens verwendbar, wo auf einer tellerflachen Ebene ohne Wellen kein Stein an die Schar des Dampfpfluges oder die Messer der Erntemaschine stößt. Diese Maschinen ersetzen aber nicht faktisch, sondern nur "virtuell", wie Marx sagen würde, Arbeiter. Ebenso bei nns fast ausnahmslos der Dampfpflug in den seltenen Fällen, wo er zur Verwendung kommt. Denu dann dient er der Tieflultur, die mittels Handarbeit im Feldban kaum je angewendet wird. Die am häufigsten angewendete Maschine unserer Landwirtschaft aber, die Drill-

1) Eine Farm von 1000 Acres gilt in vielen Grafschaften schon als schr groll... Vie gröliten Weidewirtschaften für Grobvieh belaufen sich auf nenig àber 1000 Acres." Bernstein „Zur Geschichte etc.“ 191. vgl. auch Slouinski p. 187.

3) Vgl. Sering „Agrarfrage und Sozialismus". Sep.-Abz. aus Schmollers Jabrb. 1900 p. 305 . Viel Material auch bei Hertz a. a. 0. und bei David a. a. 0. 
maschive, fordert schon bei der Aussaat eher mehr als weniger Arbeiter als die Breitsaat mit der Hand; und sie fordert vor allem während der Vegetationsperiode vermehrte Arbeitskraft, da ihr Hauptvorteil, außer der Ersparnis an Siatgut, in iler Möglichkeit liegt, die Zwischenrüume zwischen den Reihen häufig zu behacken und derart den Boden erstens von Unkrant zu befreien nud zweitens in einer den Wachstum günstigen Weise für licht, Luft und Wasser durchgängiger zu machen.

Die Maschine kann also nur einen kleinen T'eil der Abwanderung erklären.') 'Wie ist es mit der sonstigeu Vermehrung des konstanten Kapitals?

„Die Abschafiung der Korngesetze gal dem englischen Landbau einen ungeheureu Ruck. Drainierung auf der gröbten Stufenleiter, neues System der Stallfütterung und des Anbaus der künstlichen Futterkrüuter, Finführung mechanischer Düngapparate, neue Behandlung der Tonerde, gesteigerter Gebrauch mineralischer Düngmittel, Anwendung (er Jampinatschinen und aller Art never Arbeitsmaschinerie usw., intensivere Kultur überhaupt charakterisieren diese Fpoche. Der Präsident der küniglichen Gesellschaft für Agrikultur, Herr Pusey, behauptet, dab dic (relativen) Wirtschaftskosten durch die neu eingeführte Maschinerie beinahe um die Hälfte verringert worden sind. Andrerseits ward der positive Bodenertrag rasch erhöht. Größere Kapitalsauslage per Acre, also nuch beschlennigte Konzentration der Pachten, war Grundbedingung der neaen Nethode." ${ }^{2}$ )

ग) VyI. David 1. e. p. 2503 u. ๆ. 262: „Die Narxsche Auffassung, die Maschine werde in der Iandwirtschaft die gleicbe Arbeiter freisetzende Tendeuz entialten wie in der Industrie, entsprang eiuer unscharfen Beobachlung der euglischen Landiritschuft. Dort wurden in der 'Tat groBe Diassen von Landarbcitern infolore der Revolutionierung der Landwirtschaft ût rahalig genacht und in die Städte gejagt. Die landwirtschaftlicheu Maschinen trugen daran aber die geringste Schuld. Es war die Verwandlung von Ackerland in Weide oder gar in Jagdgrūnde. - In $\mathrm{Pa}$ renthese: David gliubt steif und test an die "Freisetzung* in der Industrie. Wit er die Bildung der Reservearmee mit seinen eigenen Angaben über die Aufrabmelähigkeit der Industrie (p. 260) vereinigen will, bleibt unir unverstāndlich.

2) Kapital I. 613. 
Machen nun diese Verbesserungen, von der Maschine abgesehen, deren Wirkung wir bereits erledigt haben, Arbeiter überzählig? Sicherlich nicht! Sie mögen „virtuell" Arbeiter ersetzen: "faktisch" steigern sie den Arbeiterbedarf der Wirtschaften. Nach Settegast ${ }^{1}$ ) beträgt der Bedarf an Handarbeitstagen pro $1 /$ Hektar und Jahr:

$\begin{array}{ll}\text { bei Körnel- und Feldgraswirtschaft } & 12-20 \\ \text { bei Fruchtwechselwirtschaft } & 30-50 \\ \text { bei Industriewirtschaft } & 60-130\end{array}$

Marx konstatiert denn auch selbst mehrfach, ${ }^{2}$ ) daß ${ }_{n}$ trotz seiner beständigen "relativen Übervölkerung" das Land úntervölkert ist. Dies zeigt sich nicht nur lokal auf solchen Punkten, wo der Menschenabfluß nach den Städten, Minen, Eisenbahnbaiten usw. zu rasch vorgeht, es zeigt sich überall sowohl zur Frntezeit als im Frühling und Sommer während der zahlreichen Momente, wo die sehr sorgfältige und intensive englische Agrikultur Extrahände braucht. Es sind der Landarbeiter stets zu viel für die mittleren und stets zu wenig für die ausnahmsweisen oder temporären Bedürfnisse des Laudbaus. " 3 )

Hier stutzt Marx einen Augenblick. Unter solchen Umständen wäre eine starke Erhöhung der Bestellungs- und Erntelöhne zu erwarten, wcil die temporäre und lokale Arbeitsnachfrage viel größer wäre als das gleichzeitige Angebot: ist doch. gleichzeitig die Iandberölkernng absolut an Zahl herabgegangen! Aber, so argamentiert er weiter, nder . . . Arbeitsmangel bewirkt keine Erhöhung des Arbeitslohnes, sondern Pressung von Frauen und Kindern in den Feldbau und Herabsteigen zú immer niedrigeren Altersstufen. Sobald die. Weiber- und Kinderausbeutung größeren Spielraum gewinnt, wird sie ihrerseits ein neues Nittel zur Überzähligmachung des männlichen Landarbeiters und Niederhaitung seines Lohnes. Im Osten Englands blüht

1) Die Landnirtschaft und ihr Betriel) (Breslau 1885) S. 495. Neuere Ziffern Wringt David (l. c. S. 258;59) nach Bensing. Danach ,fordert die Rübeuwirtschaft das Zehnfache an Arbeitskräften wie die alte Dreifelderwirtschaft" !

") Z. B. Kapital 1. 674.

3) Kapital I. 659 . 
eine schöne Frucht dieses cercle vicieux, das sogenannte Gangsystem." 1)

Das Argument scheint mir aus den oben bereits einmal angeführten Grïnden nicht beweiskräftig.

Wächst nämlich die Nachfrage nach Arbeitern in der Campagne der Landwirtschaft stark, während, wie angegeben, die Landbevölkerung sich sogar absolut vermindert: dann ist unmöglich zu verstehen, aus welchen Ursachen Weiber- und Kinderarbeit den Männerlohn gedrückt haben soll. Denn der Arbeiter wirft Weib und. Kind nur in der Not "unter das Juggernautrad des Kapitals"! Marx argumentiert auch hier, als wären jene Arbeiter keine „freien" Arbeiter, und als hätte der Gutsherr das unbeschränkte Robotrecht, „Weiber und Kinder in den Feldbau zu pressen". Das widerstreitet aber seiner Grundvoraussetzmng, wonach die kapitalistische Wirtschaft nur möglich ist bei dem Vorhandensein einer genügenden Anzahl „freier" Arbeiter.

Die Stelle läßt sich also nur elklären, wenn wir annehmen, Marx habe geglaubt, dal die Maschinerie mehr Arbeiter verdrängt, als die Intensivierung der Agrikultur neu erfordert habe, eine Auffassung, die mit der oben zitierten Stellen übereinstimmt, wonach in der Agrikultur die Maschine "ohne Gegenstoß ${ }^{\text {“ }}$ wirkt. Dies hätten wir demnach so zu verstehen, daß der Gegenstob der Intensivierung weit durch den Stob (del Maschine) überkompensiert werde. Dafür aber hat Marx keinen Beweis erbracht und konnte er auch keinen erbringen. Denn jede Cmfrage hätte ihn belehrt, daß schon zu seiner Zeit in Großbritannien der mit Maschinen arbeitende intensive Ackerbau mehr Hände gebrauchte, als die maschinenlose Extensivwirtschaft.

Aber vielleicht war es die Agrikultur als kapitalistische „Manufaktur", die die Landbevölkerung so massenhaft freigesetzt hat Jurch alle die Vorteile, die der kapitalistische Betrieb schon ohne Naschinenverwendung vor dem „einfachen Warenproduzenten " voraus hat: Ersparnis an Werkstätten und an der Abnutzung der Arbeitsmittel, Spezialisierung der Arbeiter, Kombination der einzelnen Arbeitskräfte zu einer Gesamtarbeitskraft, der einzelnen

1) Kapital I. 660 . 
Arbeitstage zu einen Gesamtarbeirstag, Ersparung an faux frais usw.') Marx nimmt das in der 'Tat an:

, Kooperation und Kombination der Arbeitsmittel in den Händen Weniger rufen, auf die Agrikultur angewandt, ... große, plötzliche und gewaltsame Revolutionen der Produktionsweise und daher der Lebensbedingungen und Beschäftigungsmittel der Landberölkerung hervor, in vielen Ländern lang vor der Periode der großen Industrie. " 2 )

Aber die "Grundbedingung der nenen Methode" war ja, wie wir erfuhren, die „Konzentration der Pachten“.

Ind diese Grundbedingung ist, wie wir jetzt wissen, durch eine Methode geschaffen worden, die mit der kapitalistischen Produktionsweise und ihren "Tendenzen" nichts zu schaffen hat. Marx selbst fährt an der oben zitierten stelle fort: ${ }_{n}$ Aber dieser Kampf spielt ursprünglich mehr zwischen großen and kleinen Landeigentümern als zwischen Kapital und Lohnarbeit; andrerseits, soweit Arbeiter durch Arbeitsmittel, Schafe, Pferde usw. verdrüngt werden, bilden unmittelbare Gewaltakte hier in erster Instanz die Voraussetzung der industriellen Revolution. Erst werden die Arbeiter von Grund und Boden verjagt, und dann kommen die Schafe. Der Landdiebstahl auf großer Stufenleiter ... schafft der großen Agrikultur erst ihr Anwendungsfeld. « )

Was Marx nur für die „Anfänge dieser Umwälzung der Agrikultur" annimmt, das gilt aber auch, wie gezeigt, für ihren Fortgang, nur mit dem einen Unterschiede, daß der Landraub sich mehr nnd mehr in legale Formen kleidet.

Wenn die agrikole „Manufaktor" also etwa wirklich Arbeiter überzählig gemacht haben sollte, so ist sie selbst erst entstanden dadurch, daß viel mehr Pächter und Landpioletarier vorher anderswie überzählig gemacht worden waren. Wir sehen uns hier also in Zirkel - and außerdem hat Marx aucb für diesen Prozeß keine Tatsache berichtet.

1) Kapital I. p. $288 \mathrm{ff}$.

2) Kapital I. p. 395.

๖) Die gesperrte Stelle im Orig. nicht gesperit. 
Ich stelle somit fest, daß auch für die andere Hälfte der Behauptung, die das „Gesetz der Akkumulation“ aufstellt, bei Marx kein Beleg beigebracht ist, soweit die Landwirtschaft in Frage kommt: für die Akkumulation des Proletariats am andereu Ende der gesellschaftlichen Stufenleiter.

Damit ist die Aufgabe dieses Kapitels erledigt.

\section{Kapitel. \\ Die Tatsachen des kapitalistischen Gesamtprozesses.}

\section{(Die Lrbanisierung der Bevölkerung.)}

Wir haben in den ersten Kalpiteln dieses Abschnittes die beiden Hauptabteilungen der kapitalistischen Wirtschaft isuliert betrachtet und gefunden, daß das von Marx aufgestellte "Gesetz der Akkumulation“ die in beiden zur Beobachtung gelangenden Erscheinungen nicht im mindesten erklärt. Die kapitalistische Industrie erschaffit sich ihre Reserve-Armee, die Voraussetzung des "Kapitalverhältnisses" und des Mehrwertes, nicht selbst; diese entsteht vielmehr ausschließlich in der Landwirtschalt; und hier ist es nicht der kapitalistische ProduktionsprozeB, der sie freisetzt, sondern das Grandeigentum in seiner primitiven jaristischen Gestalt.

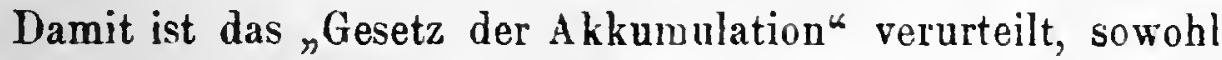
vor dem Richterstuhle der formalen logik, als auch ror dem Forum der Tatsachen. Ich könnte jetzt nach Lösung des negativen Teiles zu dem letzten, dem positiven T'eile meiner Aufgabe übergehen, nämlich den ganz anders beschaffenen Mechanismus aufweisen, der nun wirklich die Reproduktion des Kapitalverhältnisses herbeiführt and dadurch die kapitalistische Wirtschaft, die Mehrwert-Presse und das Elend des Proletariats, wenn auch nicht "verewigt", so doch aufrecht erliält. 
Indes möchte ich noch einmal zurückgreifen, um nun auch aus einer Betrachtung des kapitalistischen Gesamtprozesses einen einfachen und, wie mir scheint, schlagenden Beweis gegen das Gesetz der Akkumulation abzuleiten. Die minutiösen Untersuchungen der beiden letzten Kapitel sind gar nicht nötig, um einen unbefangenen Beurteiler von der Unichtigkeit der Marxschen These zu überzeugen: er kamn sie ohne Mühe auf den ersten Blick aus der zentralen Tatsache des kapitalistischen Gesamtprozesses ablesen, aus der Crbanisierung der Bevölkerung.

Das Gesetz der Akkumulation enthält nämlich eine Quantitätsbestimmang, die eine solche Entscheilung zuläßt. Es sagt aus, daß die "Freisetzung" von Arbeitern erfolgt, „je größer Umfang und Energie des funktionierenden Kapitals".

Vergleichen wir daraufhin Gesamtindustrie und Landwirtschaft eines kapitalistisch entfalteten Landes! Wenn das Gesetz der Akkumulation richtig ist, so muß sich zeigen, $\mathrm{daB}$ der kapitalistisch höher entwickelte Hauptzweig, derjenige, in dem das funktionierende Kapital stärker akkumuliert und zentralisiert ist, mehr Arbeitsplätze einzieht, als der schwächer entwickelte.

Nan wird versuchen, gegen diese Fragestellung zu protestieren, wird einwenden, daß Marx sein Gesetz für die Gesamtwirtschaft, nicht für ihre einzelnen Hauptzweige aufgestellt habe, daß daher die Gegenüberstellung unzulässig sèi.

Der Einwand ist aber abzuweisen. Marx hat sein allgemeines Gesetz der Akkumulation nur gewonnen aus einer Addition der Tatsachen, die, wie er zu sehen meinte, typisch in jedern einzelnen kapitalistischen Betriebe und Zweige sich zeigen: "das Wachstum des gesellschaftlichen Kapitals vollzieht sich in Wachstum vieler individueller Kapitale“. ${ }^{1}$ ) Nichts kaun uns also hindern, die Summe wieder in ihre einzelnen Addenden aufzulösen: das Gesetz muß in jeder beliebigen Summe von Einzelbetrieben wirksam sein, wenn es existiert.

Sollte noch jemand zreifeln, so mag Marx wieder selbst entscheidon. Fr schreibt: „Sobald sich die kapitalistische Prọduktion der Agrikultur, oder im Grade, worin sie sich der-

1) Kapital 1. 589. 
selben bemächtigt hat, ${ }^{\prime}$ ) ninmt mit der Akkumulation des hier funktionierenden Kapitals die Nachfrage für die ländliche Arbeiterbevölkerung absolut $a b^{“} .^{2}$ ) (nd ferner: „Ähnliche Bewegung ... in Frankreich, im Maße wie sich dort die kapitalistische Produktion der Agrikuitur bemächtigt und die „überzählige" Landbevölkerung in die Städte treibt." ${ }^{3}$ )

Aus diesen Sätzen geht hervor, daß Marx mindestens für den einen isoliert betrachteten Hauptzweig der kapitalistischen Volkswirtschaft, für die Agrikultur, der Ūberzengung ist, daß die „Freisetzung" erfolgt entsprechend dem „Umfang und der Energie ${ }^{\alpha}$ der Akkumulation. Ind für den anderen Hauptzweig, die "Manufaktur im Sime aller nicht agrikolen Industrie“, ergibt sich dasselbe, wie ausgefïhrt, aus seiner Beweismethode: je melr sich in den einzelnen Betrieben das ursprüngliche Kapital durch „ersparten“ Mehrwert akkumuliert; je mehr „repellierte Kapitalteile in Gestalt neuer Kapitalisten in den Konkurrenzkampf des Produktionszweiges eintreten, die sich natürlich mit den neuesten Produktionsmitteln ausstatten; je mehr schließlich im Proze $\beta$ der Zentralisation die von einer Stelle aus verwalteten Kapitalmassen wachsen, um so mehr vermindert sich im Einzelbetriebe das individuelle variable Kapital im Verhältnis zum individuellen Gesamtkapital; die Addition aller dieser Einzelkapitale ergibt ein nicht nur im Verhältnis zur Produktionsleiter, sondern anch zur Bevölkerung vermindertes variables gesellschaftliches Kapital, und so sinkt dern anch in der Gesamtiurustrie die Zahl der "Stellen" proportional dem Umfang und der Energie der Akkumulation und Zentralisation.

Nun stößt Marx allerdings auf einen sehr wichtigen Lnterschied zwischen der Freisetzung in der Industrie und derjenigen in der Landwirtschaft. In dieser nimmt die Nachfrage für die ländliche Bevölkerung absolut ab, ohne daß ihre Repulsion, wie in der nicht agrikolen Industrie, durch größere Attraktion ergänzt(!) wäre." $)$ Dieser wichtige Cuterschied ist schon an frülerer

1) In Original nicht gesperrt.

2) Kapital I. 607.

3) Kapital 1. 65\%/60. Anm. 170.

4) Kapital 1.607. 
Stelle des gleichen Bandes berührt: "Wenn der Gebrauch der Maschinerie im Ackerbau großenteils frei ist ron den physischen Nachteilen, die sie dem Fabrikarbeiter zufügt, wirkt sie hier noch intensiver und ohne Gegenstoß auf die "Überzähligmachung“ der Arbeiter, wie man später im Detail sehen wird. In den Grafschaften Cambridge und Suflolk z. B. hat sich das Areal des bebauten Laudes seit den letzten zwanzig Jahren sehr ausgedehnt, während die Landberölkerung in derselhen Periode nicht nur relativ, sondern absolnt abnahm." )

Er fährt an der zuerst angeführten Stelle fort: "Ein Teil der Landbevölkerung befindet sich daher fortwährend auf dem Sprunge, in städtisches oder Manufakturproletariat überzugehen, und in der Lauer auf dieser Verwandlang günstige Cmstände. (Manufaktur hier im Sinne aller nicht agrikolen Industrie.) Diese Quelle der relativen Übervölkerung fließt also beständig. Aber ihr beständiger Fluß nach den Städten setzt auf dem Lande selbst eine fortwährend latente Übervölkerung voraus, deren Umfang nur sichtbar wird, sobald sich die Abzugskanäle ausnahmsweise weit öffnen. Der Landarbeiter wird daher auf das Minimum des Salairs herabgedrücht und steht mit einem Fube stets im Sumpfe des Pauperismus". ${ }^{2}$ )

Die Tatsache ist richtig! Die "Freisetzung" in der Landwirtschaft ist nicht nur unvergleichlich viel stärker als in der Industrie, soudern sie kommt hier sogar allein vor, wie wir wissen. Aber wir sehen uns rergebens nach irgend einer Stelle um, wo Marx diese Tatsache aus seiner Theorie zu erklüren oder mit seiner Theorie in Einklang 7, bringen suchte. Er stelli sie lediglich fest und bemerkt gar nicht, da $B$ sie in unvereinbarem Widerstreit zu sei: en "Gesetz der Akkumulation" steht. Jedermann weiß, daß überall, wo der Kapitalismus auch nul seine ersten Schritte getan hat, die Akkumulation und Zentralisation des Kapitals mit rem technischen Fortschritt unvergleichlich schneller in der Industrie rorangegangen ist, als in der Landwirtschaft. 
Erfolgte also, wie das Gesetz der Akkumnlation allssagt, die Produktion einer wachsenden Surplusbevölkerung im geraden Verhältnis zu der Akkumulation und dem mit ilır verbundenen Wechsel in der organischen Zusammensetzung des Kapitals, so müßte die Industrie einen im Verhältnis zu ihrer Kopfzahl viel stärkeren Anteil an der Reservearmee bilden, als die Landwirtschaft.

Denn sie besteht aus individuellen Betrieben, die durchschnittlich auf viel höherer Produktionsleiter stehen, als die individuellen Betriebe der Agrikuliur; ihr Gesamtkapital besteht aus individuellen Kapitalen, die (daher) in viel stärkerem Maße durch Akkumulation und Zentralisation gewachsen sind und (daher) zu einem viel größeren Bestandteile aus konstantem, zu einem viel kleineren Bestandteile aus rariablem Kapital zusammengesetzt sind, als die individuellen Kapitale, die das Gesantkapital der Agrikultur zusammensetzen. Wenn die Überzähligmachung der Arbeiter wirklich irgend etwas mit dem variablen Kapital und seinem relativen Sinken zu tun hätte, so müßte zweifellos die Industrie :llein in wesentlich verstärktem Gracle die Erscheinungen anfweisen, die die Gesamtwirtschaft, geschweige denn die kapitalistisch so viel weniger entfaltete Agrikultur allein, zeigen. ${ }^{3}$ ) Statt dessen saugt die Industrie noch einen ganz enormen Teil der ländlichen Surplusberölkerung auf. L'nd umgekehrt sollte die Agrikultur einen im Verhältnis zu ihrer Kopfzahl viel kleineren Anteil an der Reserrearmee bilden: statt dessen setzt sie alljührlich mehr Ilunderttausende frei, als nach der Meinung der schlimmsten schwar'zseher jährlich Tausende der Reservearmee zugeschlagen weiden.

J)ie Produktion der Surplusbevölkerng erfolgt also augenscheinlich nichtim geraden, sondern im umgehehrten Verhältnis zu der Kapitalsakkumulation. Lnd das scheint mir ein unerschütterlicber Bereis gegen das

1) - Die Arbeitslosigkeit ist also eine ständige Erscheinung der bapitalistıschen Großiudustrie, die mit ihr untrenubar verknünft isı." Kautsisy, Erfurter Programin p. 45. Ursache: Maschine (1. 44).

Opponheimer, Marz' Gese!lschaftsiebre. 
Geșetz der Akkumulation zu sein. Ich sehe keine Möglichkeit, es damit in Einklang zu bringen, und Marx hat-den Versuch auch nirgend gemacht.

Daß er nicht einmal stutzte, als er auf die Tatsache stieb, daß in der Laudwirtschaft nur Repulsion, aber keine Attraktion stattfindet, läßt sich nur aus seinem absoluten Industriezentrismus begreifen. Ihm war die Agrikultur ein $\mathrm{Zweig}$ dei Gesamt-Industrie, wie irgend ein anderer: die vollkommene Gegensätzlichkeit der Existenzbedingungen beider Hauptzweige der Volkswirtschaft war ihm wohl bekannt, aber in den entscheidenden Überlegungen niemals gegenwärtig.

Nur so ist es zu verstehen, $\mathrm{daB}$ ein Geist von solcher Kraft achtlos an diesen ungeheuren Unterschieden der Quantität vorühersah, die bei dem ersten Versuch einer genaueren Beobachtung sich als qualitative stärkster Art herausstellen mußten und die ganze Theorie umgestaltet hätten. 


\section{VIERTER TEII.}

\section{DIE URSACHE DER}

\section{KAPITALISTTSCHEN EXPLOITATION.}





\section{X. Kapitel.}

\section{Grundeigentums-Verteilung nnd ländliche Wanderbewegung.}

Nag Karl Marx noch so sehr geirrt haben in der Erkenntnis and Darstellung des gesellschaftlichen Prozesses, der die Surplusbevölkerung schafit, diese „Masse wohlfeilen Menschenmaterials (taillable à merci et miséricorde) ${ }^{\alpha 1}$ ): zwei Kernpunkte seiner I,ehre bleiben davon unberührt.

Erstens, daß diese Beyölkerung „freier" Arbeiter durch die Schuld menschlicher Einrichtungen produziert wurde und reproduziert wird, durch der Verbesserung bedürftige und fähige Mäugel der gesellschaftlichen Organisation; daß sie also nicht geschaffen wird durch unerbittliche Gesetze der Natur selbst, wie das der gedankenlose Malthusianismus behauptet.

Zweitens: Da $B$ das Vorhandensein einer die Nachfrage auf dem Arbeitmarkte überschreitenden Bevölkerung freier Arbeiter die einzige Voraussetzung ist jeder nicht anf Sklaverei beruhenden Mehrwertwirtschaft.

Ohne "freie" Arbeiter kein Mehrwert, keine Akkumulation, keine Krösusse und Rockefellers am einen Pol, mögen sie noch so geniale Gaunel oder "captains of the industry " sein, trotz Karl Reinhold, Richard Ehrenberg und anderen Anbetern der Carlyleschen "Hero-Worship" in der Ökonomik. Ohne nfreie" Arbeiter aber auch keine Akkumulation von Elend am anderen Pol, keine Brutalisierung, kein Pauperismus und Kriminalismus

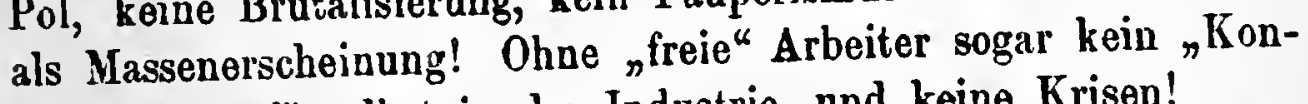
kurrenzkampf ${ }^{\prime}$ selbst in der Industrie, und keine Krisen!

1) Kapital I. 436. 
Es hat Werner Sombart weit abseits geführt, daß er gerade diesen wichtigsten und richtigsten Hauptsatz des sonst von ihm in fast allen Hauptstücken angenommenen Marxschen Systems aufgegeben und durch eine haltlose und widerspruchsvolle "Psychologie der führenden Wirtschaftssubjekte" ersetat hat, die den Kapitalismus aus dem "kapitalistischen Geist" elwachsen läßt, der irgendwie und irgendwann aus dem Nichts entstanden sein soll. ${ }^{1}$ ) "Damit verlor Sombart den einzigen sicheren Führer durch das Jabyrinth der soziologischen Erscheinungen, die sozial-okonomische - ich will aus bekannten Gründen ${ }^{2}$ ) nicht sagen, die materialistische Geschichtsaulfassung.

In diesen beiden entscheidenden Punkten stimme ich durchanus mit Marx überein. ${ }^{3}$ ). Der Luterschied unserer Auffassung begrenzt sich auf das Problem der Herkunft der Surplusbevölkerung und demzufolge auf die l'rognose der zukiunftigen Entwicklung, die ja bei Marx eine Schlubfolgerung as seiner Ableitung der Surplasbevölkerung, nämlich aus, dem (Gesetz der Akkumulation ist.

Was reproduziert also diese Existeuzbedingung aller Hehrwertwirtschaft, den freien Arbeiter, wenn er nicht durch den kapitalistischen Produktionsprozeß reproduzicrt wird?

Wir haben aus Marx' Kapital einige Quellen der ländlichen Abwanderung kennen gelernt, die Exmission der früher selbständigen Pächter und der früher unselbständigen Laularbeiter, Knechte, Insten nsw. Diese Austreibung ergab sich uns als Folge eines bestimmten Grundeigentumsrechtes.

Offenbar genügen diese Exmissionen mit Einschlulb der Inclosures von ehemaligem Gemeindeeigentum und selbst mit Finschluß so brutaler und umfangreicher „Clearings of Estates“, wie sie die Herzogin von Sutherland vollziehen ließ, nicht einual für Großbritannien, um den dauernden Abstrom der Hunderttausende vom Lande zu erklären. Sie genïgen noch weniger tür

1) Vol. meine Anzeige in der „Kultur", 1903.

2) S. Seite 8 .

3) Meine "Siedlungsgenossenschaft"; Berlin 1896, mein „Großgrundeigenlum und soziale Frage", Berlin 1898, und namentlich mein Aufsatz: „Kăufer - Verküufer“, Schmollers Jahrbūchor 1900. 
die Länder des europäischen Kontinents, wo genau die gleiche Erscheinung daternder massenhafter Abwanderung vorhanden ist, ohne daß so gewaltsame Handlungen der Grundeigentümerklasse gleichzeitig in einer Anzahl vorgekommen wären, die die Erscheinung erklären könnte. Wir müssen uns also nach anderen Zusammenhängen umsehen. Es muf, um die dauernde $\mathrm{Ab}$ wanderung zu erklären, auch eine dauernde Institution auf dem Lande aufgefunden werden.

Diese Institution ist leicht entdeckt. Die ländliche Massenwanderang ist eine Funktion der Grundeigentumsverteilung. Man mag vergleichen, was man will, große und kleine Bezirke, ganze Länder und Teile von Kreisen, immer ergilt sich: nMit dem Umfang des Troßgrundbesitzes parallel und mit dem Umfang des bäueriichen Besitzes in umgekehrter Richtung geht die Auswanderung." $\left.{ }^{1}\right)$ Ich verzichte hier auf weitere Belege dafür, die ich an anderer Stelle zusammengetragen habe. ${ }^{2}$ ) Ich halte die Formel anfrecht, die ich, um den Sachverhalt drastisch zu bezeichnen, nicht aber, um eine exakte Quantitätsbeziehung festzustellen, aufgestellt habe: „Die Wauderung wächst wie das Quadrat des Großgrundeigentums." Wer die malthusische Weise liebt, mag auch sagen: Wo das GroBgrundeigentum in arithmetischer Reihe wächst, wächst die ländliche Wanderung in geometrischer Reihe. ${ }^{3}$ )

1) v. d. Goltz, Ländliche Arbeiterklasse, p. 143.

2) Siedlungsgenossenschaft, N. $217 \mathrm{ff}$.

3) Marx ist gar uicht fern von der richtigen Erkemutuis, wenn er folgeudes schreibt: „Auf der anderen Seite reduziert das große Grundeigentun dic agrikule Berölkerung auf ein beständig siukendes Mlinimum, und setct ihr tine bestâudig wachsende, in den großen Städten zusammengredräıgte Industriebevölkerung entygegen ... . Wenn das kleine Grundeigentum uns eine halb außerhalb der Gesellschaft stehende Klasse von Barbarcn (hier ist die Quelle von Kautskys berühnten "Barbaren“) schafft, die alle Roheit primitiver Gesellschaftsformen mit allen Qualen und aller Misire zivilisierter 'Lānder verbindet, so untergräbt das große Grundeigentun die Arbeitskraft in der letzten Region, wohin sich ibre naturwüchsige Energie flüchtet, .... auf dem Lande selbst." (Kapital III, 2. p. 347/48). Lind Seite 350 desselben Bandes: „Jedoch spielt der Grundeigentümer eine Rolle im kapitalistischen Produktionsproze日, nicht nur durch den Druck, den er 
Dieser Zusammenhang zeigt sich überall, wie Max Weber einmal sagte, mit einem „überaus seltenen statistischen Eigensinn". Ei gibt den Schlüssel für den Mechanismus jeder auf freier Arbeit beruhenden Mehrwertwirtschaft.

Es handelt sich hier um die Grundlage meiner gegen den leduktiven Theoretiker Marx gerichteten Kritik der Ökonomie; und darum ist es notwendig, kurz die Deduktion wiederzugeben, mit der ich an anderer Stelle diesen Znsaumenhang zwischen Grundhesitzverteilung und Wanderbewegung aus den allgemeinen Prämissen der klassischen Nationalökonomie abgeleitet habe.

Das Axiom der klassischen Schule ist die Lehre vom „wirtshaftlichen Eigennutz", die Dietzel mit den Italienern als das "Prinzip des kleinsten Mittels" bezeichnet, und die ich aus Gründen allgemeinerer Anwendbarkeit folgendermaßen neu formuliert habe: „Die Nenschen strömen vom Orte höheren zum Orte geringeren sozialen und wirtschaftlichen Druckes auf der Linie des geringsten Widerstandes."

Aus diesem Summum principium läßt sich die Massenwanderung vom Grohgrundeigentum auf das einfachste ableiten:

Stellen wir uns ein Land ohne jedes Großgrundeigentum vor! Schon unter diesen Verhältnissen ganz gleichmäßiger Verteilung des Bodens unter selbstwirtschaftende Bauern muß bei einem wachsenden Volke eine gewisse, mïßige Wanderbewegung vom laande in die Stälte stattfinden. Denn mit der Zunahme der städtischen, industriellen Bevölkerung durch ihren eigenen Zuwachs verfeinert sich hier die Arbeitsteilung, wächst die pro liopf hergestellte und verzehrbare Produktenmasse, sinkt also der wirtschaftliche Druck über der Stadt. Dadurch sinkt zwar auch über den Lande der Drack: denn die dichtere Stadt-

allf das Kapital ausübt, auch nicht blon dadurch, daß grofes Grundrigentum cine Voraussetzung, und Bedingung der kapitalistischen Produktion, weil der Expropriation des Arbeiters von den Arbeitsbedingungen ist,.... Als "Voraussetzung und lirdingung ", d. h. Bedingung nicht nur der Produktion, sondern auch der Reproduktion des Kapitalverhältnisses - erscheint hier nicht der Grobbetrieb, soudern das Großeigentum in der Iandwirtschaft? Aber ieider die Erleuntnis bleibt unverwertet! 
bevölkerung zahlt höhere Preise für die Ackerpredukte und bietet, dank ihrer inneren Konkurreuz, ihre eigenen Produkte etwas billiger an. Jeloch. wird die Druckverminderung über dem Lande zum Teil kompensiert durch dié Verkleinerung der (auf den Kopf der dichter gewordenen Berölkerung entfallenden) Ackerfäche, die naclı dem "Gesetz der Produktion auf Land" nicht ohne weiteres die ehemalige Quote von Erzeugnissen pro Kopf liefert.

Dieser geringe Druckunterschied wird immer sofort in statu nascendi durch eine schwache Wanderbewegung vom Lande fort ausgeglichen; und zwar wandert ein Teil des überschüssigen Nachwuchses in die Städte und ergreift stältische Berufe (Abwanderung); er drückt durch sein konkurrierendes Angebot den Preis der industriellen Erzeugnisse und erhöht durch seine konkurrierende Nachfrage den Preis der Ackerprodukte. Dadurch wirl an der Peripherie des Wirtschaftskreises, wo bisher allzn hoher Transportkosten halber kein geregelter Feldbau Platz hatte, ein solcher möglich: und hierhin zieht sich ein anderer Teil des überschüssigen Nachwuchses der Landbevölkerung (Answanderung). Ein letztcr Teil des Nachwuchses bleibt als nicht überschüssig atuf dẹr väterlichen Scholle, die nach den Thünenschen Gesetze entsprechend dem Wachstum des stïdtischen Varktes nun intensirer bearbeitet wird, d. h. mehr Arbeitskiräfte auf der Flächeneinheit beschäftigt.

Es ist also mäßige Aus- und Abranderung eine notwendige Erscheinung auch jeder ;reinen“, d. h. großgrundeigentumfreien, entwickelteren Tiuschwirtschaft. Hier vollzieht die Wanderbewegung die wichtige Aufgabe, die Druckunterschiede iiher zwei Gelieten auszugleichen, über denen beiden der wirtschaftliche Druck regelmäßig, aber in rerschiedener Progression, absinkt, d. h. in denen 'die Jebenshaltung der Bevölkerungsmasse regelmäßig steigt.

Dieser sozusagen physiologische Mechanismus der Druckausgleichung funktioniert nun in der pathologischen, der „kapitalistischen", d. h. massenhaftes Großgrundeigentum enthaltenden, Volkswirtschaft folgendermaßen:

Großgrundeigentum ist, von der Seite der Distribution aus angesehen, ein Institut, das deu Bebauern des Bodens ein Fixum, 
dem Inhaber des juristischen Eigentumstitels aber den gesamten oder doch fast den gesamten Wertzuwaths (uncarned increment der Engländer) zuweist; denu der Tandarbeiter steht in festem Lohn, und der Pächter wird ron Epoche zu Epoche nm den Rentenzuwachs gesteigert.

Das Landproletariat steht also nnter konstantem Druck! Keine Verbesserung der ställtischen Arbeitsteilung, die eine Preissenkung der industriellen Erzengnisse herbeiführt, kein Wachstum des städtischen Marktes, das den Preis der Ackererzeugnisse hebt, kommt den Hintersassen des Großgrundejgentümers zigute. $\left.{ }^{1}\right)$ Der Unterschied zwischen dem Drucke, ler über dem Lande mit Grobgrundeigentum einerseits - und den wachsenden Stälten andrerseits in jedem Moment entsteht und ausgeglichen werden muß, ist also ein viel größerer, das "Gefälle" viel stärker, oder $\mathbf{m}$. a. W. die Wanderbewegung ungleich mächtiger.

Dieser Unterschied der Quantitait wird noch gesteigert durch eine verschiedene Entwicklung der städtischen Zentren, je nachdern sie von Bauern oder von Großgütern umgeben sind. Die Kleinstadt kann die einfacheren Bedürfnisse ebenso gut und billig anbieten, wie die Großstant: der Bauer ist daher der treue Kunde der kleinstädtischen Handwerker und Krämer, und die Stadt wächst mit der Dichtigkeit der bänerlichen Bevölkerung und ihrem Wohlstande. Das wirkt wieder aul die Dichtigkeit der bäuerlichen Bevölkerung zurück, da mit dem Wachstum des stïdtischen Marktes in allen Thünenschen Zonen intensivere Wirtschaft Platz greift, d. h. vermehrte Arbeitskräfte Platz finden, oder, was dasselbe sagt, die pro Kopf entfallende und ausreichende Fläche sich verkleinert.

Anders im Großyrundbezirk! Der reiche Grundherr hat verfeinerte Bedürfnisse, die er uur in der Grobstadt decken kann,

ग) Daß der Druck hier nicht gănzlich kunstaut ist, soudern dals er und wie er - in Laufe der Eutwicklung deunoch langram absinlt, davon sofort. Yan betrachte die absolute Konstanz hier als vorläufige Anuahme, als Folgerung aus der "Idee“ des Croßgrundeigentums. Unsere Schln̈sse verlieren darum nicht an Beweiskraft. Denn der Druck sinkt über Grobgrundeigentum so viel langsamer ab als über Bauernland, dab man inn in der vergleichenden Betrachtuug als praktisch konstant setzen darf. 
die Kaufkraft der Landproletarier aber wächst nicht oder doch nur um ein geringes. Daher bleiben die Landstädte hier klein und arm, sie stagnieren, und jene wohltätige Wechselbeziehung zwischen Stadt und Baluernschaft, in der ein Keil immer den anderen treibt, bleibt aus. Eine Intensivierung der Landwirtschaft "in den Thünenschen Zonen findet nicht statt, und so ist ein noch viel größerer 'leil des landwirtschaftlichen Nachwuchses „überzählig".

„Hohe spezifische Dichtigkeit der lindwirtschaftlichen Bevölherung, kräftige Entfaltung von Gewerbe, Handel und Verkehr, und infolge des industriellen (Wherbaus auch eine erhebliche Steigerung der Besiedelung üler die agrarische Basis hinaus sind also die Merkmale einer gesunden und krüftigen Volksentwicklung, wie sie im Westen der Elbe ganz überwiegend zutreflen und glücklicher'weise bestimmend gewesen sind für die Entwicklung des deutschen Volkes überhaupt. Hingegen hat sich die Arbeitsverfassung östlich der Elbe unfähig gezeigt, eine derartige Wirtschaftsentwicklung zu zeitigen, ja auch nur die C̈berschüsse der Bevölkerung festzuhalten: der Abstand $z$ wischen den Lebens- und Arbeitsbedingungen der östlichen Landwirtschaft und der industriellen Kultur des Westens hat eine Spanung hervorgerufen, welche schließlich zur Abwauderung führen mußte." $)$

Man sieht, die statistische Induktion muB eine richtige Deduktiou schon bestätigen!

Das ist in summarischer Kärze die Crsache, warum die au meisten untervölkerten Bezirke der Kulturländer, diejenigen des Cirolggrundeigentums, an stärksten „übervölkert" sind, d. h. unvergleichlich mehr Menschen abstoßen, als die dichter bevölkerten bäuerlichen Krreise unter sonst gleichen Verhältnissen des Klimas, der Bodenqualität und der Absatzverhältnisse. Ich kann hier auf die feineren Einzelheiten des Prozesses nicht eingehen; das Gesagte genügt zum Verständnis der Hauptlinien, und ich habe

") Rauchberg; Die deutsche Berufs- und Gewerbezählung rom 14. Juni 189i. Berlin 1901, p. 376/77. (Im Origrinal nicht gesperrt.) Igl. auch p. 3is. 
den gesellschaftlichen Gesamtprozeß, der ans dieser Grundtatsache folgt, so ausführlich dargestellt, daß ich mich beschränken darf, hier daranf zu verwoisen.. ${ }^{1}$ ) Im übrigen sollte, so meine ich, ein einziger Blick anf die verschiedene Entwicklung des bäuerlichen West- und des gruudherrlichen Ostdeutschland genügeu, un die Wahrheit dieser Ausführungen zu erhärten. Die Entricklung der Städte und die Verhältuisziffer der Wanderung entsprechen der Neduktion durchaus. ${ }^{2}$ )

Das ist die Quelle der „Surplusbevölkerung“, der „Reservearmee". Nicht die „kapitalistische Produktionsweise" ist die Schuldige; im Gegenteil: die kapitalistische Industrie schafft Arbeitsplätze für alle die Ilunderttausende, die ohne sie entweder gar niclıt zur Entwicklung gekommen wären - die Geburtenrate der Erbuntertanen war vielfach enorm nielrig, die Sterblichkeitsrate ungeheuer hoch ${ }^{3}$ ) - oder die im besten Falle jenseits der Ozeane bätfen neues Ackerland aufsuchen müssen; und die kapitalistische Agrikultur leistet, wenn auch viel schwächer, das gleiche: sie

1) Jein „GroBgrundeigentum und soziale Frage". Berlin 1898. I. Buch, Kapitel 3, "Pathologie des sozialen Kïrpers der Tauschwirtschaft", namentlich die "Theorie des eiuseitig sinkenden Druckes".

2) Rauchberg (1. c. p. 72) deutet eine statistische Tabelle anf p. 71 wie folgt: "Gleich auf den ersten Blick entaehmen wir, dal die spezifische Dichtigkeit in den beiden Hālften unserer l̈bersicht" (Gegenden mit grö日ter resp. kleinster Durchșchnittsflāche der landwirtschaftliclien Betriebe) „im entgegengesetzten Verbältnisse zueinander stehen. Hohe Durchschnitte der landwirtschaftlichen Betriẹbsfläche bedingen dūnnere Bevölkerung, kleine Betriebseinheiten ermōglichen hohe Bevölkerung. Die RegelmāBigkeit des Verlaufs schlägt selbst in jeder der beiden Gruppen clurch. Der kulturelle Überbau in den Formen anderer Berufe, welcher durch die Differenz zwischen der spezifisch agrarischen und der allgemeinen Dichtigkeit gekenuzeichnet wird, erhebt sich viel höher in der zweiten Gruppe: auch er stelt im umgekehrten Verhāltnisse zur Größe der land wirtschaftlichen Betriebe .... Ist es nütig, die Ziffern noch weiterhin zn kommentieren? Sie lehren eindringlicher, als Worte es vermigen, was die Agrarrerfassung des Ostens für die Entwicklung des dentschen Volkes bedeutet. Eine eiserne Fessel ist sie ilim geworden, da es nun in erneuter Jugend seinen gerraltigen Leib recken will." -

3) Vgl. meinen "Mralthus". Berlin 1900, p. 140, nach Hanssen, Aufhebung der Leibeigenschaft etc. (St. Petersburg 1861) p. 29. 
hält den Prozeß der Landflucht eher auf, als daß sie ihn beschleunigt: denn sie braucht ve: mehrte menschliche Arbcitskräfte pro Flächeneinheit. ${ }^{1}$ )

Nein, der Kapitalismus, das Kapital und seine Akkumulation sind unschuldig an diesem Massenvorgang. Die Schuld trägt allein die geltende Grundeigentumsverteilung; sie ist nicht nur, wie Marx selbst festgestellt hat, die Crsache der Produktion der „freien" Arbeiter - „die Expropriation des ländlichen Produzenten . . . . von Grund und Boden bildet die Frundlage des ganzen Prozesses" ${ }^{2}$ ) - sondern auch ihrer davernden Reproduktion, und damit der Reproduktion des "Liapitalverhältnisses" selbst, der einzigen Existenzgrundlage aller kapitalistischen Exploitation.

Diese Grundbesitzverteilung ist alsó nicht nur die Ursache der Exmission von selbständigen Pächtern und unselbständigen Tagelöhnel'n und Insten, die die Grundlage der von Marx falsch. gedeuteten Zentralisation in der britischen Landleröllerung ausmichte, sondern auch der sozusagen "freiwilligen" Iaadfucht.

Daher stammt jene Surplusbevölkerung nf:eier" Ar', eiter, jene Maschinenbediener, die die Handwerker und Manufikturarbeiter der vor- und frühtapitalistischen Epoche durch ilir Prodult unterboten aus dem Narkte warfen; daher die Bewerber um die nenen, durch die kapitalistische Industrie neu erschlossenen Arbeitsplätze, die den dort Entrurzelten eine nenc, höhere Existenz dargeboten hätten.' Nicht die „Maschinerie“, sondern die vom ehemaligen Landproletarier bediente Maschinerie hat den Handwerker "freigesetzt"; und vor allem: nicht die Maschine. nicht das "Kapital" war es, das ihm alle neu erschlossenen Stellen sperrte, sondern wieder der Landarbeiter, der um alle diese Stellen mit seinem Hunger-Wettbewerb konkurrierte. Und nur diese Konkurrenz war es schließlich, die den Industrieproletarier

1) $\mathrm{DaB}$ dieser Nehrbedarf bei uns in Deutschland durch ausläudische Wanderarbeiter gedeckt werden darf und kann, deren Konkurreuz den inländischen l.andproletarier noch schneller fortfegt, ist natürlich bein Argument gegen die Deduktion. Sie stammen rom polnischen und ungarischen - GroDgrundeigentum, das sie ausstübt.

2) Kapital I. 681/82. 
7wang, "Weil und Kind unter das Juggernautrad des Kapitals zil schleudern", trotzdem die Nachfrage auf dem Arbeitsmarlite sehr viel stärker wuchs, als die Gesamtbevölkerung durch ihre Zuwachsrate.

Daß diese klare Wahrheit so lange rerborgen bleiben konnte, ist lediglich Folge des unseligen Industriezentrismus. Hätton die Landarbeiter einer leiblich verschiedenen liasse angehört, wären es Neger oder Kulis gewesen, so hätte die Ricardo-Marxsche Theorie ron der „Freisetzung durch die Maschine ${ }^{4}$ niemals entstchen können.

\section{Kapitel.}

\section{Antikititisches Zwischenspiel.}

Meine Erklärung der Surplusberölkerung ist mir kürzlich von selir heachtenswerter Seite bestritten worlen, und zwar von Werver Sombart, der, in den Hauptlinien Marxist und als solcher Industriezentrist, die Abwanderung mit Marx auf die Anstöße zurückfülırt, die seitens der kapitalistischen Industrie auf die Landwirtschaft ausgeübt werden. Er polemisiert gegen mich, freilich auch hier, olme mich zu nennen. Ich zitiere die Stelle wörtlich, weil ich nirgend bessere Argumente für die bestrittene Belauptung finden köunte: ${ }^{1}$ )

Somit haben wir den Abstrom der Bevölkerung, den Exodus rom Iande, als eine mit Notwendigkeit im Gefolge kapitalistischer Produhtionsweise anftretende allgemeine Erscheinung kemnen gelernt. Als eine illgemeine Erscheinung, die alsu gleichermaßen klein- und großbüuerliche Gegenden wie die Gebiete des Grofgrundbesitzes betrifit, keineswegs, wie wohl behailptet worden ist, auf letztere beschränkt bleibt. Es mußte auf diese Allgemeinheit der beregten Erscheinung ohne weiteres

1) Ler moderne Kapitalismus. II 151. Die gesperrten Stellen sind auch im Origi:-al gesperrt. 
theoretisch' geschlossen werden, auch wenn wir nicht so reich an Belegen wären für die Tatsache, daß der Abstrom der Bevölkerung aus bäuerlichen Distrikteu ebenso rorhanden ist, wie aus Großgïterdistrikten. Vielleicht, $\mathrm{daB}$ er sich dort etwas schwächer erweist; aber vorhanden ist er ganz gewiB.

„Es genügt, zum Beweis aus dem reichen Zahlenmaterial, das uns zur Verfügung steht, die folgenden Ziffern mitzuteilen, die die Bevölkerungsbewegung durch Wanderung für die einzelnen Gebietsteile Deutschlands während des Jahrfünft 1885-1890 zum Ausdruck bringen. Es ist daraus ersichtlich, daß der Exodus in Gruppe I mit vorherrschendem Großgruntbesitz allerdings ain stärksten, daß er aber auch vorhinden ist. in Gruppe II und III, den Agrardistrikten nit vorwiegendem Mittel- und Kleinbesitz:

\begin{tabular}{|c|c|c|c|c|}
\hline Gruppe & $\begin{array}{l}\text { Geburten- } \\
\text { überschull }\end{array}$ & $\begin{array}{l}\text { Bevölkerungs- } \\
\text { zumahne }\end{array}$ & $\begin{array}{l}\text { Gewinn } \\
\text { durch } \\
\text { absulut }\end{array}$ & $\begin{array}{l}\text { odor Verlust } \\
\text { Wauderung } \\
\text { v. d. Gehurten- } \\
\text { üherschuß }\end{array}$ \\
\hline I. Osstl. PrcuBen & 851770 & 212666 & $-63910 t$ & $-75,04 \%$ \\
\hline $\begin{array}{l}\text { II. Westl.Preußen u. } \\
\text { Mitteldeutschland }\end{array}$ & 611578 & 531089 & -80449 & $-13,15 \%$ \\
\hline $\begin{array}{l}\text { Staaten } \\
\text { V. Industriezentren }\end{array}$ & $\begin{array}{l}500787 \\
937688\end{array}$ & $\begin{array}{r}347520 \\
1480191\end{array}$ & $\begin{array}{l}-153267 \\
+542503\end{array}$ & $\begin{array}{l}-30,61 \% / 0 \\
+57,86 \%\end{array}$ \\
\hline
\end{tabular}

Soweit Sombart. Dazu bemerke ich folgendes.

Erstens: Sombart rühnt sich, der Entdecker der ersten „ökonomischen Städtetheorie ${ }^{«}$ zu sein. Er findet es nzum Weinen traurig, daß heutzutage $\therefore$. so etwas noch erst ausdrücklich ausgesprochen werden muß $\beta^{*}{ }^{1}$ ) Hätte er meine Werke nSiedlungsgenossenschaft" und "Großgrundeigentum und soziale Frage", die er mit einer eleganten Handbewegung als ihn "unbefriedigend " abtut, $\left.{ }^{2}\right)$ wirklich gelesen, wie er behauptet, so hätte er in dem zweiterwähnten eine Theorie der ,isolierten Stadt" 3) gefunden, die ich ihm sechs resp. vier Jahre vor seinem Werke vorgeahnt habe. „Ich habe", so steht dort") zu lesen, „auf Grund des Thünenschen Schemas, so viel ich sehe zum ersten

1) II. p. 191.

2) I. 154 Anm.

3) Großgrundeigentum p. $58 \mathrm{ff}$.

4) Grobgrundeigentum p. 489. 
Male, verfolgt, wie sich eine Stadt aus der Urproduktion entwickelt" (und zwar schon 1896, in der "Siedlungsgenossenschaft $\left.^{(}\right)$. An anderer Stelle heißt es: ${ }^{1}$ ) „Die Stadt stellt also bei wachsender Bevölkerung ein Minimum dar, welches Bevölkerung ansaugt." Und: ${ }^{2}$ ) „Jedenfalls finden wir also als Eigentümlichkeit eines wachsenden Volkes, daß sich die Zahl der Gewerbetreibenden stärker vermehrt als die der Bauern."

Diese Tatsache ist geradezu das Grundgesetz jeder denkbaren „ökonomischen Städtetheorie“, und darum, so meine ich, sollte der erste Entdecker einer solchen sich nicht darüber wundern, daß auch in "Agrardistrikten mit vorwiegendem Mittelund Kleinbetrieb der Exodus vom Lande vorhanden ist". Freilich: daß Sombart jenen wichtigsten Satz völlig begriffen hat; ist mir einigermaßen zweifelhaft gegenüber der folgenden Stelle: ${ }^{3}$ ) "Handwerk ist nur möglich, wenn "quantitativ die Produktivität der landwirtschaftlichen Arbeit . . einen solchen Grad erreicht. hat, daß einer genug für zwei Nahrungsmittel und Rohstoffe zu erzeugen vermag. Erst daun offenbar kanin die Verarbeitung und Bearbeitung jener: zu gewerblichen Lrzeugnissen so sehr verfeinert werden, daß nun eine Person sich ausschließlich dieser 'Tätigkeit widmet." Ich will hoffen, daß dies nur schief ausgedrückt ist: wie es dasteht, ist es vollkommen falsch und zeigt mindestens, daß Sombart seine „Entdeckung " nicht genügend durchgedacht hat. Damit Handwerk möglich sei, ist nur erforderlich, dals der Bauer im Durchschnitt ein wenig mehr Nahrungsmittel und Rohstoffe erzeuge, als für scine eigene Versorgung nütig. Hat jeder Baner $5 \%$ produit net, so lebt ein Handwerker eben von den Überschüssen von 20 Banern. Wenn Sombart recht hätte, dürften wir in Preußen eben mit dom Handwerk angefangen haben, denn ein preußischer Bauer erzengt erst seit wenigen Jaliren "fụ̈ zwei" - und in Rußland wäre städtisches Leben noch unmöglich, da es noch ca. $80 \%$ Bauern hat, von denen also nur je vier „für fünf" erzeugen.

1) Großgrundeigentum p. 70.

2) Großgrundeigentum p. 76.

3) Sombart 1. c. 1. 140. 
Joch genug davon! Ich komme jetz zu membn zweiten Eimisind.

Somhart, der sish gern in den Mantel des Philosophen hïllt, kennt und zitiert das horuhnte Kantsche Ideal wissenschaftlicher

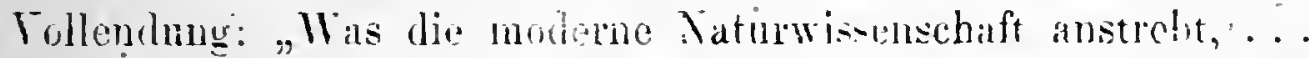
ist die lükenlose brsetzung lor bualitat durch die () nantitä, die in einer nuthematischen Formel-ihren letzten und rollkommensten Ausdruck findet. Fist dann. wenn sich für irgond einen Torgang in der Xatur eine mathentische lomel aubtellon läbt; so hat uus Kant helehrt, hahen wir das liecit. rou naturgesetzlicher" Erkenntnis zu sprechen." ${ }^{1}$ ) Er mag sich eimmal im Lichte dieses Kriteriuns eigentlicher Wissenschaft seine Behatuptung anschauen, dad. der Exorlus rom l.inde "eine aligemeine Erscheinung, aus biaurlichen bistrikten ebenso vorhanten ist wis atis Grohingitertezirken": eine Behauptung; the er sofort selbst ciurde die lieststelltung illustriert, dah aus dem einen Bezirke mehr als " $\%$, aus deln zweiten weniger als $1 \%$, alls dem driten weniger als $\%$, des Geburtenüberschusses fortwindert! Ti: 13 : 30!! Dabei ist uoch alles in Bansch und Bogen gerechnet, die Ahwinderung ron den Gürem in Oston nicht. getremut von derjenigeu von don Ihörern, das grobbämerliche Bayern (auch srofbäuerliches Grundeigeutm, fält unter meine Definition des Grobgrundeigentums als einer Tläche, die im regelwähigen Betriebe fremder Arbeitskräte bediut) nicht retrenut ron den übrigen, klein- und mittelbäuerlichen süddeutschen staaten!

Das soll eine Widerlegung sein? Lis is einc bestätignug, und ich veruichte anf jerle andere! lie Wanderung ron den Grofgüterdistrikten ist kimhhaft, ins Cnghenre, gesteigert und das ist das Morknal aller Krankheit! Es gribt keine der. Physiologie fremde Erscheinnng in in l'athologie: es gibt nur steigerung normaler Frscheinumgen!

lch überlasse Sombart die Bere:hnung, $\left.{ }^{2}\right)$ was aus der Reservoarmee und der kapitalistischen Wirtschalt geworden wäre, welin

1) Sombart, Lic deutsene Volkswirtschati in 19. Jahrhnnciert. Borlin $1903,1.159$.

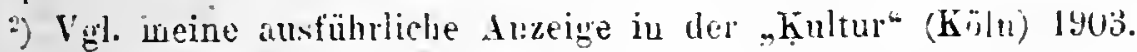

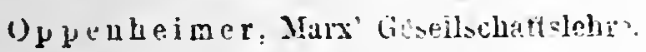


auch aus dem östlichen Preußen statt 75 nur $13 \%$ fortgewandert wären, statt 639000 nur 120000 , wenn also von hier statt rund $390000 \mathrm{nur}$ rund $72000 \mathrm{Köpfe}$, d. h. weniger rund $220000 \mathrm{Köpfe}$, oder 70000-120000 Arbeiter beiderlei Geschlechts, in dem einen Jahrfünft in die Industriezentren eingewandert wären. ${ }^{3}$ ) Ich will Kraft, Zeit und Raum nicht weiter auf diese Argumente verschwenden. ${ }^{3}$ )

Ich komme jetzt za einem zweiten Einwande ron marxistischer Seite. Eluard Bernstein schreibt: ${ }^{3}$ )

${ }$ Es ist neuerdings bestritten worden, daß die kapitalistische

1) Am 14. Juni 1995 waren in Industrie und Handwerk arbeitslos, abgesehen ron 69227 wegen rorübergehender Arbeitsunfähigkeit (Krankheit) Beschäftignngslosen: 97782 Arbeiter, gleich 2,57\% der Gesamtzahl aller Arbeiter dieser Wweire. Am 2. Dezember des gleichen Jahres raren die entsmrechenden Zifferu 116846 und 274625. Indes habeu die Winterzahlen bekantlich wenig Bedeutung, da sie die regelmäbige Saison-Arbeitslosigkeit einschließen. (Nach dem, konservativen Handbuch“*)

$\Rightarrow$ Die „Statist. Korrespondenz des K. Preuß. Stat. Bür.“ 1902 No. $3 i$ bringt folgende Vitteilung:

, Fon der im Staate geborenen und als ortsanwesend erwittelten, in dicsen Simue als "selhaft" zu bezeichnenden Bevölkerung haben

$$
\begin{array}{llll}
\text { Ostpreulen . . . } 40 \$ 642 & \text { Schlesien . . . . } 306328 \\
\text { Westpreußen. . . } 158726 & \text { Sachsen.. . . . } 114107 \\
\text { Pommeru... . } 187712 & \text { Hessen-N. . . . . } 67320 \\
\text { Posen... . . . } 286032 & \text { Hohenzollern. . . } 1428
\end{array}
$$

Köpfe infolge innerer. Wanderungen abgegcben, da sich am Zähltage dort um die genanute Zahl weniger aus Preußen gebürtige Personen befunden habeu, als in Staatsgebiet aus der betr. Provinz Gebürtige vorhandeu waren. Es gewanwen durch inuere Wanderung:

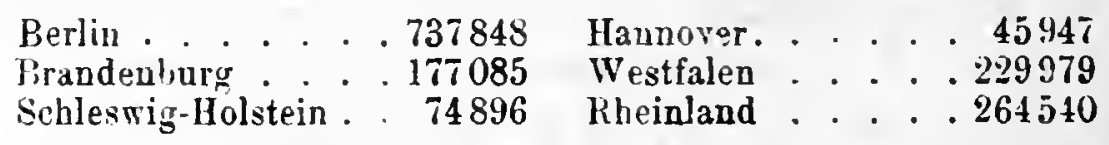

Köpte." Es befanden sich also am Tage der Zählung unter den Einwuhnern Berlins und seiner Vororte rund 900000 nicht in Berlin Geborene, ron denen rund $700(6)$ aus den ostelbischen Proviuzen des Großgütertypus stammten. Lhre hiuder sind nicht miteingerecbnet, soweit sie schon in Berlin geboren sind!

Komineutar überflüssig:

3) Zur Geschichte und Theorie des Sozialismus. Berlin-Bern 1901. p. 79. Anw. 
Produntion aus sich heraus die industrielle Reservearmee schaffe. Tatsächlich biete die Inrustrie unter dem Kapitalismus Arbeitern in steigeudem Marle Cnterkunft. Die Erscheinung der „Reservearmee" aber sei eine Folge des aus der Feudalyeit übernommenen Groligrum!hesitzes und des entsprechenden Bodenrechts, das zur Entrülkerung des tlachen Landes hezw. einem kontinuierlicher Strom srhlechthezahlter Mitglieder der Landbevölkerung (Arbeiter, Kleinbatlern bezw. doren Söhńe etc.) in die Städte führe. Diese Thenrie, die mit besonderer Schärfe von Dr. Franz Oppenheimer vertreten wird, hann schnn deshall, nicht ohne weiteres von der Hand gewiesen werden, weil in der Tat die wirtschaftlich vorgeschrittenen Länder teils cinen relativen, teils aber, und zwar guade, wo der irnhigrurdhesitz überwiegt, sugar einen relativen und ahsoluten Rückging der landwirtschaftlichen Bevölkerung vel\%eichen, dagegen eine beständige \%unahme der industriellen Arluterchalt aufweisen. Sie hat also anscheinend die erfahrungsmäijgen Tatsachen fïr sich, während das empirische Beweismateria! hei Harx nnlenghar viele längel aufweist.

„Indes übersieht Oppenheimer zwei Umstinde. Jirstens, daß die Zunahme der inúustriellen Borölkerung der hezeichneten Länder bis in eine sehr vorgeschrittene Epoche hinein - und, wenn wir, wie billig, alle in den Weltmarkt hineingezogenen Länder in Betracht ziehen, - selbst hente noch zn einem großen Teil auf der $A b l o ̈ s u n g$ der Industrie aus ihrer alten Verbindung mit der Landwirtschaft und anf geographischen Verschiebungen, d. h. dem Rückgang der industriellen Arbeit der Landbevölkerung und der lndustrie zurückgebliebener länder beruht. Die Vorführurig einzelner Jänder gibt daher kein richtiges Bild der Wirkungen des Kapitalismus. Wir mïssen daher entweder das ganze ungeheure Gebiet des Weltmarkts untersucher oder uns auf die Analyse der Geschichte bestimuter Industrien verlegen. In ersterer wie in letzterer Hinsirht stolien wir aher anf verschiedene Beispiele, die, wie z. B. die EntwichInug der Baumwollindustrie, Ifarx recht geben.

"Zweitens läBt Oppenleimer außer Betracht, duß wir uns heute in den vorgeschrittenen Ländern schon nicht mehr in der Ära des ungefesselten Waltens des kapitalistischen Systems und 
der freien Konkurrenz befinden, diesem vielmehr durch Fabrikund Sanitätsgesetze, Volksschulwesen, Kollektivaktion der Arbeiter und ähnliche Gegenkräfte Schranken gesetzt sind, die eine volle Verwirklichung seiner Tendenzen verhindern.

„Wenn also die Wirklichkeit anders aussieht, als es nach den Deduktionen von Marx der Fall sein müßte, so beweist das noch nicht die Unrichtigkeit dieser Deduktionen und die Richtigkeit der Lehre von der Selbstheilungskraft der freien Konkurrenz bezw. dem Verschwinden der industriellen Reservearmee bei Ablösung des Großgrundbesitzes. Oppenheimers Kritik trifft einseitige und übertriebene Folgerungen aus den Marxschen Deduktionen, läßt aber den Kern dieser unberührt. Bei Marx spielen wiederholt in die ökonomische Entwicklung ethische oder ästhetische sowie politische Urteile hinein und bewirken eine Verkennung von Lücken oder selbst Widersprüchen der ersteren."

Soweit Bernstein!

Dazu bemerke ich:

Erstens: Wenn zugegeben wird, daß meine Theorie $n$ die erfahrungsmäBigen Tatsachen anscheinend für sich hat, während das empirische Beweismaterial bei Marx unleugbar viele Mängel aufweist"; wenn in der Tat "die Wirklichkeit andẹrs aussieht, als es nach den Deduktionen von Marx der Fall sein müßte"; wenn eingestandenermaßen „bei Marx wiederholt in die ökonomische Entwicklung ethische oder ästhetische sowie politische Urteile hineinspielen. und eine Verkennung von Lücken oder selbst Widersprüchen der ersteren bewirken" — — dann ist die Beweislast auf seiten der Verteidiger der Marxschen Lehre, nicht auf der meinen. Bernstein hätte zeigen müssen, erstens, daß meine Theorie falsch, d. h. daß es nicht die Grundbesitzverteilung ist, welche die Reservearmee erschafft, und zweitens, daß Marx' Theorie dennoch, trotz aller "Lücken und Widersprüche“, „im Kern" richtig ist. Ich aber hätte his zu diesem Doppelbeweis keine Verpfichtung gehabt, meinerseits die Marxsche.Theorie als solche zu kritisieren.

Zweitens: Bernsteins Einwände gehören zum Teil nicht zur Sache, zum anderen Teile sind sie ohne Beweiskraft, wie ich mich benühen werde nachzuweisen. 
Nicht zur Sache gehörig ist sein "Zweitens". Ich erkenne nicht, inwiefern die "Gegenkrätte des kapitalistischen Systems und der freien Konkurrenz" auf die Art der Bildung der Reservearmee eingewirkt haben sollen. Es kann nur gemeint sein, dal. Arbeiterschutzgesetze, Kollektivaktion etc. sie der Quantität nach (durch Verkürzung des Arbeitstages) und der Intensität ihrer Leiden nach (durch Versichorung, gewerkschaftliche Hülfe etc.) eingeschränkt haben: hier aber handelt es sich nicht um Quantität und Intensität, sondern um ihren I'rsprung! Bernstein, der Kenuer Marxens und Englands, kann nicht etwa haben sagen wollen, daß zwar heute die Industrie keine Arbeiter mehr freisetze, das aber früher getan habe. Dies würde gegen die Tatsachen und ihre Darstellung im "Kapital" Zeter schreien und außerdem das "absolute allgemeine" Gesetz der Akkumulation samt seincn Konsequenzen preisgeben.

Nicht zur Sache gehörig ist ferner sein Einwand aus den "geographischen Verschiebungen", insofern es sich um „zurückgebliebene Länder" handelt, die von kapitalistisch entfalteten Wirtschaftsgebieten exploitiert werden. Und zwar aus folgendem Grunde:

In den kapitalistisch noch nicht entfalteten Ländern sind Handwerker und Hausfleiß treibende Bauern ihres Erwerbes beraubt worden, als der Import der kapitalistischen GroBindustrio sie koukurrierend unterbot: ein Gegenstück zu dem Ruin des historischen Handwerks im nationalen Gebiete der kapitalistischen Wirtschaften selbst. Die Tatsache und ihre Erklärung sind viel älter als Marx, und er hat nie beansprucht, hierfür eine neue Erklärung gefunden zu haben. Alles liegt auf der Hand.

Was Marx in "Gesetz der Akkumulation" behauptete und bewiesen zu haben glaubte, war die Erklärung der Tatsache, daß „der Arbeiter beständig ans dem kapitalistischen l'roduktionsprozef herauskomunt, wie er in ihn eintrat - persönliche Quelle des Reichtums, aber entblöBt von allen Mitteln, diesen Reichtum für sich zu verwirklichen". ${ }^{1}$ ) Es handelt sich um das Schicksal des britischen Arbeiters, des Proletariers selbst. Und dessen Schicksal wird auf dem Arbeitsmarkte ent- 
schieden, nicht aber auf dein Warenmarkte, wie das des selbständigen Handwerkers.

Da nun Bernstein nicht wird behaupten wollen, daß die expropriierten Weber usw. Indiens, Spaniens und der Türkei nach dem Verlust ihrer Existenzgrundlage massenhaft auf deu britischen Arbeitsmarkt geworfen worden sind, so ist sein Einwand nicht zur Sache gehörig. Er hätte einen Sinn, wenn man eine Gesamtbilanz der kapitalistischen Weltprodnktion aufstellen wollte; dann muß man das dortige Elend auf die Debetseite der Rechnung stellen: aber bei der Betrachtung der Lohn- und sonstigen sozialen Verhältnisse der Proletarier in kapitalistischen Volkswirtschaften „rührt uns“ der Ausländer so „wenig“ wie Hern Thiers. ${ }^{2}$ ) Ja, diese Vernichtung des ausländischen Gewerbfleißes hätte im Gegenteil für die englischen Arbeiter eine $\mathrm{Cr}$ sache stärkster Lohnerhöhungen werden müssen, da der Markt ihres Produktes und damit die Nachfrage nach Arbeitskraft ungeheuei dadurch vergrößert wurde. Die Frage, um die es sich hier handelt, ist, weshalb trotzdem keine entsprechende Lobnerhöhung eingetreten ist.

Wir "müssen also nicht das ganze ungeheure Gebiet des Weltmarkts untersuchen“. Er tut hier nichts zur Sache, wo es sich ausschlieflich um den nationalen Arbeitsmarkt bandelt. Und wir können ebensowenig „uns auf die Analyse der Geschichte bestimmter Industrien verlegen“. Das ist nämlich: unausführbar. Wollten wir z. B. eine Analyse der Textilindustrie GroBbritanniens vornehmen, so hätten wir von der Anzahl der heute in der Großindustrie beschäftigten Lohnarbeiter die "expropriierten“ Handwerker und freigesetzten Manufakturarbeiter. der Branche zu subtrahieren, wofür an sich schon die Statistik nicht ausreicht. Wir müßten aber dann anf der anderen Seite die für den Dienst dreser Industrie neu eingestellten Bergleute in Eisen-, Kohlen-, Kupfer-, Blei- und Zinngruben usw., in Maschinenfabriken und liasanstalten, die Bauarbeiter, Eisenbahnangestellten, Frachtfuhrlente, Matrosen und Dampfschiffbauer usw. addieren und kämen so: iu einen regressus infinitus.

1) Kapital I. 407. Anm. 1160 . 
Wollte man es aber democh versuchen, so würde man zu seinem Erstaunen ersehen, daß selbst die „verschiedenen Beispiele Marx Unrecht geben". Ich erinnere an die oben angeführten Daten gerade über das auch von Bernstein angeführte Sclulbeispiel, die britische Baumwollindustrie. Ihre Arbeiterschaft wächst beträchtlich stärker als die Bevölkerung.

Bleibt als einziger Einwand die ,Ablösung der Industrie aus ihrer alten Verbindung mit der Landwirtschaft" im Inlande.

Bernstein will folgendes einwenden: Die Industrie in den Städten hat durch ihre kapitalistische Konkurrenz nicht nor städtische, sondern auch dörfliche Handwerker, und nicht nur solche, sondern auch vielfach ,bäuerliche" Elemente expropriiert, die zwar statistisch als "Landlente" gezählt wurden, aber dennoch einen bedentenden Teil ihres Einkommens aus gewerblicher Nebenbeschäftigung gewannen. Der Verlust dieses Nebeneinkommens brach ihr wirtschaftliches Rïckgrat, machte ihre landwirtschaftliche Position unhaltbar und trieb sie in die Städte. Statistisch erscheint es dank dieser rein örtlicheu, nicht aber rein beruflichen Verschiebung der Bevölkerung, als sei die Zahlul der von der Industrie neu erschlossenen Arbeitsplätze viel stärker gewachsen, als es in Wahrheit der Fall ist.

Ich will gern zugeben, dais hier ein richtiger Gedanke zugrunde liegt. Tatsächlich erscheint durch dieses $n$ statistische Quiproquo* ${ }^{* 1}$ ) die Zunahme der Inciustrieberölkerung ein wenig vergrößert. Aber andrerseits ist es 'offenbar falsch, den ganzen Zuwachs der Städte durch diese örtliche, nicht aber berufliche Verschiebung erklären zu wollen.

Ich will gegen Marx - Bernstein billigerweise mit britischen Ziffern operieren:

Das „Vereinigte Königreich“ hatte während der kapitalistischen Epoche folgende Berölkerungszahlen:

$$
\begin{aligned}
& 1754: 10658000 \\
& 1801: 15717000
\end{aligned}
$$

5) Vyl. Pohle; Deutschland am Scheiderege" (Leipzig 1903) p. 43, der ganz denselben Einwand gegen mich geltend macht. 


$$
\begin{aligned}
& \left.1891: 35003000^{\prime}\right) \\
& \left.1900: 41220000^{3}\right)
\end{aligned}
$$

Macht bis heute einen Zuwachs von rund 30 Millinmen Köpfen. Es kommt auf ein paar Hunderttansend nicht an.

Großbritannien war schon 1754 ein stark gewerblich entfaltetes Land und befand sich mitten im Siegeszuge des Kapitalismus. Seine Städte waren schon bedeutend. Die zwölf größten Städto hatten 1801 bereits eine Einwohnerschaft von $1461000^{3}$ ) (1887 : 7434000).

Aber ich will dem Gegner entgegenkommen. Ich unterstelle, daß 1754 Großbritannien noch durchaus Naturalwirtschaft gehabt habe, keine Stadt, keinen Handwerker, keine Manufaktur, nichts von alledem! Nur Bauern und Großlandwirtschaften! Ich unterstelle ferner, daß volle drei Viertel aller Arbeit jener Banern etc. der gewerblichen Tätigkeit gewidmet gewesen sei, nur ein Viertel der Landwirtschaft: selbst unter diesen Voraussetzungen köunte die örtliche Verschiebung nur einen städtischen Zuwachs von $71 / 2$ Millionen Köpfen erklären, d. h. gerade ein Viertel des faktisch erfolgten.

Also auch damit ist nichts anzufangen. Sollte Bernstein etwa bemängeln, daß ich zwei so weit auseinanderliegende Zeitpunkte vergleiche, so bin ich gern bereit, soweit wie er nur irgend-wünscht, entgegenzukommen: er wird finden, daß auch eine Vergleichung näherer Zeitpunkte immer das gleiche Resultat ergibt. Im übrigen könnte ich dann den Nachweis fordern, daß innerhalb der kapitalistischen Entwicklung Perioden ganz verschiedener IIerkunft der ja immer vorhanden geweseneu Reservearmee bestanden haben, ein Nachweis, der angesichts der Kontinuität des Prozesses nicht zu erbringen ist, und der außerdem Marx' "ahisolutes, allgemeines Gesetz der Akkumulation" als nicht absolut und nicht allgemein preisgehen müßte. In der Tat ist der Abstrom der ländlichen Bevölkerung in völlig kontinuierlichein Stromo mit nur geringen Schwankungen der Stärke in

b) Mulhall, p. 44 .

2) Hickınann, Taschenatlas. Wien 1900, p. 32.

3) Mulhall, l. с., p. 44 j. 
allen Perioden erfolgt, ohne daß auch nur in einer einzigen rie Expropriation der ländlichen Gewerbe auch nur einen bedeutenden Bruchteil der Entwurzelung erklären könnte. Lnd diese (Hleichartigkeit der Entivicklung herechtigt mich, beliebige Endpunkte zu rergleichen. Was allen einzehen Addenden gemeinsam ist, mul: sich in jeder Snmme finden.

Einen lititen Einwand, der mir - unglaubịcherweise mïntlich un! anch auf Druckpapier häufig gemacht worden ist, kann ich mit wigen Worten ahfertigen. Man verweist mich auf Linder ohme ,Frofogrundeigentum", wie die Schweiz, Frankreich, die Vereinigten staaten, und weist mir triumphierend nach, dab hier die kapitalistische Entwicklung sich gan $\angle$ analog wie in leutschlaul, Grolibritannien oder Rußland verhalte.

Nun halve ich sehr deutlich und präzis erklärt, ${ }^{1}$ ) was ich unter ,Großgrundeigentum" verstehe, nämlich: „jedes landwirtschaftlich genutzte Stïck Boden, dessen Ertrag derart geteilt wird, daß die darauf wirtschaftlich arbeitenden Subjekte ein unveränderliches oder doch nur wenig veränderliches Fixum, der Inhaber des juristischen Eigentumstitels aber den ganzen Rest erhält." Es ist auf der folgenden Seite ausdrücklich ausgesprochen, daß unter diese Definition auch, mittleres und sogar kleines Grundeigentum fällt, wenn zu seinem regelmäligigen Betriebe Lohnarbeiter verwendet werden, wie in Weinbergen, Handelsgärten usw.". Derartiges Großeigentum ist in allen genannten Ländern reichlich genug rorhanden: in Frankreich gab es 1892: 106000 Betriebe von 40-100 ha und gar 33000, von mehr als 100 ha.")

Doch will ich auf diese definitorischen Feimheiten gar kein Gewicht legen. Jenn ich habe an der zitierten Stelle ferner gesagt, daß "dieses Großgrundeigentr n kleineren Lmfanges seine Fähigkeit, fremde Arbeit auszubeuten, nur da erhalten kann, wo ein bedeutendes agrarisches Groligrundeigentum engeren Sinmes in demselben Wirtschaftskreise, (also nicht etwa in denselben politischen Gremzen) vorhanden ist."

i) Grobgrundeigentum, p. 103.

¿) Kautsky 1. e. 202: vgl, anch Beilistein, "Toranssetzungen", p. 63. 
Denn die ländliche Abwanderung strömt auswandernd über die politischen Grenzen und drückt auf den Kurs der Arbeit auf den ausländischen Arbeitsmärkten. Ende 1901 befanden sich 1037788 Ausiänder in Frankreich ${ }^{1}$ ): es werden wohl nicht auss'hlieflich amerikanische Millionäre gewesen sein; - die Zahl der Ausläuder in der Schweiz schätzt man auf mehr als $10 \%$ der Kopfzahl der Schweizer Bürger: es werden nicht ausschließlich sommerfrischler gewesen sein. Die Ausländer in den Vereinigten $\therefore$ laaten, Auswürflinge des europäischen Großgrundeigentums, zählen nach vielen Millionen; - und auf unseren dentschen Arbeitsmarkt drücken Italiener, Böhmen, Holländer, Ungarn und namentlich slavische Erntearbeiter aus Galizien und RussischPolen. Wie hoch der Lohn unserer Landarbeiter und damit derjenige der Industriearbeiter springen würde, weun unsere Ostgrenze gegen diese Hungerkonkurrenz gesperrt würde, ist gar nicht zu berechnen.

Danit ist wolıl dieser geistreichste aller Einwände erledigt.

\section{Kapitel. \\ Skizze einer Lohntheorie.}

Die Erürterungen des neunten Kapitels ermöglichen es, eines der hoffnungslosesten Probleme der modernen national-ökonomischen Theorie zu lösen, das Lohnproblem.

Die klassische Lohntheorie ist mit Recht vollkommen aufgegulien, namentlich ihre Grundlage, der Lohnfonds, der sich als ein völlig ungreifbarer „Begriff ${ }^{«}$ herausgestellt hat. Sein letzter Rest. fristete nur noch als „variabler Bestandteil des gesellschaftlichei liesantkapitals ${ }^{*}$ in der Marxschen Theoretik ein einigermatitu prekäres Dasein. Die andere Hälfte der bourgeois-öko- 
nomischen Lohntheorie, das „Bevölkerungsgeset: ${ }^{*}$, schwebt daher baltlos in der Luft.

So steht die heutige Wissenschaft ratlos ror dem folgenden scheinbar unlösbaren Problem: wie ist es zu erklären, daß die industriellen Löhne, mindestens die Nominallöhne, trotz aller Rückschläge in Krisenzeiten, auf die Daner eine steigende Tendenz haben, obgleich doch das Angebot auf dem Arbeitsmarkte in del Regel, von einzelnen Momenten exaltierter Hausseperioden abgesehen, die Nachfrage übersteint?

Dah Arbeitskraft eine "Ware" ist, d. b., daß ihr Preis durch das Verhältnis ron Angebot und Nachfiage bestimmt wird, läßt sich unmöglich bestreiten. Und dennoch steigt dieser Preis bei dauernd vorhandenem Überangebot der Ware. Unbegreiflich! Die ganze Konkurrenz-Theorie kommt ins Schwanken!

Cherallier') behauptet, vielleicht in Anlehnung an Carey ${ }^{2}$ )Bastiat, daf der Lohn mit der Produktivität der Arbeit steige. Bei lichte besehen ist ,eine Behauptung nichts besseres ais eine etwas anspruchsvoll auftretende Uinschreibung der Tatsachen, wie sie die neueste Industrieentwicklung darbietet. Er stößt sich nicht daran, daß wir Zeiten steigender Produktivität und dennoch scharf fallender Industrieiöhne kennen - ich erinnere nur an die deutsche Entwicklong uach ca. 1450 oder an den Anfang der kapitalistischen Epoche in Großbritannien - und er gibt vor allem keinerlei Andeutnng, wie sich die Parallelität: Produktivität-Lohn im Getriebe des Preiskampfes durchsetzen sollte.

Die deutschen Nationalökonomen, soweit sie sich nicht mit Nalthusschen Trugschlüssen al,finden, ziehen sich auf die Behauptung zurück, es gebe gar kein einheitliches Lohnniveau, sondern unzählige ganz verschiedene tohnklassen, jede mit ihrem eigenen Arbeitsmarkte, mit ihren eigenen Ansprüchen und historisch gegebenen Gewolnheiten. Daher sei das Suchen nach einer Theorie „les" Lobns gegenstandslos, denn es gebe garnicht ${ }_{n}$ den" loohn!

1) Chevallier, ,les salaires au XIX siècle* (Paris 1887).

$\because$ Vgl. Jarx Kapital I. 525,6 . 
Ich habe diese Ausflucht oben (p. 60) gregen Ed. Bernstein als „einen Verzweiflungsakt der dekadentesten Vulgärökonomik“ bezeichnet und will dieses Urteil hier begrünlen.

Daß es verschiedene Lohnklassen gibt, war wahlich keine Entdeckung, die Ad. Smith, Ricardo mnd Marx zll machen versäumen konnten. Hat doch smith aufs glïcklichste und ausführlichste die Bedingungen entwickelt, die zur Difierenzierung der Lohnklassen führen mufiten: Schwierigkeit, Gefahrlichkeit. lange Lehrzeit usw. Aber sie waren denn duch zu gute Köpfe, als daß sie über den Verschierienheiten die Einhoit hätteu übersehen könneu: sie sahen den Wald trotz der Bäume.

Wenn wir die Skali der Johnklassen in einem gegebenen Augenblick betrachten, so linden wir, dab die Tuterschiede ihres Lohnniveaus in der Hauptsache bestimmt sind dur.h die relative Seltenlleit der für die Ausübung der rerschiedenen Berufe elforderlichen Eigenschaften: Begabung des Körpers, de; Geistes oder Willens - und materielle Ausstattung: lange Jehrzeit, Kapital nzw. Das ist sozusagen die Statik der Lohnklassen.

$\therefore$ Diese gegenseitigen Beziehungen der Lolmklassen werden aber fortwährend gestürt durch Vetänderungen in der relativen Seltenheit der persönlichen Vorbedingungen, sei es, daß die Nachfrage nach einem Berufe stärker oder schwächer zunimmt, als die Bevöłkerung selbst, sei es, daß gewisse Eigenschaften im 1)urchschnitt seltener oder häufiger werden, z. B. durch die öffentliche Schulbildung. Diese Gleichgewichtsstörungen tendieren nun immer sofort, und zwar durch das Spiel der freien Konkurrenz, auf Ausgleichung, auf Rückkehr zum statischen Gleichgewicht.

Fortwährend drängt gegen jedes Lohnuiveau der Wettbewer/, der nächst unteren Klassen, schon unter gewöhnlichen L'mständen. Wenn aber, durch irgend eine Veränderung der „relativen Seltenheit", ein höheres Johnniveau steigt, dann ziehen die unteren Klassen es durch ihren sofort. entsprechend stärker einsetzenden Wettbewerb auf die „natürliche J)istanz" herab, indem entweder erwachsene Angehörige dieser Klasse einen erhöhten Impuls zu größercr Energiespannung erhalten, oder, indem der Nachwuchs bei der Berufswahl sich der hegünstigten Lohnklasse besonders zahlreich zuwendet. Diese Bewegung macht die Gesamtheit aller 
Lohnklassen zu einem fein differenzierten, aber nichtsdestoweniger einheitlichen Gebilde, das sein dynamisches Gleichgewicht durch alle Störungen hindurch bewahrt. Das ist die Dynamik der Lohnklassen.

Es ist demnach unmöglich, daß irgend eine Lolnklasse falle oder steige, ohne daß alle anderen Lohnklassen in gleicher Richtung beeinflußt werden. Der Sporn des Wettbewerhes wird je nachdem schärfer. oder stumpfer, und so stellt sich die natürliche Distanz auf einem tieferen oder höheren Durchschnitt. wieder ein.

Dieser Einfluß einer Lohnklasse auf alle anderen ist aus klaren Gründen um so geringer, je höher sie in der Skala steht. Denn um so weniger: zahlreich ist sie auch, und so wird der Einfluß namentlich nach unten, auf die großen Massen hin, schnell minimal, bis zur Lnmerkichkeit. Je tiefer aber eine Klasse in der Lohnskala steht, um so größer wird der Einfluß, der durch Veränderungen ihres Lohnniveaus auf die anderen Lohnklassen ansgeübt wird. Denn um so zahlreicher ist sie alich. und eine starke Vermehrung oder Verminderung des von ihr ausgehenden konkurierenden Drängens nach ohen wird bedeutende Verschiebungen in den Nachbarklassen hervorrufen, ehe die natiirliche Distanz herrestellt ist.

Den größten Einfluß werden also Veränderungen im Lohnnicetu der tiefsten, zahlreichsten Lohnklasse ausüben müssen. Man stelle sich ror, durn irgend ein Wunder erhöhe sich der l.ohn unqualifizierter städtischer Tagelöhner plötzlich auf $3000 \mathrm{Mark}$ jährlich, zunächst ohne eine Beteiligung der übrigen Klassen. Jann wird aus allen oberen Lohnklassen bis zu denen über 3000 Mark ein so enolmer 7adrang in die Luterklasse eintreten, daß hier der Iohn gedrückt und dort - durch Verminderung des Angebots - gehoben wirl, bis sich almählich - nach einem so plötzlichen Ereignis vielleicht erst nach Jahrzennten -- die uatürliche Distanz entsprechend der Seltenheit der Torbedingungen wiederhergestellt hätte, und zwar auf einem bedeutend erhölten Durchschnittsniveau. Cingekehrt muß jede Senkung des Lohnnireaus der untersten Klasse eine Senkung der oberen Lohnstufen erzwingen, weil dann die Konkurrenz schärfer nach oben greift. 
Dieses Durchschnittsniveau aller Johnklassen in ihrer natiirlichen Distanz voneinander, dieser organische, elastische und doch enge Zusammenhang, das ist dasjenige, was die großen Theoretiker A. Smith, Ricardo und Marx') als „das" Lohnniveau betrachtet haben. Wenn sie rom Steigen oder Fallen des Lohnes sprachen, so meinten sie das Steigen und Fallen dieser Pyramide von Lohnstufen, wie sie auch vom Steigen und Fallen des "Profits" sprachen, obgleich ihnen wahrlich nicht entging, daß es sehr yerschiedene "Profitstufen" oder "Profitklassen" gab, je nach Risiko, Unternehmerbegabung, Bequemlichkeit, sozialer Ehre einer Unternehmung usw.

Man hat sich lange damit getröstet; daß der Reallohn der untersten städtischen Lohnklasse, der "Ungelernten", nicht steigt. Für sie sollte, so meinte z. B. Schönberg, das ,eherne Lohngeset $\%$ " seine Richtigkeit haben. In den höheren Lohnklassen aber w üchse die „relative Seltenheit", und so stiege hier cler Tohn.

Der Trost war von kurzer Dauer! Nimand kann mehr daran zweifeln, daß in Großbritannien der Reallohn auch der Ungelernten sehr beträchtlich gestiegen ist: Giffens. Untersuchungen lassen kaum Widerspruch zu. Lind auch für Deutschland läßt sich' die 'Tatsache kaum noch bestreiten. Es ist also nichts mit dem ehernen Lohngesetz fïr die Lngelernten! Und dennoch herrscht fast immer ein Überangebot auf ihrem Teilmarkte?!

Nun: das Problem ist nur für den Industriezentristen unlösbar. Für die geozentrische" Auffassung bietet es nicht die mindeste Schwierigkeit.

Die niederste Lohnklasse, die zahlreichste und schlechtest gestellte, diejenige, deren Konkurrenz das Emporstreben aller anderen Klassen zurückhält, wird nämlich nicht durch die „Ungelernten " der Industrie gebildet, sondern in jeder Volkswirtschaft mit Freizügigheit durch die Landarbeiter!

Der ländliche irt itsmarkt ist nun aber nicht überführt, sondern unterführt! Die Nachfrage nach Arbeitskraft wird hier dank der Masserifortwanderung durch das Angebot nicht nur

1) Siehe Kapital III. 1, 120/1 die einschlägigen ausgezeichneten Darlegungen zur Tohntheorie. 
nicht übertroffen, sondern bleibt in eivem steigenden Maße nnbefriedigt, je mehr die intensive, kapitalistische Agriknitur sich verbreitet. Darum muß auf diesem Teilmarkte der Preis der Ware Arbeitskraft regelmäßig steigen - nod darnm steigt die Lohnklasse der städtischen Ungelernten trotz den eherien Lohngesetz, und die böheren Lohnklassen trotz dem Tiberangeiıot ron Arbeit auf ihren Teilmärkten. Die Basis der iohnp: ramith. hebt sich, und mit ihr heben sich alle höheren Storkwerke.

Das ist des Rätsels einfache Iösung! Wer schwierigkeiten hat, sich in abstrakten Formeln zurechtzufinden, kam sich den Vorgang ebenso einfach durch folgende praktische Torlegung klar machen: die Industrie hraucht fortwährend 7:nzus lindlicher Arbeitskräfte, um ihren Bedarf an "Händen " zu derhen. Sie ın 6 daher den Landproletaliern immer ein Einkommen anisieten, das ihr bisheriges Lohnniveau genügend übersteigt, nm sie zum Fortwandern zu bewegen, wobei übrigens die Imlnstrie anch häufig die Konkurrenz überseeischer Koloniałgehiete zu schlageı hat. Dadurch steigt del Laudarbeiterlohn anf ein höheres Niveau, da das Angebot auf diesem Teilmarkte mit der Abwanderung sinkt, und die Grundherren gezwungen sind, höhere l,öhne zu bewilligen. Dieses böhere Landlohnniveau muß die Industrie beim nächsten Bedarf wieder überbieten, und so steigt langsam in Stadt and Land del durchschnittliche Lohn aller Stuten, die ihren "natürlichen" Abstand bewahren.

Das gilt, wohlgemerkt, uur von Wirtsilaltsgebieten mit voller Freizügigkeit. Wo aber Jer freie $Z$ ug vom Lande durch die Schollenpflichtigkeit, oder der freie Zug in die Stälte durch „Kirchspiel-“ und Armengesetze oder züuftlerische Privilegieu gehemmt ist, da bilden die Jandproletarier eine abgesonderte Lohuklasse für sich, ohne Verbindung mit den städtischeu l.ohnarbeitern, deren J.ohnpyramide unter diesen Lmständen wirklich die Klasse der städtischen U'ngelernten zur Grundlage hat. Dann kann das Rentenrecht des Croßgrundeigentums seine Hintersissen. die hier dem Drucke nicht auszuweichen vermögen. allerdings bis anf oder unter das alsolute Existenzminimum herabpressen, wie es z. B. in Irland geschiah.

Wen!n nun die städtische Entwicklung, der „Kapitalismus“, 
die Fesseln des freien Zuges sprengt, dann vollzieht sich die Ausgleichung zwischen den beiden bishei geschiedenen Lohnklassen mit einem Schlage, explosiv; der gestaute Strom des Landyroletariats überschwemmt die Industrie mit seinem Ilnngerangebot, bietet seine Arbeitskraft zu einem Preise an, der seinen unendlich niederein „historisch gegebenen Lebensansprïchen" genügt, und reißt dadurch fürs erste die städtischen Löhne plötzlich in die Tiefe. Dann erscheint es den industriezentrisch befangenen Volkswirten, als habe der „Kapitalismus" das himmelschreiende Elend, die schmutrige Not, die Brutalität und Verkommenheit in den Städten entstehen lassen: in der Tat aber hat er nur das längst anf dem Jande vorhandene, verborgene Elend in den Stäiten zum Forschein kommen lassen und gerade daiurch den ersten Anstof zur Besserung und schließlichen Heilung gegeben.' Die Zeche bezahlen die ehemaligen städtischen Handwerker und Manufakturarbeiter, deren Lohn bis nahe anf das Niveun irischer Pächter-Proletarier gerissen wird, und die nun plützlich auch nur noch Kartoffeln und Wasser zu bezahlen vermögren, wịnrend ihr John hislang für Fleisch, Weizenbrot und Porter ausreichte.

Das ist der gewaltige Vorgang, der Augen wie die Ricardos nud sogar Marxens täuschte.

\section{Kapitel.}

\section{Die Tendenz der kapitalistischen Entwicklung.}

Das grofe Problem, dessen Lösung 11ach Marx'- eigenem Zeugnis seine gigantische lebensarbeit gewidmet war, ist die liage nach den „mit eherner Notwendigkeit wirkenden und sich durchsetzenden Tendenzen “') der kapitalistischen Wirtschaft: "Es ist (ber letzte Endzweck dieses Werkes, das ökonomische Bewegungsgesetz der modernen Gesellschaft zn enthüllen. “" )

1) Vornort zur ersten Auflare des niapital:", p. VI.

$\Rightarrow$ Vorwort zur ersten Auflage des ,Kapital", p. VIII. 
Fr. Engels formuliert das Problem ein wenig anders. Ihm ist es die Aufgabe des wissenschaftlichen Sozialismus. in Gegensatz zur Ctopie, „die Mittel zur Beseitigung der entdeckten MiRstände ebenfalls in den veränderten Produktionsverhältnissen selbst vermittels des Kopfes zu entdecken, nicht etwa aus dem Kopfe zu erfinden." $)$ Hier ist die spezifische Lösung des sozialistischen Dioskurenpaars in der Problemstellung zum Teil schon mitenthalten: die „produktionistische Spielart" der ökonomischen Gesellschaftsauffassung ist als bewiesen, vielleicht auch als beweisfrei unterstellt, während sie doch erst aus der Lntersuchung sich ergeben konnte.

Wie das Problem aber von Marx selbst gestellt ist, wird niemand rlaran etwas erinnern können; es ist allerdings Aufgabe der soziologischen Theorie, eine wissenschaftlich fundierte Prognose der gesellschaftlichen Entwicklung zu gewinnen: und dazu gibt es nur einen Weg: die genaue Erkenntnis der in Vergangenheit und Gegenwart wirksam gewesenen und wirkenden „Tendenzen “. ${ }^{2}$ ) Zeigen sich solche von genügender Dauer und Kraft, ungekreuzt durch erhebliche Gegenkräfte, so wird man berechtigt sein, mit einiger Wahrscheinlichkeit den Schluß zu ziehen, dab sie auch in der nächsten Zukunft die Entwicklung beherrschen werden.

Aber die Stellung eines Problems und seine Lösung sind ¿ wei verschiedene Dinge. Die Marx-Engelssche Lösung ist falsch. Sie beruht gänzlich auf dem Gesetz der Akkumulation - und das ist, wie jetzt mit allen. Methoden der Kritik nachgewiesen, eine uuhaltbare Konstruktion. Es lassen sich daher auch seine Konsequenzen nicht länger verteidigen, weder der kollektivistische „Zukunftsstaat", noch die Zusammenbruchstherorie, noch schlieflich die produktionistische Geschichtsauffassung. Die Tendenz, die Narx in der ihn umgebenden Gesellschaft erkannt zu haben glaubte, existiert nicht nur nicht als "mit eherner Notwendigkeit sich durchsetzend"; sie wird atch nicht bloß von Gegenkräftsit

1) Autidühring, p. 286.

2) „Tendenz, d. h. ein Gesetz, desser absolute Durchführung durch "ejenwirkende Umstände aufgehalten, verlangsamt, abgeschwächt wird ${ }^{*}$ Kapital III. 1, p. 215.

1) peuhe imor, Marx' Gesellschaftslehre. 
anfgehalten, wie einige revisionistische Garvisten sich mul indere überyeugen möchten, da ihnen die Entschlossenheit zu einen radiki'e: Bruche mit ihrer Vergangenheit mangelt: sondern sie existiert überliaupr nicht!

Jis es minglinh, eine andere Tendenz von solcher hraft und Datuer, so waig ron erheblishen Gegenkräften gekreuzt, zu ,entdecken", dab man berechtigt ist, sie mit einiger Wahrscineinlichkeit in die Zukunft zu projizieren; oder.m. a. W.: ist es möglich. ein wissencchaftlich funilierte Prognose unserer Gesellschaftselutwirklung zu formulieren?

Ich glaube wohl, daB es möglich ist. Die Politik selbst, nath dem geschichtsmaterialistischen Kredo nur einer der Reflexe der Wirtschaftsentwicklung im Bewußtseia der Zeitgenossen, führt. uus auf die Spur dieser 'Tendenz, die wir suchen. Sie dreht sich als um ihren Angelpunkt um das Schicksal derselben Institation, die nach unserer Deutnng die einzige Quelle des „Kapitalverbältnisses" und damit des "Kapitalismus" ist: des Großgruudeigentums. Soll man es retten, kann man es retten, wie kann man es retten, ohne die Wurzeln der allgemeinen Yolkswohlfahirt zu unterbinden? - das ist das Problem aller inneren und fast auch aller äußeren Politik des deutschen Reiches. Denn anch der Exportindustrialismns, der viel gelästerte, mitsamt der Flotten- und Kolonialpolitik ist ja nur notwendig, weil man es für erforderlich hält, zugunsten jener Institution die Kaufkraft des Binnenmarktes zu vermindern, während man gieichzeitig durch Erhaltung des CroBgrundeigentums die Expansion der Industrie gewaltig fö̀dert, da es die Quelle ihrer Arbeiterarmee ist. Sn wird es natülich notwendig, den Warenexport zu forzieren. - Ind so ist die Geschichte des Grundeigentums die "Teheimgeschichte"1) nicht nur der watiken Gesellschaft.

Man muß, so meine ich, schon sehr stark in konservativromantisclien Anschannugen befangen sein, wenn man heute noch glauben kann, das Institut sei zu retten. Es geht augenscheinlich hoffnungslos zugrunde; und zwar wird es wie zwischen zwei Mühlsteinen zwischen Aus- und Abwanderung, den unver-

1) Kapiial I. 48. Anm. 33. 
meidlihen symptomen seines bloßen Diseins, zerriehen. Die ron ilm verschnldete Auswanderung hat jone ïberseeische Kunkurrenz geschnfen, die den Preis ïmtlicher Produkte geworfeu hat, die eine privathapitalistische Großlandwirtschaft mit Erfolg produzzieren kann: und die Abwanderung entführt ihm die Arbeitskräfte, mit deren Hilfe allcin es allenfalls den tällichen Schlägen der Konjunktur, Lassalles „orphischer Kette", ausweichen künnte, indem es auf die Erzeugung der Weltmarktsprodukte Vericht leistere und sich der Erzeugung hochwertiger Produkte für einen Nahmarkt, kurz, intensivster Wirtschaft zuwendete. Die Auswanderung badingt sinkende Proise. lie Ahwanderung steigrende löhne: tas bedentet dia aimähliche lenichtung der Grundronte ron beiden Seiten her.

lst an awarten, daff diesm Promen der Grundrentenrer-

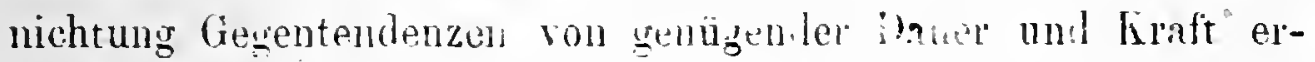
wachsen werden? Lch glaube nicht! Noch sind in allen Weltteilen ungeheure Ackerbreiten nicht unter dem Ptluge, nocb ist die Mehrzahl der geurharten Folder hörinst extensiv bewirtsuaftet. Mag sich der den Marktpreis bestirmmende Gestehunaspreis des "Grenzlsauern" auch erhöhen, wenn er in Zukunft einmal intensiver wirtschaftet, mögen weitere Transportwege 7 überwinden sein: diese Erhöhung wird rermutlich auf unabsehbars Zeit hinaus in starkem Yabe kompensiert, vielleicht überkompensiert werden durch das muathaltsame sinken der Frachten mit dem rapiden Wachstum namentlich der Schiffsefefibe.

Auf der anderen Seite ist nicht abzusehen, woher die Kraft kommen sullte. dia die Steigerung der Tamlarheiterlöhne iuf die Dauer aufhalten könnte. Die Zuwanterung ansianlischer Entearbeiter ist heute schon so groß, dah sie die Grundbesitzer in ihrer Heimat zu empfindlichen Lohnerböhungen zwingt: ss steigt also das Normalniveau, die Basis der Pyramide, auch hier ragelmälig. Außerdem kani der preußische Staat unmöglich die röllige Slavisierung seiner Ostmuvinzen dulden. Es wird also diesseits oder jenseits der Grenze einmal das "non plus ultra" ausgesprochen werdes.

Und Zölle sowie ähnliche künstliche Preiserhöhungen können, darüber ist sich alle Wissenschaft im klaren, a uf die Dauer die Preise nicht heben. 
Es wird also in absehbarer Zeit der kritische Punkt erreicht sein, wo auf der überwiegenden Mehrzahl der Großgüter das Rentenbezugsiecht seinen wirtschaftlichen Inhalt verliert, und wo der Staat angerufen werden wird, seine alte herrschende Klasse aus ihrer Notlage zu erlösen, wie er am Anfang des 19. Jahrhunderts angerufen wurde, sie aus einer ähnlichen Notlage zu erlösen, als das Arbeitbezugsrecht gegen die feudalen Hintersassen seinen wirtschaftlichen Inhalt verloren hätte. Dann wird der Boden in das Eigentum von Bauern oder Bauerngenossenschaften ${ }^{1}$ ) überführt werden müssen.

1) David, in seiner agrarpolitischen Auffassung ein echter Südwestdeutscher, Schwärmer des Klein--und Verächter des Großbetriebes in der I,andwirtschaft, polemisiert in seinem zitierten Werke gegen die landwirtschaftlichen Produktivgenossenschafteu (p. 700 ff.) (vgl. anch Neue Zeit 1894/5, II. p. 686), die ich namentlich als (̇ berführung ans dem Großgute in das Bauerndorf empfehle, aher auch nach wie vor in bestimmten klimatischen lagen und unter gewissen historisch gegebenen Verhältuissen für die überlegene Betriebsform halte, weil sie die Vorteile des kleinen mit denen des grolien Betriebes, die auch David anerkennt (p. 101,-104, 109), verbindet. David beruft sich für sein verwerfendes Votmm auf den allerdings ausnahmslos eingetretenen Mißerfolg der britischen Ackergenossenschaften (p. $582 \mathrm{ff}$ ). Wenn man aber genauer hinschəut, so meint er nur das sog. ,cooperative farming “, d. h. Landgüter, die im Eigentum der Konsumvereine resp. GroBhandelsgenossenschaften sind. Das sind aber nichts weniger als "Produktivgenossenschaften", denn es sind mit Lohnarbeitern bewirtschaftete, von einem besoldeten Administrator verwaltete priratkapitalistische Großbetriebe, (die notorisch inergiebigste Wirtschaftsform), die dänm nichts genossenschaftliches an sich haben, weil ihr Besitzer ein Konsumverein ist. - Ebensowenig sind, um das hier einzuschalten, die ron David nicht angezogenen sog. "productive associations" Produktivgenossenschaften, sondern Aktiengesellschaften kleiver Arbeiterkapitalisten, die durch ein paar Lohnarbeiter oder allenfalls arbeitende Genossen einen Fetzen Land bestellen lassen. Ihr berūhmtes Vorbild ist die Gurdonsche Gründung Assington. In beiden Fällen fehlt das Charakteristikun der echten Produktivgenossenschaft: die Bestellung des Gemeineigentums durch alle Genossen und nur durch Genossen, und die volle Verteilung des Reingewinns pro rata der Leistung, wodurch Sorgfalt und FleiB über das Mal der Taglohnarbeit gesteigert werden (vgl. meinen Aufsatz in Nr. 36 der "Genossenschaftlichen Blātter" 1901). Auf beide Arten darf sich David also nicht gegeu mich berufen. Seit 1832 Rahaline (vgl. meine "Siedlungsgenossenschaft", p. 405 ff.) 
Wenn Adolf Wagner, wie seine letzten Schriften ${ }^{1}$ ) beweisen, diesen Ausgang aus politischen Gründen noch immer für ein nationales Englïck hält, so hat der theoretische Ökonomist nicht mit ihm darüber $z u$ rechten: wenn er aber nach jahrelanger Debatte über diesen Punkt das Großgrundeigentum immer noch mit dem Arguınent verteidigt, der Großbetrieb sei für die Entwicklung der landwirtschaftlichen Technik unentbehrlich, so kann man nur immer wieder feststallen, daß auch Domänen, Kommunalgüter und großeProduktivgenossenschaften Großbetriebe sind, und zwar solche, welche viel mehr Gewähr für eine rationelle Musterwirtschaft bieten, als das durch Luxusverbrauch und Erbrerschuldung immer wieder des Betriebs- und MeliorationsKapitals beraubte, immer höher verschuldete Privateigentum.

Wir haben also für die nächste Zeit zu erwarten, daß der Lohn der Landarbeiter langsam aber dauerud steigt, und daß nit dieser ihrer Basis auch die industriellen Lohnklassen sich heben, sodaß die materielle und soziale Lage des Proletariats in beiden Hauptzweigen der Volkswirtschaft steigende Tendenz hat.

Im weiteren Fortgang der Entwicklung wird, in dem Maße wie die schwächer fundierten Großbetriebe zusammenbrechen, die Basis der Lohnpyramide immer mehr, statt von Landproletariern, von selbstwirtschaftenden Bauern auf genossenschaftlich besessenem, d. h. unverschuldbarem Boden gebildet werden; und deren Einkommen-Niveau wird immer weiter steigen, dank jenem wohltätisen. Wechselverhältnis zwischen Stadt und Land, wie wir es in 9. Kapitel als Charakteristikum der „reinen Wirtschaft" darspestellt hahen. Mau mag bei Darid ${ }^{2}$ ) nachlesen, was selbst unter den pathologischen Verhältnissen eines rom Großgrund-

zerstürt wurde, hat es einc echte landwirtschaftiiche Produktivgenossenschaft in Großhritannien vicht mehr gegehen: hoffeutlich gelingt es Mr. Gras: dem Generalsekrctīr des Genossenschaftskongresses; seinen zăh verteidigten Plan einer unit nuinen Forschlägen identishen Genossenschaft dieser Art bald durchzusetzen.

1) Ȧgrar- und Iudustriestaat, Jena 1902, jassim.

$\Rightarrow$ 1. . 1. $541 \mathrm{ff}$, rgl. a. deuselben, Sorialistiche Monatshefte 1903,

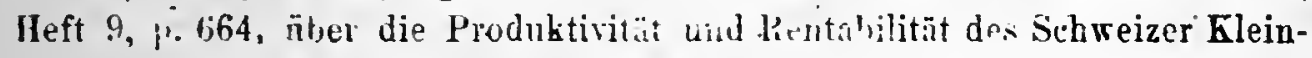
letriehes wath Mr. Latur. 
eisentum verheerten Weltmarktes für alle landwirtschaftlichen Produkte ein reines Bauern̈land wie Dänemark, ohue Zollschutz, nur durch den Zauberstab der Assoziation zu leisten imstande war und ist. ${ }^{1}$ )

Je mehr Großgüter in Banernhände übergeführt werden müssen, um so höher muß der Lohn der noch übrigen Landproletarier steigen; denn liese innere Kolonisation bedarf un. gemein vermehrter Arbeitskräfte: ein Rittergut hat nacl der Parzellierung die drei-bis vierfache Bevölkerung! ${ }^{2}$ ) So wird die Lebenshaltung der breiten Landbevölkerung noch schneller steigen, ihre Kaufkraft für industrielle Produkte rapide wachsen, die Abwanderung aber mit der "Verbauerung" des Landes sinken; und so wird das stärltische Tohn-Niveau und die soziale Klassierung der Arbeiter bei steigender Nachfrage und sinkendem Angebot der Ware Arbeitskraft gleichfalls schnell und dauernd wachsen. Am Schlub des gimzeu Prozesses muß das Großgrundeigentum auch in seinen lebenskräftigsten Exemplaren, den Fideikommissen etc., gïnzlich verschwunden sein, vielleicht mit Hilfe der Gesetzgebung. Und darn kann und wird sich die „reine Wirtschaft" einstellen.

Ich habe eine ganze Anzahl von historischen Beweisen dafür beigebracht, daß in einem Wirtschaftskreise ohne Grofgrandeigentum, der theoretischen Dedultion genan entsprechend, jede Arbeit ihren "vollen Arbeitsertrag" genießt, d.h. daß weder Grundrente noch Profit zur Erhebung gelangen. Mein eines Beispiel umfaßt vier Jahrhunderte dentscher Geschichte. ${ }^{3}$ ) Niemand hat hisher den Tersuch einer Widerlegung unternommen.") Aber man matg diesen Zustand des erreichten "Sozialismas" oder besser des „Liberalismus“,, 5 ) für ein unerreichbares Ideal

1) Vgl. auch meinen Aufsatz: „Verwirklichte Ltopien“, Berl. Zukunft, 1900, No. 31.

3) Sering, Innere kolonisation, p. 196.

3) Grobgrundeigentum, Buch 2, Kapitel 2.

4) Ygl. meine Abhandlung: ,häufer-Yerkāufer", Schmollers Jabrb. 1900, p. $158 \mathrm{fr}$.

5) Der Sozialismus ist ein 7.iel: eine ron allen , Gerraltanteilen" (Rente, Zius; Profit) befreite Volkswirtschaft; der Kollektivismus ist nur ein Mittel 
halten: dis eine wird niemand leugnen hönnen, der den grundlegeiden Gedanken dieses Buches annimmt, daß im Fortgang der Entwicllung ein Zustand der Gesellschaft zu erwarten ist. der dem heutigen, immer noch sehr ühlen, Zustande von jedera Gesichtspunkt sozialer Betrachtung atts weit überlegen ist una sich dem Ideal einer rationellen Gesellschaftsgestaltung mindestens $\therefore$ weit nähert, wie eine skeptische Betrichtnn des menschlichen Charakters irgend erhoffen läßt. ob alle Blütenträume reifen werden, ist kein Gegenstand der wissenschaftlichen Erörterung mehr, sondern Temperamentssache. Was aber heate mit gröbter Wahrscheinlichkeit rorausgesagt werden kann, genügt bereits, um alle pessimistischen Gedanken weit zti verbanneu. Die Tendenz. der kapitalistischen Gesellschaft zeigt nicht erst in den Abgrund der sozialen Revolution, um dann steil zum tausendjährigen Reiche emporzuführen, sondern! sie verfolgt eine kräftic aufsteigende Kurve, inmer noch zu langsam für uns als leidende und mitleidende, kurzlebige Menschen, aher schnel! genug für uns als Historiker, denen die Generationen nur Sekunden des Menschheitsrages darstellen.

Lnd Hebel und Ziel zugleich dieser Entfaltung zu Licht and Gü̈ck ist die pulitische und wirtschaftliche Freiheit, das ldeal des alten, sozialen Liberalismus!

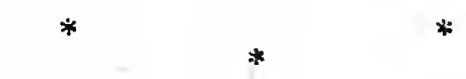

Wenn wir behaupten, daßs so viele, so schwere und so.weitrerzweigte Übel ihre ein 'ge Trsache in einer Institution halen, deren quantitative Bedeutung in der morlernen Volkswirtschaft auf den ersten Blick riel zu gering erscheint, als daß sie so

\% diesem Ziele, nach Marx, der das C̈bel in der freien Konkurrenz sucht, das einzige. Junes Ziel ist aber anch nahezu dasjenige des Alt-Liberalismus der Physiokraten und Adam Smith’: Harmonie aller Interessen! Darüber l.ald mehr in einer Rententheorie. „Dieser Idealzustand ist das eigentliche Eudaiel der sozialistischen Bewegung. Der gewöhnlinh als "Endziel berechneten kollektivistischen Produktionsheise komnt dongegenüber nur die Redeutung eines Nittels zun Zweck ztl.* (Darid, Sozialismus und Landwirtschaft, Berlin 1903, 1. 608). 
breite Wirkungen äußern könute; - wenn wir die noch viel kiihnere Behauptung wagen, daß mit dem Verschwinden dieser einen lustitution sich automatis:h ein von so vielen. der Besten für unmöglich, ja für undenkbar gehaltener Zustand allgemeiner Wohlfahrt und rernünftiger fileichheit der Lchensbedingungen einstellen wird, so verlangt das philosojhische Gewissen nach einer Aufklärung über das eigenste, immerste Wese:ı diesor su hart rerklagten Einrichtung.

Ich will daher diese im wesentlichen kritische Ahhandlung mit einer kurzen Skizze ${ }^{1}$ ) über das Wesen dus (rrofigrundeigentums vom geschichtsphilosophischen Gesichtspunkte s'liiiefien. sie wird, so möchte ich hoffen, manche skeptische Anwandlung beschwichtigen.

Die Bedürfnisbefriedigungmittel der Mersohheit als Allcomeinheit sind nur durch Arleit zu gewinnen. Ich nenne die Arbeit und den als ïquivalent geschäłzten Tausch von Arbeitprodukten das ökonomische Mittel der Bedürfnisbefriedigung.

Der einzelne Mensch aher kann seine Bedürfnisse auch dadurch befriedigen, da or sich die Arbeitprridulite anderer Menschen ohne äquivalente Gegenleistung aueignet. J)iese Art nenne ich das politische Mittel der Bediurfnisbefriedigung. Das primitive politische Mittel ist der Raub und der Kanbrieg, in der alten Welt in allen Erdteilon gerichtet ron Hirten (Nomaden) gegen Ackerbauer. Sein Ziel ist arbeitfreies Einkommen von Anderer Bodenarbeit, d. h. Grundrente.

Aus dem ungeregelten Raube stammfremder Hirten entfaltet sich durch mehrere $Z$ wischenstufen hindurch die greregelte Besteuerung der Bauein durch einen im Lande festgesetzten Hirtenadel. Das Ziel bleibt das glaiche, die Grundrente; nur das Mittel hat sich geänlert; es heißt jetzt: der Staat! El ist das entfaltete politische Hittel! Jeder Staat der uns be-

1) Eine ausführliche Darstellung der „sozialökonoınischen Geschichtsauffassung erscheint gleichzeitig in Paul Barths „Vierteljahrsschr. f. wiss. Phil. u. Soziologie*. 
kannten Weltgeschichte ist entstanden') durch politische Unterworfung von Ackerbauern durch IIrten zum Zwecke der bequemeren, sichereren und reichlicheren Erhebung der Grundreste; demselben Zwecke dient der Rechtsschutz nach innen und der Waffenschutz nach außen: so schütat auch der Imker "seine“ Bienen gegen den diebischen Nachbarn und den räuberischen Bären. Alles Staatsrecht hat ursprïnglich keinen anderen $Z$ weck, als die Sicherung dieses ersten und für alle Zeit wichtigsten Staatszweckes, derGewinnung eines möglichst hohen und möglichst dauerhaften arbeitfreien Einkornmens der Herrenklasse. ${ }^{2}$ )

Arbeitpflicht und Stecerpflicht: das w.iren die nnmittellaren Quellen dieses "Herreneinkommens", wie es Rodbertus treffend bezeichnet. Seine materielle Projektion war das Grofogrundeigentum! In seinem Begriff liegt Stenerptlicht oder Arbeitpticht oder beides eingeschlossen.

Ich habe zeigen können, ${ }^{3}$ ) dab alles Grobgrundeigentum der primitiven Staaten nur entstehen konnte und nur entstanden ist auf Grund der legalen Herrschaft des Menschen über den Menschen, also auf Grund der Sklaverei resp. Hörigkeit, d. h. durch das politische Mittel. Aus dem ökonomischen Mittel, durch ökonomische Differenzierung, wie fast alle Ökonomisten and Historiker annehmen, ist es nicht entstanden und konnte es nicht entstehen.

Das heutige Groligrundeigentum ist ein unmittelbarer geschichtlicher Abkömmling jenes primitiven Vorfahren. Selbst die modernen, durch Zusammenkauf entstandenen, großen, z. B. Jagdgüter, konnten nur entstehen auf Grund einer Vermögens- und Einkommensverteilnng, die massenhaftes al t es Großgrundeigentum zur Voraussetzung hat, lesp. auf Crund des Vorhanlenseins massenhafter "freier" Landproletarier, das allein gestattet, aus

1) Ratzel, Välkerhunde, 1., p. 26. I)as wußte schon Ilerder (Schriften zur Phil. d. Gesch. 5. Teil, p. 215. Cottasche Ausgabe 1827/30).

$\left.{ }^{2}\right)$ Vgl. L. Gumplonitz, Die soziologische Stratsidee, 2. Aufl., Innsbruck 1902, und II. C. (Heinvich Cunow) Nene Zeit 1890/1, J.. p. 569 in einer Polemik gegen Schäffle.

3) Mein „GroBgrundeigentum", I. Buch, Kap. I. 
solchen kapitalistischen Gebilden eine Rente zu erwirtschaften: so in Nordamerikil!

Lnsere heutige Volkswirtschaft beruht auf dem Grundsatze der menschlichen Gleichheit und Freiheit. Nach dem Niturrechte, den "Menschenrechten", soll kein Mensch mehr eines anderen Menschen Nittel sein dïrfen. Tinsere Statatsverfissung und Wirtschaftsordnung ist m. it. W. der Absicht nach aufgebant ausschlieblich auf dem ökonom ischen Mittel: nur die eigene Arbeit und der in der freien Konkurrenz des Mirktes zur Äquiralenz regulierte Tausch sollen die Mittel der materiellen Bedürfuisbefriedigung schaffen. Es ist eine Ordnoms, in der jeder nur für sich, nur unter dem Antriebe seines wohlberatenen Eigennuizes tätig sein soll.

In diese Wirtschaft ragt das Grobgrundeigentum als letzter Rest aus einer Verfassung und Wirtschaftsordnung hinein, die auf einer völlig verschiedenen Grondlate beruhte. - In ihr war der eine Teil der Menshheit rechilinh verpflichtet, für den anderen Teil olme Eutrelt zu arheiten; las entfaltete politische Vittel, der Staat, el\%ung ron dor beherwaten Mase das Opfer eines Teiles ibrer Arbeitkraft oder ihros Arbeiterzelagnisses. Das Cobigrandeigentum ist foudale Machtposition, wie Bann- md Zunfiprivilegien, Schollenpflicht igkeit und Robotpflicht, wie Zölle und Prämien, Grundruls- nnd Strandrecht. Lnd Adau sinith wußte genau, warum er die Beseitigung dieser feurlalen irachtposition, dieses ,Honnunls", mit allen anderen forderte.') Diese Forderung ror allem unterscheidet den alten, sozialen Liberalismus, der ein Mcuschbeitsziel war, ron seinem 7errhilde, dem Manchesterliberalisums der Ricardo und Malthus, der eine Klassenthemrie der Bonrgeoisie ist.

Man lieb diese Bastion des alton Cewaltstates, des Feudalwesens, stehen, teils aus Unkenutnis, weil sie, ökonomisch Inaskiert, dem eigentlichen, notwendigen Eigentum sehr ähnlich war (so in Frankreich 1789); teils, weil sie durch Interessen-

:! I gl. A. Suith. l. c. p. I 4323 . Näheres in meiner demnächst ercheiuenden Rentertheorie. 
gruppen geschützt war, die mit politischen Vitteln damals nicht überwunden werden kounten (so in Preußen 1811).

Lnd so ist es denn rom Standpunkte des Geschichtsphilosophen nichts Erstaunliches, daß von dem Augenblick an, wo der „liberäle" Staat nit der Freizügigkeit geboreu war, der Kampf des (iesellschaftsorganismus gegen den Fremdkörpe: eiusetzte, der Kampf, d. h. die "Krankheit" als ein Prozeß, der anf Ausstoßung der Krankheitsursache tendiert und nicht zur Ralse komn kann, ehe die Ausstoßung nicht erricht ist. Eine feudade Machtposition ist nur im Feudalstaate lebensfihig: im Verfassungstaate mul sie zu Erscheinung $n$ führen, die eins von heiden, den Verfassungstaat oder den Feudalrest, zerstören. Den Prozeß dieser Krankheit, die wie alle Krankheit gleichzeitig Heilungvorgang ist: nennen wir: „Kapitalismus!“, einen Peozeß, der entstanden ist and unterlalten wird durch die Wanderbewegnug, die nach dem fiesetze rom einseitig sinkenden Drucke überall da eintreten muR. wo grofies Grundeigentum und Freizügigkeit nebeneinander bestehen. ${ }^{2}$ )

Jetzt wird auch rerständlich sein, wie eine anscheinend verhältnismäßig so kleine Ursache so große Wirkungen haben kann. Jedermann weiß, wie allgemeine und schwere Erscheinungen ein einziger splitter, als liremdkörper, im lebenden Organisinus auszulösen rermag.

i) Jian sieht, die Theorie lünft anf das Carey-Rodbertus-Dühringscine ..Gewalteigentun* hiuans, das hie Kraft hat, . Fewaltauteile an der Tolksprorluktion zu erpressen. Sie urterscheidct sich in der Tat wn ihren Vorgängern nicht in der Behauptuns: sondern nur darin, dab sie zum ersteninale den gesellschaftlichen Proceß anfdeckt, der zu der Bildung der .Gewaltunteile" führt.

Ich bin nun wirklich nengierig, ol, Katisly und die seiueu auch gegen diese ..Nenanfämung der tausendmal widerlegted Dühriugschen Theorie - ragen rerden, die unglïeliseline Eugalssche streitschrift wieder auszuqielen. \%ur Warmung bemerk in, daf Engels fortwährend die öknnomische disicht mit dem jkonomischen Vittel rerwechselt (vgl. p. 135, 159 usw.).

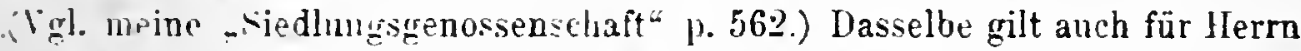
Franz Stalli, der mioh durch die gleiche Verwechslung zu einer höchst unangeurhmen Tiskussiou über dicses Thema zwang (Sozialistische Munatshefte 1599, ए. 402, 630). 
An diesel Krankheit ist der antike Stadtstaat regelmäßjg zugrunde gegangen: latifundia Italiam perdidere! Marx war augenscheinlich von dem Bilde dieser "zyklischen Katastrophen" der alten. Welt beherrscht, als er den kommenden Zusammenbruch der modernen Gesellschaft mit der Kraft und dem Pathos eines Jesaja schilderte: den Untergang aller Mittelstände in Stadt und Land, die Anhäufung eines ungeheuren, nichtshäbigen Proletariats in schwellenden Riesenstädten voller Krankheit, Not, Unsittlichkeit und Empörung an dem einen Pole - und eines übermütigen Reichtums einer immer kleineren Minderbeit am anderen Pole. Hier waltete in der Tat das Gesetz der Akkumulation!

Aber die moderne Gesellschaft beruht nicht auf Sklavenarbeit, sondern auf freier Lohnarbeit. Sie drängt darum nicht ein verkommenes Lumpenproletariat, sondern eine Bevölkerung sittlich und geistig emporstrebender Menschen in den Großstädten zusammen; sie vernichtet die Mittelstände nicht, sondern vermehrt den landwirtschaftlichen und ersetzt wenigstens den städtischen Mittelstand, und sie tendiert daher nicht auf Revolution und Vernichtung, sondern anf Evolution, anf volle, glückhafte Selbstentwicklung aus der Puppe des Feudalsystems, die sie heute noch, schon vermorscht und durchlöchert, aber immer noch schnūrend und hemmend, amschließt. Bald wird sie auskriechen, und dann erst wird die Gesellschaft der vollen bürgerlichen und wirtschaftlichen Freiheit ihre schimmernden Flügel entfalten.

Für diejenigen, die der dialektischen Methode* vertrauen, mag eine Version der berühmten Marxschen Prophezeiung dieses Kapitel enden:

,Das feudale Bodenmonopol wird zur Fessel der Produktionsweise, die mit und unter ihm aufgeblüht ist. Die Wanderhewegung des Landproletariats entwertet seine Erzeugnisse und vermehrt seine Produktionskosten. Das Großgrundeigentum bricht zusammen. Dic Stunde des feudalen Eigentums schlägt. Die Expropriateurs werden expropriiert. 
„Die feudale Aneignungsweise, daher das fendale Privatgrundeigentnm, ist die erste Negation des individuellen, auf eigene Arbeit gegründeten Privatgrundeigeutums. Aber die feudale Aneignung erzeugt mit der Notwendigkeit eines Naturprozesses ihre eigene Negation. Fs ist Negation der Negation. Diese stellt. nicht das Privatgrundeigentum wieder her, wohl aber das individuelle Eigentum auf Grundlage der Errungenschaften der kapitalistischen Ära: der Kooperation und des Gemeinbesitzes der Erde. . . . . . . Hier handelt es sich um die Expropriation weniger Usurpatoren durch die Volksmasse."

3) Vergl. Kapital I. $728,9$. 


\section{Schlußwort. \\ Die Klassentheorie.}

Wie konnte ein. Yarx an den chtscheidenden Stellen seiner rehre sich in solche Trugschlüsse vorwirrell, wic kounte er die Tatsachen so falsch dente'n? Dic Elirfurcht geinetet, dem zureichenden Grunde für seine Irrtiimer nàclizuspüren.

Jas, was min die "Vorstellungsseite" des Irrtums nemnen hönnte, habe ich schon dargestelit: es war. aet vou licardo übe:nommenc "Industriezentrismus" der Klassiker. Viel entscheidender aher war das, was man die "Willensseite" nenuen kömnte:

In Marx dachte und trieb der Klassenwille des zum Selbstbewußtsein erwachenden Proletariats; seine Theorie ist die proletarische Klassentheorie. Nur, wenn man sie als solche betrachtet, gewinnt man den richtigen Ștalidpunkt für ihre (irölie und Bedeutung und für eine gerechte Finschätzung ihrer Irrtiimer.

Des Menschen Wille ist streng determiniert - das ist das Axiom jeder Gesedlichaftswissenschaft, "uhne das sie unmöglich wäre -, aber er dünkt sich frei. Er handelt unter dem Druck objelitiv gegebener Verhältnisse naturgesetzlich, glault aber dank der bekannten Seibsttäuschung aus sittlichen oder vernünftigen Hotiven zu handeln: „Naturgeselzlich handelt der Ifensch, und menschlich denkt er hinterdrein." ${ }^{1}$ )

Das gilt, wie für jedes Individuum, so auch für jede Klasse. Fine Kilasse. d. h. eine Nenschenmasse mit gomeinsamen politisch-wirtschatitlichen Interessen, "strömt" ebenfalls naturgesetzlich. unter dem Druck objektiv gegethener Verhältnisse, „rom

1) Gumplowitz, frundr? der Soziologie, Wien 1885. p. 37. 
Urte hüheren zum Orte geringeren Druks aul der Linie des geringsten II iderstandes": and anch sie rethlertigt: nenschlich, ihre Handhugsweise ror lernulft und sitilichleit durch eine likscentheorie, wie ihr wa ein Panier im Klasenkampf rorangehi. ${ }^{2}$ )

So ist die lethe lun den ,zykischen Katastrophen" die Klassenthente der feudilon Herrenkiast'; sie liuft immer darauf

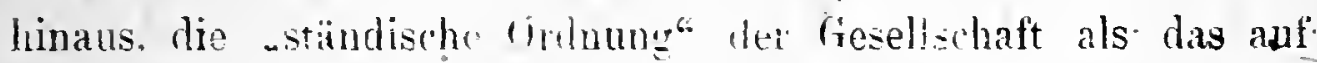
die Dane: unerschünetiche Ergetuli nbjekir ge bener Begabungsdifferenzei zn reehtfertigen. inöge nun die angehlich

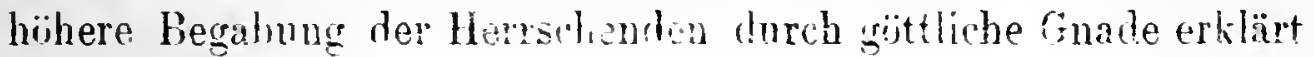
werden: die legitimistiwh - theolorische Lehre! - oder durch Alstammung von besserm Blute: die Rassenthericr. - ")

$S_{0}$ ist ferner der ,. Manhesterlineralismes" alosentheorie der Bourgeoisie, eine Lehre, dio fïr den Krin ni zrrei Fronten zugeschuitten it. Sic rerhtfertigt einerseits len bimpf gegen the alte Herrentuse mit den liberalen liedankeli on Natnrecht und Freihe:t and anderseits die wirtschatiche disbeutuig der Arbeiterklisse it den haltlosen Koustriktionen des „ehernen" Lohn- und Bevölkerungsgesetzes, durch dic die Verantwortung fär die himmelschreiendeu Greuel der kapitalistischen Produktionsweise auf die Schultern der unverantw ortlichen Natur abgewälzt werden sollen.

Auch das Proletariat bedurfte zur Verteidigung seiner politisch-wirtschaftlichen Aktion einer igenen Klassentheorie, die

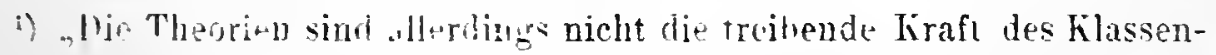

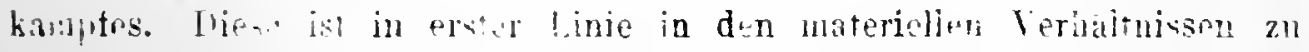

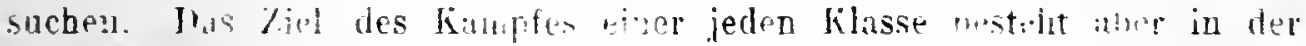

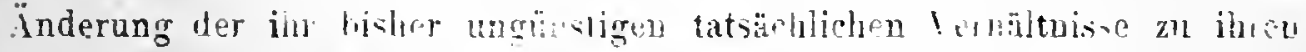

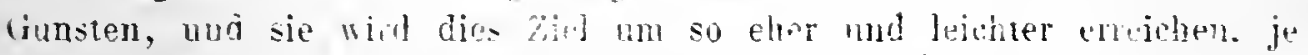
mehr sie von allen lllusinen i,efreit ist, je mehr in bingeluen den Tatsachen entspricht. Es ist demuach tür die sozialistische, wie iür jede audere Klassenbewegung trotz. ilres inateriellen Charalitus durchans nicht gleichgültig, anf wellher theoreischen Grmalage, sic fußt." A. Kintsky,

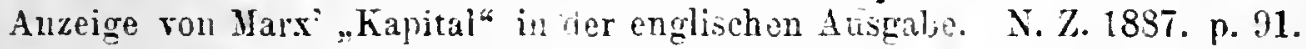

2) Veryl. meiuen Aufsatz: ,Das Gesetz der zyblischen Katastrophen N. D. Rdsch. XllI Heft 12 und weine Auzeige ron Chamberlaius ,Grundlagen drs XIX. Jabrh." Frkf. Zeitung 1902, Nr. 119, 120, 12.2. 
nach dersellen Richtung wies, in der es zu "strömen" gezwungen war. Welches war diese Richtung?

Dem Proletariat war der Kampf anfgezwungen sownhl gegen die alte, noch einen starken T'eil ihrel Matht bewahrenile Iferrenklasse der Fendalität, als auch gegen die nene Ilerrenklasse ror Bourgeoisie. Seine Klassentheorie multe also sein: ersicus antifeudalistisch, d.h. demokratisch, und weiteus antimatirsterlich, d.h. sozialistisch, und zwar kollektivistisch.

Sie konnte nicht anders als sozialistish sein, d. h. mußte rechtfertigen das Streben auf - und den (x):mbein i' eine ron aller wirtschaftlichen Ausbentung befreite staats- und finsellschaftsordnung, m. a. W. an eine dimernde Beseitigung allen .Mehrwerts", allen arbeitsfreien Einkommens in der Cestilt ron Zins, Profit und Grundrente. Denn es wiren klärlich diese "Herreneinkommen “, unter" denen has Proletiriat litt.

Und die proletarische Klassentheorie konnte auch nirli: anders als kollektivistisch sein, d. h. munte rechtfertign dis Streben auf - und den Glauben an eine künftige marktlose Wirtschaft für und durch die Gesellschaft". Deun vichts schien gewisser - selbst die manchusterliche Theorie wagte nicht es zil leugnen -..daß jene Harrencinkommen dem Proletariat abgepreßt wurden durch die verderibliche Macht der "freipin Konkurrenz", die auf dem Arbeitsmarkte den Lohn nierlerdrïckte und auf dem Waremmarkte die Ungewitter der Krisen heraufbeschwor, die sich zermalmend üler der Arbeiterklasse entluden.

Nur wenu die proletarische Klassentheorie die. Verurteilung der "freien Konkurrenz", d. h. die Forderung der marktiosen Wirtschaft enthielt, konnte die Arbeiterklasse den für eine kräftige fiilrung des Klassenkampfes unenthehrlichen handgreiilicheir Gegensatz gegen das Programm derjenigen Klasse gewinnen, die zu allererst zu bekümpfen war, der Bouryeoisie.

Eine solche, sowohl antifeudalistische, wie auch antimanchesterliche Klassentheorie bot Karl Warx in seinem "Kipital" iem Proletariat dar.

Sie rechtfertigte nicht nur den radikalsten Kampf der Demokratie gegen die Feudalität, sondern auch den Sozialicmus durch lie Mehrwertlehre; dorch den wissenschaftlichen Nachweis 
des von den Manchesterliberalen hartnäckig bestrittenen Raubes an dem Ergebnis der Arbeit - und den Kollektivismus durch die Aufdeckung jener "Tendenz" der kapitalistischen Entwicklung, alles Kapitalvermögen in immer wenigeren Händen an dem einen Pol, - und alle Arbeitskraft nackt und bloß an dem anderen Pol zu akkumulieren: eine Entwicklung, die in der Tat, wenn sie so verlief, nur zur kollektivistischen Wirtschaft führen konnte:

Genau diese Theorie brauchte die proletarische Klassenbewegung, und darum nahm sie sie begeistert auf. Sie brauchte sie für ihren Klassenkampf. Das wird in unübertrefflicher Präzision durch die folgenden Ausführungen eines der angesehensten marxistischen 'Theoretiker bestätigt:

„Für den Standpunkt des Klassenkampfes war das große theoretische Problem: die Entstehung des Mehrwertes, d. h. die wissenschafliche Erklärung der Ausbeutung, sowie die Tendenz der Vergesellschaftung des Produktionsprozesses, d. h. die wissenschafliche Erklärung der objektiven Grundlagen der sozialistischen Umwälzung.

„Beide Probleme beantwortet bereits der erste Band (des "Kapital"), der "die Expropriation der Expropriateure" als unausbleibliches Endergebnis der Produktion des Mehrwertes und der fortschreitenden Kapitalskonzentration folgert. Damit war das eigentliche theoretische Bedürfnis der Arbeiterbewegung im großen und ganzen befriedigt." ")

Nichts kann charakteristischer sein, als diese vortrefflichen Ausführungen, welche die Theorie ganz richtig werten nach ihrer Brauchbarkeit "für den Standpunkt des Klassenkimpfes“.

Von diesem Standpunkt aus gewinnen wir jetzt auch ein leichtes Verständnis für die rom Standpunkte reiner Wissenscháft so sonderbare Tatsache, das die Bourgeois-Ökonomie durchgehends

1) Rosa Luxemburg, "Stillstand und Fortschritt im Marxismus". "Vorwärts" rom 14. Mãrz 1903. Äbnlich K. Kautsky: „Die Wissenschaft hat also noch bedeutendes zu erwarten. Der wissenschaflichen Bedentung von Marx kann aber nichts mehr hinzugefügt werden. Durch die Erforschung der historischen und ökonomischen Bewegungsgesetze hat Marx sich an die Seite der größten Denker und Forscher gestellt." (Nekrolog auf Marx. N. Z. I. (1SS3) p. 44S.)

oppenheimer, Marx' Gesellschaitslehre. 
nicht die Zitadelle des Marxschen Systems berannt hat, sein Akkumulationsgesetz, sondern ein strategisch unbedeutendes Außenwerk, die Nehrwertlehre.

Diese stellt nämlich „vom Standpụnkte des Klassenkampfs" zwischen Bourgeoisie und Proletariat die weitaus wichtigste Position dar. Die Anerkennung des "Mehrwerts" als eine Tatsache ist das Schiboleth, das den Sozialisten vom Bourgeois-. Ökonomen unterscheidet. Nur solange man diese Tatsache hartnäckig fortzuleugnen versuchte, konnte man die Ablehnung des Sozialismus und die Verteidigung der kapitalistischen Wirtschaft rechtfertigen. Nur aus diesem - natïrlich unbewußten Grunde, nicht aber aus Mangel an Verständnisfähigkeit, wie die Narxisten anzunehmen pflegen, richteten die bürgerlichen Volkswirte ihre Angriffe gegen diesen Teil der proletarischen Lehre. In welcher Gestalt - ob liberal oder kollektivistisch - der Sozialismus gerechtfertigt sein sollte, war ilure geringste Sorge: er sollte überhaupt nicht zu rechtfertigen sein.

„Es ist das entscheidende Verdienst von Marx und vielleicht das einzige, das allen Angriffen der Kritik und allen harten Schlägen der Zeit widersteht: die sozialistisclie Idee und die Arbeiterbewegung einander genähert und miteinander verbunden zu haben. " 1)

Das heißt den Nagel auf den Kopf treffen! Daß Marx dem Proletariat eine Klassentheorie bot, wie sie der damalige Zustand des Klassenkampfes gebieterisch erforderte, ist sein geschichtliches Verdienst und ist die Ursache gerade so seines ungeheuren Erfolges wie der inneren Schwächen seines Systems.

Seines ungeheuren Erfolges! Nur dadurch ist er der vergötterte Lehrer des klassenbewußten Proletariats der ganzen Welt, nur dadurch ist sein "Kapital" die Proletarierbibel geworden. Nur dadurch! Daßh er diese proletarische Klassentheorie mit

1) Jaurès, Aus Theorie und Praxis. Deutsch von A. Südekum (BerlinBern 1902) p. 12. 
so genialer Kraft aufbaute, das ist, wie ich meine, trotz der entgegengesetzten Meinung der Marxisten, nicht die Ursache, sondern eher ein Hindernis des Massenerfolges gewesen. Die Klassen sind faute de mieux auch mit den miserabelsten Plaidoyers der Verteidiger ihrer Interessen zufriedengestellt, wie der Erfolg so elender Geisteserzeugnisse, wie des Malthusianismus und des Chamberlainismus beweist; und anch die Arbeiterklasse hätte unter dẹ Panier einer logisch und soziologisch viel schwächeren Theorie ebenso gekämpft und gesiegt. Sie hätte aber umgekehrt frïher anch eine vollkommenere sozialliberale Theorie abgelehnt, als die Proud'hons. Die Zeit war noch nicht́ reif dafür. Heute, nachdem das Industrieproletariat im wesentlichen in seinem Klassenbewubtsein gefestigt und als Partei organisiert ist, und nachdem andererseits die Bourgeoisie die altliberale Maske so gut wie gänz hat fallen lassen, hat eine sozialliberale Gesellschaftslehre eher Aussichten, von der Volksmasse akzeptiert zu werden. Offiziell wird das freilich erst dann geschehen, ẃenn es sich nicht länger verbergen' läßt, daß die Marxsche Lehre aus einem Sporu zum Hemmschuh. des proletarischen Emanzipationskampfes zu werden droht, oder mit andern Worten: daß sie nach einer anderen Richtung zu weisen beginnt als die "naturgesetzliche" Strömung einschlagen muß; wemn also Theorie und Taktik in Konflikte kommen, die man durchaus nicht mehr umgehen kann. Dieser kritische Punkt ist, wie ich meine, nicht mehr allzufern: denn mit dem Marxismus kann die Volkspartei unmöglich das platte Land erobern und ohne diese Eroberung ist ihr wenigstens in Doutschland der Weg zur politischen Macht versperrt. Der orthodoxe Anhänger der materialistischen Geschichtsauffassung, dem alle Veränderungen des gesellschaftlichen Bewußtseins nur der subjektive Reflex objektiver ökonomischer Veränderungen sind, wird sogar aus dem unaufhaltsamen Vordringen des "Revisionismus" innerhalb der Sozialdemokratie, und namentlich aus der siegreichen Propaganda des ketzerischen Agrarprogramms erschließen müssen, daß jener kritische Punkt nicht mehr fern sein kann.

Hierin also erblicke ich die Ursache der ungeheuren äußeren Erfolge des Marxischen Systems, aber auch seiner inneren 
Schwächen. Denn der Klassenwille war es, der den Denker im letzten Augenblicke fortriß und über alle Klüfte der "Vorstellung“ forttrug zu seinem lange ror der Gedankenarbeit intuitiv erschauten Ziele, der Fundierung einer kollektivistischen Gesellschaftstheorie: "Ein Dualismus, der darin besteht, daß das Werk" (das "Kapital") "wissenschaftliche Untersuchung sein und doch eine; lange vor seiner Konzipierung fertige These beweisen will. ... Dieser große wissenschaftliche Geist war doch schließlich Gefangener einer Doktrin." ") „Der Narxismus schleppt.noch gewisse Reste von Utopismus mit sich herum. “2)

Diese Reste muß die Wissenschaft ausscheiden. Aber wenn auch gerade diejenigen Ergebnisse seines Lebenswerkès werden fallen müssen, die der kämpfende Volksmann für die entscheidenden hielt, so bleibt es denwoch eine wissenschaftliche Leistung allerersten Ranges, ein Zeughaus des Geistes, aus dem sich noch ganze Geschlechter ilır Rüstzeug holen werden, eine Cyklopenburg; au der nicht nur der objektive Denker, sondern sogar der Klassengegner voll staunender Ehrfurcht emporblickt. Karl Marx wird weiterleben als ein Beobachter von fast beispielloser Śchärle des Blicks für das wirtschaftliche Leben seiner Zeit, als ein ölionomischer Denker, der kühne und schöpferische Genialitït in der Erfassung der theoretischen Znsammenhänge verband mit der Kraft subtilster, eindringlichster Kritik seiner Vorgänger; - als ein Historiker sondergleichen ron wahrhaft prophetischer Kraft in der Intuition des geschichtlichen Entwicklungsganges; - als ein Philosoph, dessen Denken ebenso breit spannte wie tief bohrte: - als ein Wecker der Gewissen voll Kraft, Fener und tiefster Sittlichkeit. Wie ihn heute die Arbeiterklasse verehrt, so wird ihn dereinst die Menschheit verehren als einen der großen Förderer des (rlücks und der Freiheit, als einer ihrer grolien Denker. -

1) Ed. Bernstein, „Voraussetzungen“, p. 177.

2) Ed. Bernstein, „Voraussetzungen“, p. 179. 


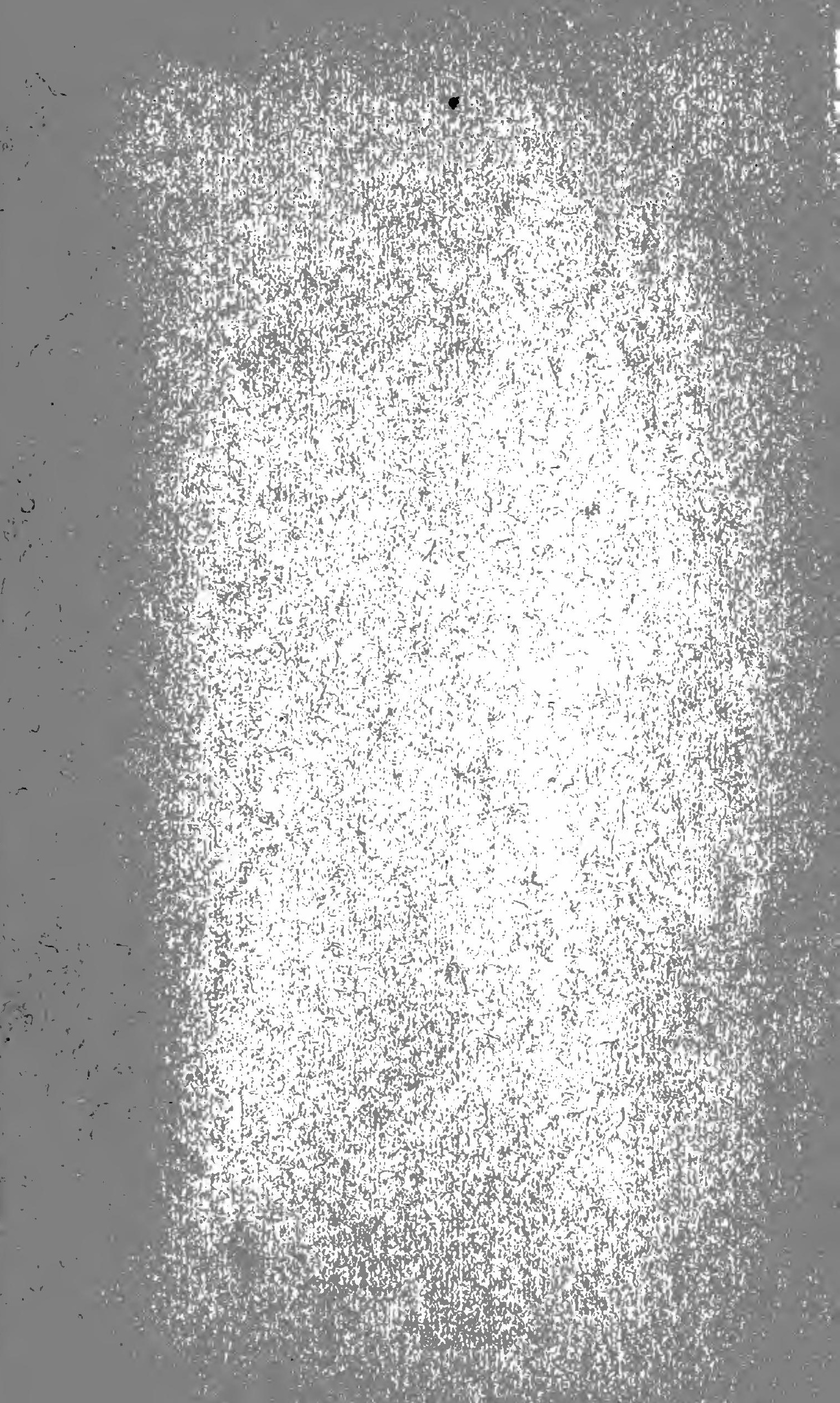




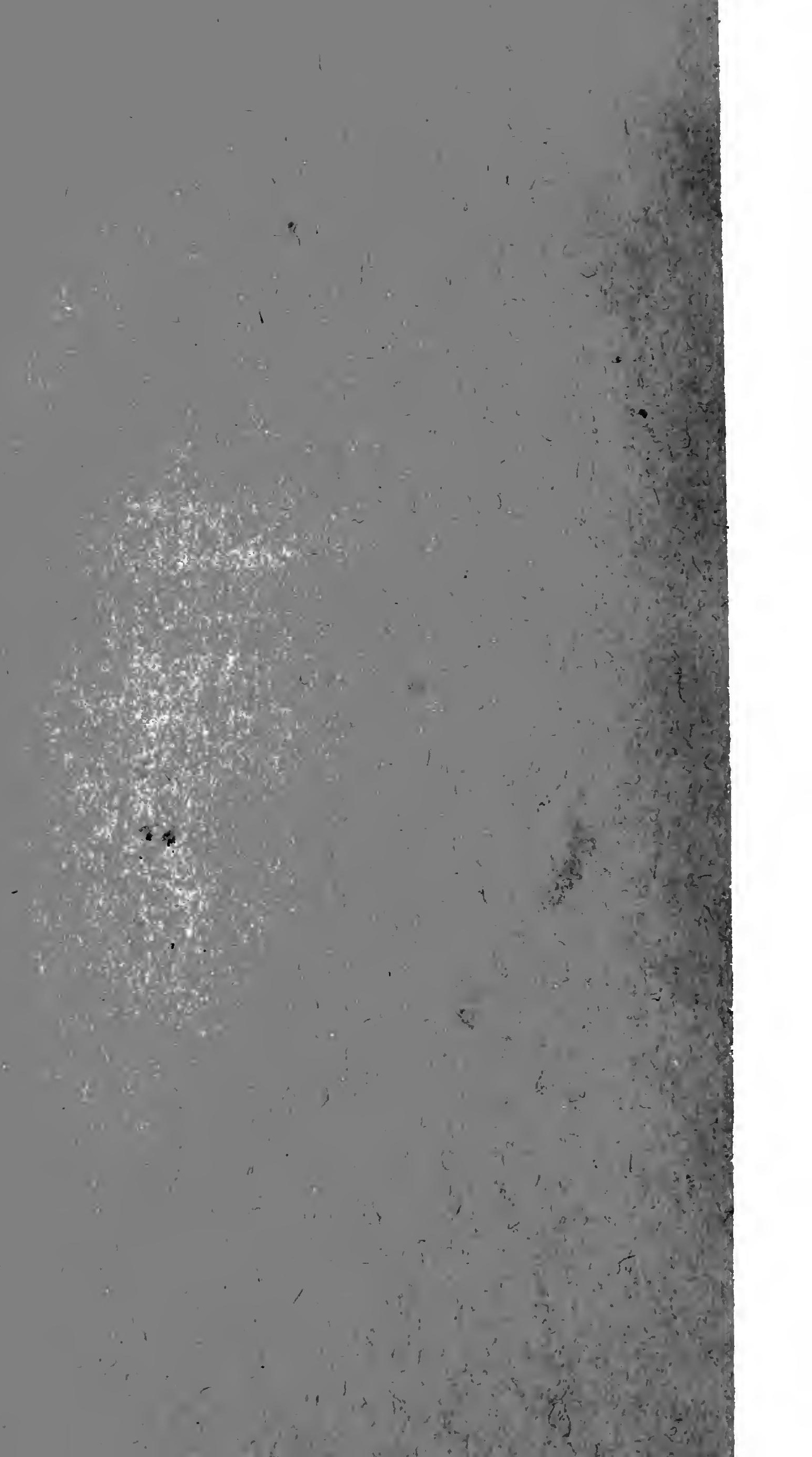




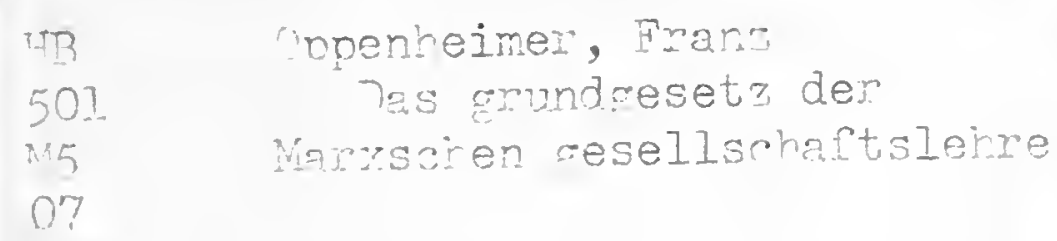

PLEASE DO NOT REMOVE CARDS OR SLIPS FROM THIS POCKET UNIVERSITY OF TORONTO LIBRARY 


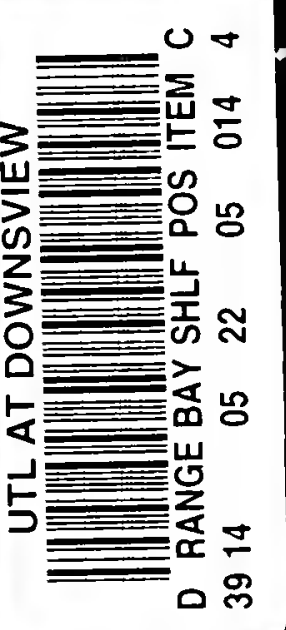

